Portland State University

PDXScholar

1996

\title{
Connection, Service and Community: an Examination of Factors that Contribute to Student and Staff Success
}

Robert Vieira

Portland State University

Follow this and additional works at: https://pdxscholar.library.pdx.edu/open_access_etds Let us know how access to this document benefits you.

\section{Recommended Citation}

Vieira, Robert, "Connection, Service and Community: an Examination of Factors that Contribute to Student and Staff Success" (1996). Dissertations and Theses. Paper 1336.

https://doi.org/10.15760/etd.1335

This Dissertation is brought to you for free and open access. It has been accepted for inclusion in Dissertations and Theses by an authorized administrator of PDXScholar. Please contact us if we can make this document more accessible: pdxscholar@pdx.edu. 


\title{
CONNECTION, SERVICE AND COMMUNITY: AN EXAMINATION OF FACTORS THAT CONTRIBUTE TO STUDENT
}

AND STAFF SUCCESS

\author{
by \\ ROBERT VIEIRA
}

\begin{abstract}
A dissertation submitted in partial fulfillment of the requirements for the degree of
\end{abstract}

\author{
DOCTOR OF EDUCATION \\ in \\ EDUCATIONAL LEADERSHIP: \\ POSTSECONDARY EDUCATION
}

Portland State University

Q1996 
UMI Number: 9626733

\section{Copyright 1996 by \\ Vieira, Robert Lynn}

All rights reserved.

UMI Microform 9626733

Copyright 1996, by UMI Company. All rights reserved.

This microform edition is protected against unauthorized copying under Title 17, United States Code.

\section{UMI}

300 North Zeeb Road

Ann Arbor, MI 48103 


\section{DISSERTATION APPROVAL}

The abstract and dissertation of Robert Vieira for the Doctor of Education in Educational Leadership:

Postsecondary Education were presented March 6, 1996, and accepted by the dissertation committee and the doctoral program.

\section{COMMITTEE APPROVALS:}
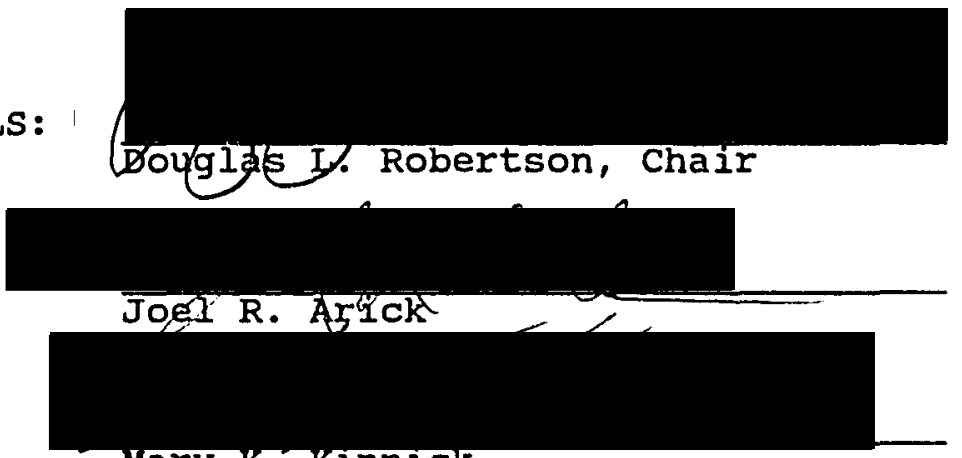

Mary K. Kinnick

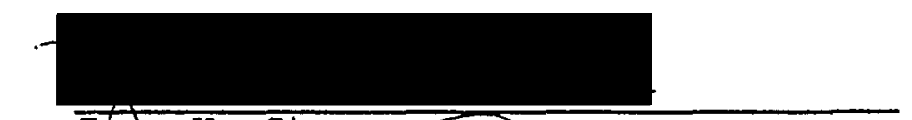

Joan H. Strouse

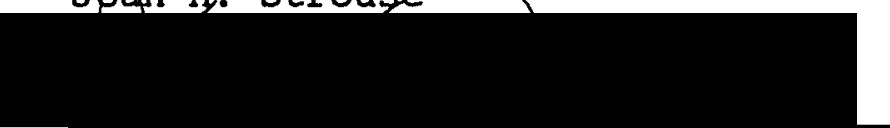

Sherwin L. Davidson

Representative of the office of Graduate Studies

DOCTORAL PROGRAM APPROVAL:

R̈owert B. Evernart, Dean

School of Education

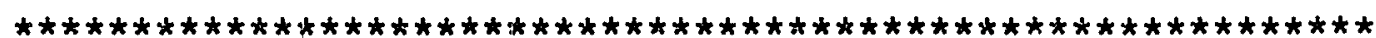

ACCEPTED FOR PORTLAND STATE UNIVERSITY BY THE LIBRARY

by

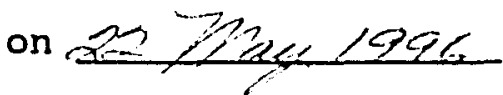


ABSTRACT

An abstract of the dissertation of Robert Vieira for the Doctor of Education in Educational Leadership: Postsecondary Education presented March 6, 1996.

Title: Connection, Service and Community: An Examination of Factors that Contribute to student and staff success

This study examined the general hypothesis that student interactions with front line staff members in higher education settings have a positive impact upon student experiences, and ultimately, their persistence in colleges and universities. This study also examined the reciprocal hypothesis that this same interaction has a positive impact upon staff job satisfaction and service quality.

Several bodies of literature were reviewed as a framework for the examination of these questions, including student persistence and related factors, job satisfaction, total quality management and service quality.

A quasi-eniperimental research design was employed to examine an intervention linking new freshmen with individual staff members in a mentor/adviser relationship, and to test the effects of this interaction upon student persistence and satisfaction, staff job satisfaction, and service. The 
effects of the intervention upon staff and students were measured through the use of pre and post intervention surveys. Also, interviews of subjects were conducted to provide insight into the effects of the intervention, and the day-to-day experience of students and staff. In addition, data were gathered from student and staff control groups for comparison to the experimental groups.

Results suggest that positive student interaction with staff does have an effect upon persistence and satisfaction with the institution. Factors related to this loutcome include high levels of interaction with community members, especially faculty, and a feeling of connection and integration with the institution. Also, data suggest that poor relationships with staff can have the opposite effect, contributing to student dissatisfaction and disconnection. Similarly, data indicate that staff benefit from this relationship also, as demonstrated by increased job satisfaction, satisfaction with interactions with students, and the feeling that their work has value for the educational process. Other findings reveal that certain factors contribute to positive interactions with students and the promotion of quality service (empowerment, teamwork, reward, training and association with other service providers), while other factors detract from that relationship (hierarchy, lack of empowerment, territoriality of information, dissociation from other service(providers). 
Recommendations for improvement of student persistence and staff job satisfaction are made as a result of these findings and conclusions. 


\section{DEDICATION}

This dissertation is dedicated to my wonderful family.

To John Vieira, Ann Vieira, and Henry Vieira, for their patience and understanding and for sharing Dad with this effort for so long.

This is especially dedicated to Abby Crumpacker Vieira, for her enduring support, her common sense and her uncommon strength, and for always believing in me. I

I love you all. 


\section{ACKNOWLEDGEMENTS}

Many individuals have provided invaluable assistance and support in the development of this dissertation.

My sincere thanks go to my dissertation committee, Joel Arick, Sherwin Davidson, Mary Kinnick, Doug Robertson and Joan strouse for their feedback, thoughtful criticism, and their patience. Joel Arick provided essential support related to my statistical analyses. Doug Robertson, my chair, deserves special acknowledgement for the many hours he spent reviewing my work, giving me indispensable advice, and for genefally holding my hand. In addition to these individuals, $I$ would be remiss in not mentioning the valuable statistical assistance which Joyce Harris provided, Pati sluys' inestimable help in the final editing and typing of this document, and finally, Kathy Greey's ongoing assistance and encouragement in the library over the course of many years.

My appreciation goes also to President Judith Ramaley and Provost Michael Reardon for helping make it possible for me to work full-time and complete this effort.

Family, friends and colleagues who have been supportive over the course of this endeavor are almost too numerous to mention. They include, Mary Cumpston for her 
friendship and wise counsel long appreciated, and special thanks to Robert Mercer for demonstrating that losing one's hair does not necessarily mean losing one's mind. Finally, I especially want to acknowledge the contribution of the staff who participated in this study, and others like them who have frequent contact with our students. It is their service and dedication, too often unacknowledged, that contributes so significantly to college student success and satisfaction. 
TABLE OF CONTENTS

PAGE

ACKNOWLEDGEMENTS. . . . . . . . . . . . . . . . . ii

IIST OF TABLES. . . . . . . . . . . . . . . . viii

LIST OF FIGURES . . . . . . . . . . . . . . . . . . $x$

\section{CHAPTER}

I INTRODUCTION . . . . . . . . . . . . . 1

Statement of the problem . . . . . . 4

Rationale. . . . . . . . . 6

Classified staff and student Persistence

Quality Service/Customer Service and student Persistence

Employee Job Satisfaction and Service to students

Purpose of the study . . . . . . . . 11

Scope of the study . . . . . . . . . 12

organization of the study. . . . . . . 13

Significance of the Study. . . . . . . 14

II LITERATURE REVIEW. . . . . . . . . . . 16

Theoretical Models of Student

Attrition. . . . . . . . . . 17

Spady's Model

Tinto's Model

Pascarella's Model

Bean's Model 


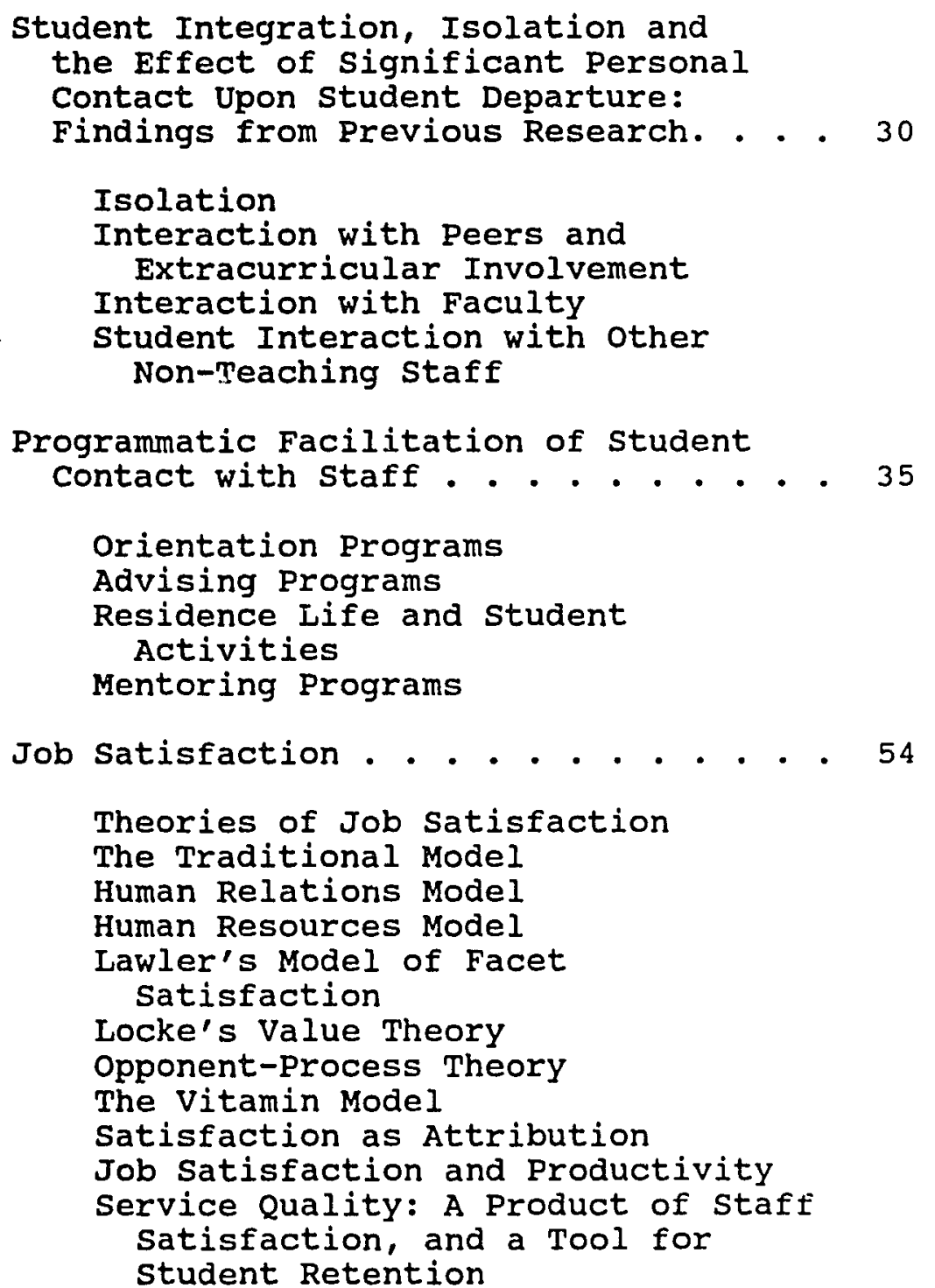

Summary. . . . . . . . . . . 77

III METHODOLOGY. . . . . . . . . . . 80

Subjects . . . . . . . . . . 82

Students

Staff

The Experimental Intervention

Data Collection and Analysis.. . . . 90

Data collection: Quantitative Methods 
Data Collection: Qualitative Methods

Data Analysis. . . . . . . . . . 97

Student Related Analyses

Staff Related Analyses

Summary. . . . . . . . . . . 103

IV RESULTS OF THE STUDY . . . . . . . . . . 104

Introduction . . . . . . . . . . 104

characteristics of subjects. . . . . 105

Students

staff

Presentation of the Results. . . . . . 110

Student Analyses

Staff Analyses

$\mathrm{V}$ CONCLUSIONS, LIMITATIONS, IMPLICATIONS

FOR RESEARCH, AND RECOMMENDATIONS FOR

PRACTICE . . . . . . . . . . . . 172

Introduction . . . . . . . . . . . 172

Conclusions. . . . . . . . . . . 174

Conclusion \#1

Conclusion \#2

Conclusion \#3

Conclusion \#4

Conclusion \#5

Conclusion \#6

Conclusion \#7

Conclusion \#8

Conclusion \#9

Limitations of the study . . . . . . 197

Implications for Future Research . . . 199

Significance to Educational Leadership and Recommendations for Practice. . . 201

Recommendation \#1

Recommendation \#2

Recommendation \#3 
vii

Recommendation \#4

Recommendation \#5

Recommendation \#6

Recommendation \#7

Recommendation \#8

Summary. • • • • • • • . • . . 215

REFERENCES. . . . . . . . . . . . . . 217

APPENDIX

A STUDENT SURVEYS. . . . . . . . . . 233

B STAFF SURVEYS. . . . . . . . . . 240

C JOB DESCRIPTIVE INDEX. . . . . . . 248 


\section{LIST OF TABLES}

TABLE

PAGE

1. The Evolution of Management Theory . . . 56

2. Synthesis of Job Satisfaction Research . . 68

3. Gender, Race of student Subjects . . . . 106

4. High School GPA of student subjects. . . 107

5. Years of Work and Education of Staff . . 107

6. Degree Attainment of Staff . . . . . 108

7. Primary Functions of staff Subjects'

Departments. . . . . . . . . . 109

8. Staff Subjects' Description of Work. . . 110

9. Comparison of Group Persistence Rates. . 112

10. Factors Relating to Persistence. . . . . 115

11. Factors which Contribute to Persistence. - 115

12. Student in Interaction with other Community Members. . . . . . . . . 122

13. Student Feeling of Connectedness . . . . 126

14. Persistence and Satisfaction with Experimental Intervention. . . . . . 138

15. Mean Scores of Overall Job Satisfaction. . 142

16. Pre and Post Survey Mean Job Satisfaction Scores. . . . . . . . . 143

17. Mean Scores of the JDI Work Scale. . . . 143

18. Pre and Post JDI Scores. . . . . . . 144

19. Comparison of Mean Scores to JDI 3145 
20. Comparison of Mean Feeling of Contributing Scores by Group. . . . . 153

21. Comparison of Pre and Post Intervention Mean Satisfaction Scores: Experimental Group . . . . . . . . . . . . 154

22. Comparison of Pre and Post Intervention Mean Satisfaction Scores: Control Group . . . . . . . . . . . 155 


\section{LIST OF FIGURES}

FIGURE

PAGE

1. Tinto's Model of Student Persistence . . 21

2. Pascarella's Model of Student Persistence. . . . . . . . . . 25

3. Bean's Model of Student Persistence. . . 28

4. Maslow's Hierarchy of Needs. . . . . . 60

5. Premise and Rationale for Employee and Customer Attachment.'. . . . . . . . 72

6. Student, staff, Institutional outcomes, and Related ititerature ... . . . . 78 


\section{CHAPTER I}

\section{INTRODUCTION}

In his most recent book on student retention, Leaving College, Tinto (1993) asserted that:

In the interactive system of a college, almost any institutional action, whether in admissions, counseling, advising, academic programs, or student life will eventually affect student persistence and will do so in often unintended and quite unexpected ways. (p. 205)

An individual familiar with higher education settings would find it hard not to agree with Tinto's observation. Intuitively, we understand that persistence is a product of students individual experiences, their individual interactions with the institution, and the cumulative effect of those interactions expressed as the institution's climate.

Beyond intuition, Tinto's (1993) contention that many institutional elements (particularly teaching faculty) have an impact upon student outcomes, especially persistence, is well supported by an extensive body of research. Among other things, this research describes how student persistence and attrition are influenced by a complicated interaction between the personal characteristics, intentions and experiences of a student and the various elements of the college setting. Central 
to this literature are the comprehensive models developed by Spady $(1970,1971)$ and Tinto, both of which emphasize the importance of the student's level of integration into the social and academic structures of the institution. Both of these models also suggest that informal out-of-class interaction with faculty is one of the most important elements leading to integration into the institution. Substantial evidence has been developed that supports this aspect of these models (Pascarella, 1980; Pascarella, Duby, Terenzini, \& Iverson, 1983).

Focusing on this interaction between students and teaching faculty, others have examined the characteristics of individuals which enhance and inhibit the process. Wilson, Gaff, Dienst, Wood, and Bavry (1975), Astin (1977), and Phelan (1979) all provide evidence that the personal characteristics of students have a significant impact on the extent of student interaction with faculty. others have found that individual characteristics of faculty members, both job related and social-psychological characteristics, influence the frequency and quality of faculty-student interaction (Gamson, 1966, 1967; Vreeland \& Bidwell, 1966; Wilson et al., 1975).

What these studies do not describe, and largely ignore, is how other employees, particularly classified employees (clerical and other support staff), affect student retention. Do their interactions with students 
affect persistence? Are there ways to enhance these relationships or actions which inhibit them? To the extent that these interactions occur, do they have an effect on the overall job satisfaction of classified employees? In an era of continuing high student attrition, shrinking resources for higher education, and greater understanding of how individuals at all levels of the institution may contribute' to the accomplishment of institutional goals (e.g., total quality management), we need to take a closer look at how all of our human resources, not just teaching faculty, can contribute to the goals of student persistence and how that contribution may also affect how individuals feel about their jobs. Schlossberg (1989) and Schlossberg, Lynch, and Chickering (1989) have explored the concept of "mattering" as it pertains to how individuals feel in relationship to others within a community or organization. This feeling of "mattering," that you command others' attention, that others care what you think, that they are proud of your accomplishments, that others depend upon you and appreciate your work could have profound effects both upon student retention and upon staff satisfaction. This study examines a model in which the recipient of attention (the student) and the provider of attention (the staff member) both feel more like they "matter" within the institutional setting as a product of an intentional institutional 
intervention linking the two. The dual benefits which this model suggests may provide us with significant guidance for improving student and employee outcomes in an era of reduced budgets and staff reductions.

\section{Statement of the Problem}

Tinto (1993) stated part of the challenge facing higher education institutions very succinctly:

More students leave their college or university prior to degree completion than stay. Of the nearly 2.4 million students who in 1993 will be entering higher education for the first time, over 1.5 million will leave their first institution without receiving a degree. of those, approximately 1.1 million will leave higher education altogether without ever completing a degree program, two or four-year. (p. 1)

In support of this statement, Tinto cited several studies which have examined the incidence of student persistence, in addition to identifying when attrition is most likely to occur. The most recent of these studies is a survey of institutions conducted by the American College Testing Program (ACT) over a 10-year period (American College Testing Program, 1983, 1986, 1990, 1992). According to the 1992 report the first year attrition rate of the class of 1990 was reported to be $26.8 \%$ among four-year institutions. Tinto estimated that this rises to $30 \%$ among four year public colleges when part-time students are taken into consideration. 
Over time this rate has remained surprisingly steady. As reported to the $\mathrm{ACT}$ the 1990 rate was $28.6 \%$, in 1986 29.6\%, and in $198329.1 \%$. These reports are similar to that found in a national survey of higher education institutions (Chaney \& Farris, 1991) which reported a one year attrition rate of 23.4 among students beginning in Fall of 1988, and the National Longitudinal study of the high school class of 1972 conducted by the United states Department of Education National Center for Educational Statistics (1977) which reported a rate of 27.8 .

In some institutions these rates are even higher. For example at one urban comprehensive university, $27 \%$ of all entering freshmen withdraw by the end of their third term and only $48 \%$ remain by the beginning of the next fall term (Portland state University, 1995). Because of this pattern of student withdrawal, Tinto (1987) and others (Noel, Levitz, \& Saluri, 1985) agreed that the first year may be the most critical time period for establishing relationships which will contribute to student success and satisfaction.

In addition to the incidence and timing of student attrition, the challenge for improving persistence is related to the increasing scarcity of human resources which may be brought to bear upon the problem. Across the country colleges and universities are being asked to do more with fewer resources (Mangan, 1991). At the same 
time the demand on the faculty's time is increasing rather than decreasing. Increased examination of teaching loads by legislators struggling with reduced state revenues can only result in fewer opportunities for students to interact with faculty (Jacobsen, 1992). Developing new approaches to student retention could help colleges and universities fill this growing human resources gap.

student attrition is increasing, and resources which may be used to address this increase are shrinking. The interrelationship of these general problems is addressed by this study, along with more specific strategies which might help to improve the quality of the student experience and maximize the use of institutional resources.

\section{Rationale}

While many formal studies have highlighted the importance and process of students' interaction with faculty, it would be a mistake to assume that teaching faculty are the only institutional employees whose interaction with students have a positive impact upon student persistence. As Noel, Levitz, and Saluri (1985) pointed out,

If we want to create a staying environment. . . responsiveness to student needs must extend to everyone on campus--the telephone operator, the receptionist, the clerk at the cashier's window. (p. 17) 
They argued that in striving to have an impact on student retention, institutions need people who feel that students

"are the most important people on campus--not the interruption of their work, but the purpose of it" (p. 18).

\section{Classified Staff and student}

\section{Persistence}

This argument would lead one to the conclusion that student interaction with classified staff has a potential impact upon student persistence, just as student interaction with teaching faculty does. Evidence indicates that this is particularly true in institutions where size, bureaucracy and research-related expectations of faculty reduce students' opportunities to interact with faculty (Astin, 1977). This has also been found to be true in urban and non-residential campuses where student time is a scarce resource (Chickering, 1974). As demands on teaching faculty increase, it becomes more possible and probable that opportunities for interaction occur more frequently with classified staff who already interact with students on a daily basis.

Despite this evidence, surprisingly few studies have focused on the importance of classified staff in relationship to student persistence. These few include Beal and Noel's (1980) study which found that a number of non-teaching functions are critical retention factors. 
Also, Neumann (1985) and Pascarella, Smart, and Ethington (1986) found that non-teaching factors are particularly important retention factors in non-residential settings. Another study found that at least in one institution, there was common agreement that the roles of classified staff, especially secretaries, included significant advising of students (Bernotavicz \& Clasby, 1984). Beyond this work and anecdotal evidence (Vieira, 1991) this segment of university empioyees has been relatively ignored by formal research efforts related to student outcomes.

\section{Quality Service/Customer Service and Student Persistence}

While these employees have not been central to the focus on outcomes in educational, settings, the value of the interaction between staff and "customers" has not been lost on other sectors of our increasingly service-based economy. One need only undertake a cursory review of the literature related to service industries to discover that personal interaction between the customer and service provider is at the heart of many services (czepial, Soloman, \& Supprenent, 1988). As one manager portrayed it in one study:

In a service business, you are dealing with something that is primarily idelivered by people, to people. Your pepple are las much of a product in the consumer's mind as any other attribute of that service. (Knisely, 1984, p. 44) 
Albrecht and Zemke (1985) have described this as the service imperative that every organization must face, "responding efficiently and effectively to customers and consumers who expect quality and service as part of every service" (p. 18).

Learning from the experience of the business sector, colleges and universities are finding it increasingly important to attend to this imperative as well. This body of literature clearly identifies the value of focusing our attention upon our staff as valuable human resources for the improvement of college outcomes and for providing quality service. But we should not assume that the potential for positive outcomes produced by the interaction of students with staff is only a one way street. Indeed, there is much to suggest that this type of involvement has potential for creating positive employee outcomes as well.

Employee Job Satisfaction and Service to students

This mutually beneficial relationship was hinted at in a report of one recent activity related to student outcomes (Vieira, 1991). When asked about their participation and the outcomes of a project in which classified staff contacted students by phone and offered their assistance for returning to the university, staff members frequently mentioned the satisfaction that they 
felt in being able to help students. This anecdotal information hints at the existence of another outcome which may be associated with student/staff interaction: increased staff job satisfaction.

The concept of Job Satisfaction, defined as "the feelings a worker has about his job" (Smith, Kendall, \& Hulin, 1969, p. 12), is described and supported by a wealth of theory which reaches back to Taylor's (1911) proposal for scientific management and its focus upon efficiency. Closely related to the dimensions of work motivation and job enrichment, these theories include: the Need Hierarchy theory (Maslow, 1943), Achievement Motivation theory (Atkinson, 1964; Mcclelland, 1951; Murray, 19/38), Motivation-Hygiene theory (Herzberg, 1966), Equity theory (Adams, 1963; Festinger, 1957; Homans, 1961), Expectancy Valence theory (Lawler, 1973; Lewin, 1935; Vroom, 1964), ERG theory (Alderfer, 1969, 1972) and Goal setting theory (Locke, 1968, 1970, 1976). Based primarily upon psychological principles as they relate to an individual in a work setting, these theories generally attempt to describe the causes for satisfaction and dissatisfaction in work settings, and the relationship of those causes to the performance of work.

These theories have formed the basis for literally hundreds of research projects and articles on job satisfaction in education. For example, a recent 
annotated bibliography listed more than 1,000 references to studies of job satisfaction in elementary, secondary and college teachers and administrators (Lester, 1988). But once again, like the literature of student retention, relatively little attention has been paid to non-instructional staff. In a recent review of the literature, Mascciochi (1990) found that only a handful of studies addressed the job satisfaction of non-teaching school district employees. This lack of research on non-instructional employees applies to higher education as well.

In summary, student persistence continues to be an impartant concern in higher education. As Tinto (1993) indicated, more students leave their college or university prior to degree completion than stay. At the same time, most research on factors which contribute to student persistence in higher education has not addressed the potential positive impact of non-instructional staff, particularly in terms of the relationship of their interaction with student persistence. Moreover, there has been no investigation of the effect of this interaction upon staff satisfaction with their jobs.

Purpose of the study

The purpose of this study was to examine the problem of student persistence in a comprehensive urban university 
from several perspectives. First, this study examined the relationship between student/classified staff interaction and student persistence. Second, in examining this question, this study also sought to establish whether this interaction had the effect of improving or enhancing institutional human resburces, specifically classified staff job satisfaction.| Finally, this study tested a model program for improving student persistence and staff satisfaction by linking students with classified staff members who played the role of mentor advisors.

\section{Scope of the study}

This study focused upon a planned intervention designed to link entering freshmen with institutional staff members trained to providelspecific assistance. The intervention, called "staff Link," was a test of a method for improving student retention and staff job satisfaction.

The student population selected for this intervention were entering freshmen, without prior college credit who began in Fall 1991 and re-enrolled winter 1992. The experimental student group was composed of 45 students who volunteered to participate in the study from a mailing list of 150 randomly selected freshmen. Forty-five other freshmen were randomly selected a's the student control group. 
Forty-five classified staff members composed the staff experimental group, and were assigned to the student experimental group as advisor/mentors. Forty-five other classified staff members were randomly selected as the control staff group.

Quantitative and qualitative methods were used to attempt to measure the effect of the program on student retention and staff job satisfaction.

$$
\text { organization of the study }
$$

This study is organized into five chapters:

Chapter I, the introduction, describes the: (a) statement of the problem, (b) rationale, (c) purpose of the study, (d) scope of the study, and (e) the organization of the study.

Chapter II reviews the related literature and is divided into four major sections: (a) The theoretical models of student retention theory, research, and applications; (b) Student integration, and the effect of significant personal interaction upon student departure; (c) Programmatic facilitation of student contact with staff and faculty; and (d) Job satisfaction and its relationship to service quality.

Chapter III describes the design of the study and the methods and procedures used to analyze the data. Chapter IV reports the results of the study. 
Chapter V presents conclusions, limitations, implications for research, and related recommendations.

\section{Significance of the study}

Relatively little is known about the contribution to educational outcomes from classified staff in higher education settings. This study will help higher education to better understand and better utilize this category of employee, and to test a program which uses these employees as informal advisors for students and is designed to increase student persistence.

knowledge of the full range of available human resources becomes increasingly significant as funding for higher education shrinks across the nation, and the need for identifying new resources and strategies for addressing problems of student persistence becomes more important. Also, because it was conducted on an urban campus, this study will have particular meaning and value for other urban campuses which frequently have lower rates of student persistence, influenced by: size (social integration tends to decrease and isolation to increase [Pascarella \& Terenzini, 1991]); setting (urban campuses tend to attract more adult learners whose other life responsibilities affect their persistence [Astin, 1975]); and the lack of on-campus residences (commuter students may find it more difficult to make contact with faculty 
and other students than those in residence hall settings [Chickering, 1974]). The intervention designed for the study, if successful in improving persistence, might also prove to be a useful strategy for other urban campuses. For university administrators, identification of new opportunities for improving staff satisfaction may be equally important as improving student persistence. In fact, one might hypothesize that the two outcomes may be connected--employees who are more satisfied and enriched by their job are more likely to provide better service and thereby improve students' chances for success in the institution. In this way, this study could provide valuable guidance for various aspects of organizational design and human resources management.

It is expected that the results of this study will assist institutions in better understanding the important contribution of non-instructional staff to the educational process, and through that understanding be better able to utilize those human resources for achieving positive student and staff qutcomes. 
CHAPTER II

\section{LITERATURE REVIEW}

The literature reviewed for this study is divided into four sections which support and guide this analysis. The first three sections broadly explore the subject of student retention. Section one, "Theoretical models of student attrition and retention," provides a review of well known and considered models of retention and attrition. This literature helps to create a context and foundation for the examination of student retention in this study. Similarly, section two of the literature review, "Student integration, isolation and the effect of significant personal contact upon student departure," focuses upon issues affecting retention and attrition, but also looks more deeply at how the conditions of isolation and contact affect a student's persistence. Focusing even more closely, section three, "Programmatic facilitation of student contact with staff," reviews research and discussion of what has worked in improving the student experience and especially student retention.

Finally, section four, "Job satisfaction of classified staff including general theories, selected research and Total Quality Management (TQM)," reviews the 
literature related to job satisfaction, and in particular how relatively new management strategies like TQM and quality service initiatives may relate to the satisfaction of staff in colleges in universities.

\section{Theoretical Models of} student Attrition

Lewin (1951) stated that "there is nothing so practical as a good theory" (p. 169). The theoretical models of Spady (1970), Tinto (1975, 1987), Pascarella (1980) and Bean (1982) provide the practical theoretical framework of student attrition and retention which supports this study. While these models help us to better understand the processes of student persistence and retention, it should be acknowledged that not all departure is negative, nor is all enrollment intended to lead to degree completion. put simply, not every student intends to obtain a degree. The rapid change in work places, and increasing sociological change have brought more non-traditional students into higher education institutions not always intent upon obtaining a degree. This is especially true in two year institutions and community colleges, along with four year sector institutions which are reaching out to new students, or, like many urban institutions, which have typically served non-traditional students. 
As these models are considered, it is important to note that intentions play an important role in the retention and departure of students from institutions, and that persistence and departure from higher education is becoming increasingly complex phenomena to understand.

\section{Spady's Model}

Spady (1970, 1971) was one of the first to suggest a comprehensive model of the dropout process which did more than simply identify variables which were correlates to the dropout process. His goal was to "Move beyond merely summarizing what variables correlate with college success" (Spady, 1970, p. 64), to develop a model which would treat relevant clusters of variable simultaneously.

Spady (1971) based his model on the implications of social integration suggested by Durkheim's (1897/1951) treatise on the nature of suicide. In Durkheim's theory suicide results from, among other things, a lack of integration with the life of the society. According to the theory, suicide is more likely to occur in the absence of moral consciousness and where there is insufficient collective affiliation. Similarly, likening dropping out to suicide, spady theorized that a lack of integration in the college "society" could lead to what could be conceived of as educational termination.

Spady (1971) likened these concepts to the two factors which he identifies as having impact upon the 
dropout decision: (a) normative congruence and (b) friendship support. Parallel to moral consciousness, Spady defined normative congruence as the condition of an individual whose attitudes, interests, and personality are compatible with the attributes and values of the environment.' Similarly, he found the condition of friendship support to correspond with Durkheim's (1897/ 1951) notion of collective affiliation.

Spady (1971) described his model as an elementary Durkheimian model consisting of five independent variables, four of which influence the fifth, social integration, which in turn interacts with the other four to influence persistence. Two other variables which intervene between social integration and dropping out are satisfaction with the college experience and commitment to the institution. Spady added these, assuming that satisfaction with the institution is based upon one's academic and social rewards, and that commitment is sustained by both a sense of integration and sufficient positive rewards. Underlying all of these variables in the model are the circumstances of a student's family background. Those circumstances are considered to be at least partly the source for both academic potential and many of the elements of normative congruence. Finally, Spady assumed a definitive time sequence and depicted direct causal connections between pairs of variables. 
Tinto's Model

Borrowing from spady (1971), Tinto (1975) based his original theory of dropping out on Durkheim's (1897/1951) theory of suicide, but went beyond to define a longitudinal process of interaction of the individual with the institution which caused dropout or persistence. Tinto explained his theory as follows:

The process of dropout from college can be viewed as a longitudinal process of interaction between the individual and thelacademic and social systems of the college, during which a person's experiences in those systems (as measured by his normative and structural integration) continually modify his goal and institutional commitments in ways which lead to persistence or varying forms of dropout. ( $p$. 94)

As seen in Figure 1, an individual's initial goal and institutional commitment are products of family background, individual attributes, and pre-college schooling. These commitments in turn predict and help determine an individual's integration within the academic and social systems of the institution. Correspondingly, this integration leads to increased goal and institutional commitment and college completion, or the reverse, lack of integration leads to low commitment and eventual dropout. In this way goal and institutional commitment are both input and process variables and "the dynamic component of an individual's progression through the educational system" (Tinto, 1975, p. 104). 


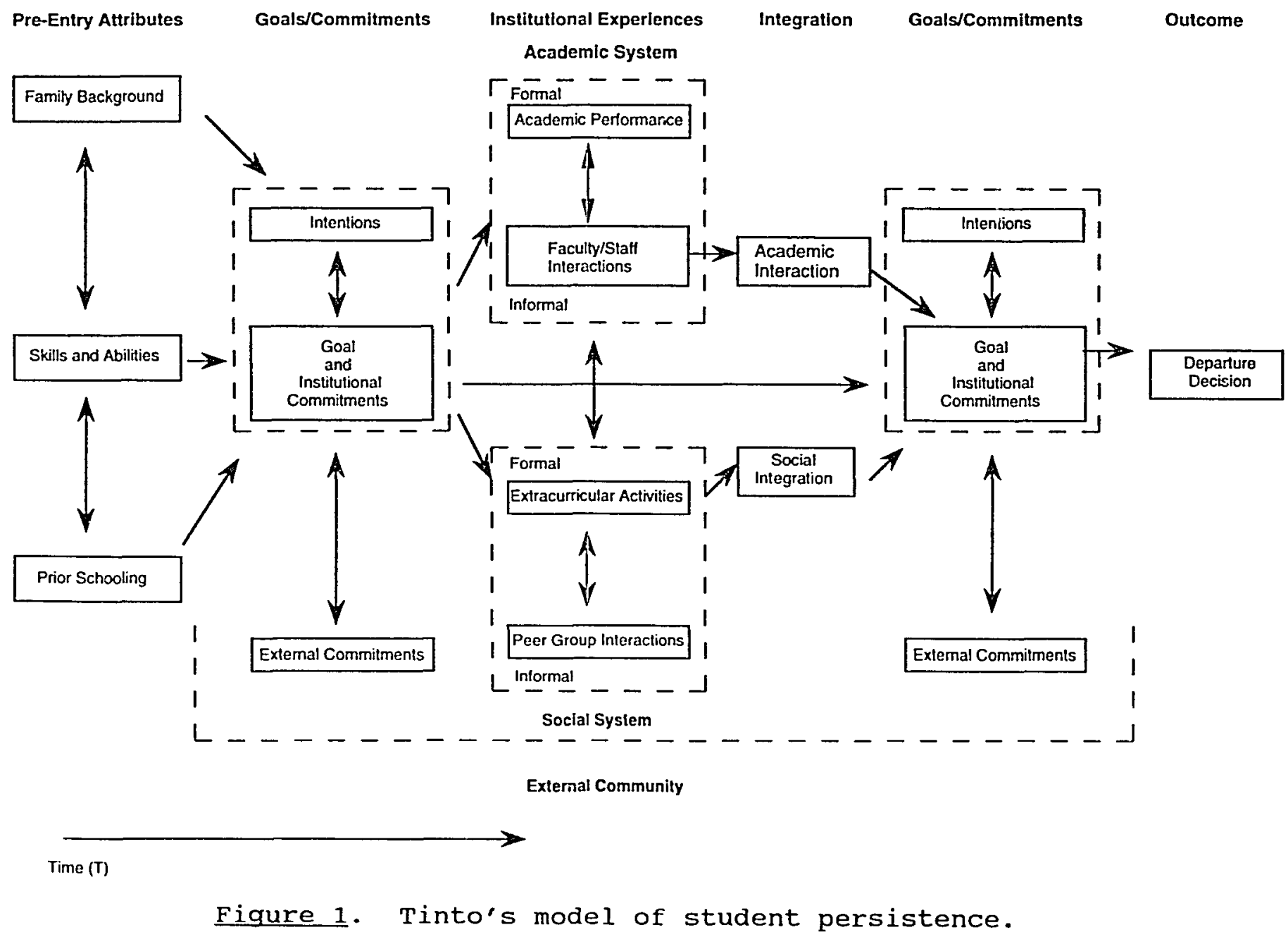


Tinto (1987) noted too, that integration in one system (academic or social) does not necessarily presume success as measured by persistence. Excessive social interaction (social integration) can also lead to poor academic performance, bad grades and dismissal. similarly, academic integration, to the exclusion of all social interaction can lead to poor social integration and voluntary withdrawal.

Expanding upon his original model, Tinto $(1987,1993)$ later emphasized two other important aspects of what he saw as the longitudinal process of withdrawal:

1. the timing of institutional interventions to promote integration and;

2. the importance of student contact with other members of the "social and academic community of the college."

Tinto (1987) noted that there are critical periods in a student's career when an institution may most effectively intervene to reduce the probability of a student dropping out. Beginning with the admissions application process, students form impressions through their interaction with the institution which can have an effect on an individual's integration and subsequent dropout decisions. Therefore, he argued, it is important for the institution to develop realistic and accurate 
representations of the institution in order to avoid early disappointment which might lead to dropping out.

Along with this critical contact, Tinto (1993) argued that the transition period to college (especially during the first year) is an important time for institutional intervention. Examples of intervention programs include early advising programs, dormitory clusters and peer mentors. Retention of students, Tinto said, primarily:

hinges on the establishment of a healthy, caring environment which enables all individuals, not just some, to find a niche in the social and intellectual communities of the institution . . not unlike other human communities... an institution's capacity to retain students is directily related to its ability to reach out and make contact with students and integrate them into the social and intellectual fabric of institutional life. (pp. 204-205)

\section{Pascarella's Model}

Student contact with other institutional members (specifically faculty) is also a central theme in Pascarella's (1980) model of student persistence. Citing a significant body of literature which identifies the impact of informal student faculty contact on educational outcomes and the lack of a conceptual model which adequately focused upon this relationship, Pascarella developed a model which would better explain how this important variable interacted with other individual and institutional variables (Figure 2). The model first proposes that a student's background characteristics (family background, aptitudes, aspirations, personality, 
secondary school achievement, expectations, and openness to change) interact with institutional factors (faculty culture, organizational structure, institutional image, administrative policies and decisions, size, admissions and academic standards). Pascarella stated that: students with certain preenrollment dispositions and traits tend to apply to, be accepted by, and enroll in those institutions that accentuate initial dispositions and traits. (p. 570)

According to the model, a student's background influences the extent and quality of their informal contact with faculty, their other college experiences, and various measures of educational outcomes. This interaction creates a reciprocal and self perpetuating relationship between the dispositions and traits of certain kinds of students and institutions.

Along with the effect of a student"s informal contact with faculty and other college experiences, students are influenced by institutional factors, as well, in the model. These include institutional culture, policies, size and standards, along with other factors. Finally the model identifies the potential reciprocal relationship between informal contacts with faculty and other college experiences, and the potential reciprocal relationship both of these variables has with educational outcomes. These outcomes (academic performance, intellectual development, personal development, education/career aspirations, college satisfaction, institutional integration) in turn have a direct bearing, either 


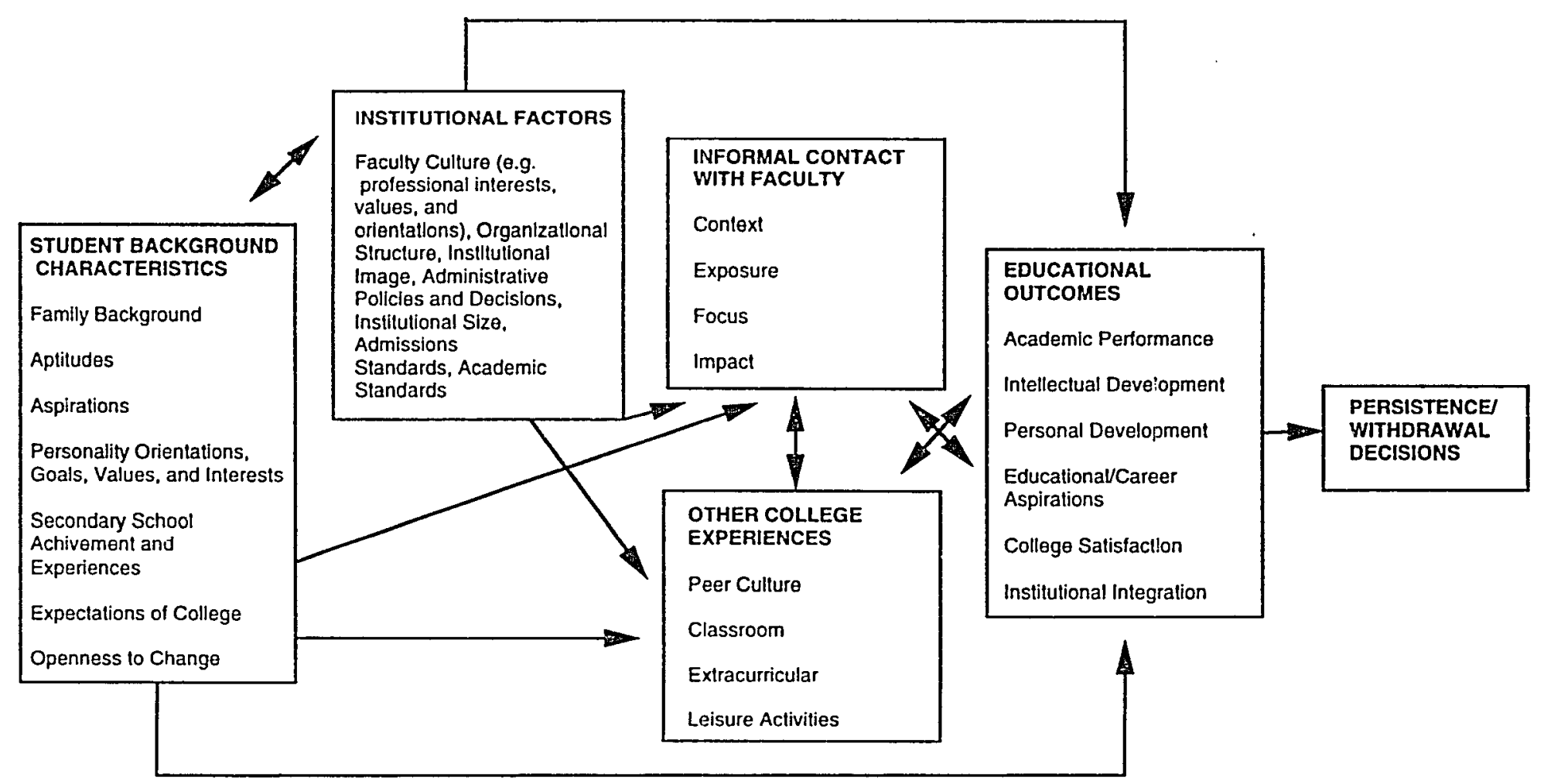

Figure 2. Pascarella's model of student persistence. 
positively or negatively, upon a student's persistence and withdrawal decisions.

\section{Bean's Model}

While Pascarella (1980) focused on the nature and potential importance of the student-faculty interaction, Bean's (1982) model looks most closely at student intent to leave, and the precursors to that intent. Bean relied on the work of Fishbein and Aizen (1975) in predicting specific intentions and behaviors for developing his model. In their conceptual madel, behavior is an outcome preceded by intention to perform the behavior, attitudes and subjective norms concerning the behavior, which are preceded by beliefs about the consequences of the behavior and normative beliefs about the behavior. Bean synthesized elements from this and other models including that of Tinto (1982) and Spady (1971)/ to develop what he called the "synthetic model" of student attrition.

Similar to Fishbein and Aizen, Bean's|model suggested that intent to stay or to dropout is affected by outcomes and attitudes which are a product of a student's interaction with organizational, environmental, and individual background variables which they bring/to college. In explanation of the model, Bean stated/that:

The purpose of the model is not a full explanation of the dropout process across institutions or at a national level; instead, it indicates the information about a student that, if it were known, would likely indicate that 
students' probability of dropping out and some reasons why. (p. 25)

The synthetic model (Figure 3) identifies four classes of variables: (a) background variables (the characteristics and experiences which a student brings to college), (b) organizational variables (those interactions which the student has with the organization), (c) environmental variables (those variable over which the organization has little or no control--e.g., economic and social trends, family approval), and (d) outcome and attitudinal variable (the subjective evaluation of the educational experience, e.g., satisfaction, boredom, loyalty). In explanation of his model Bean (1982) provided examples of these variables and noted where the variables from other models are integrated into this synthesis. Bean noted that since his model includes the element of "intent" it allows institutions to not only explain the attrition process at a particular school, but to identify students whose attributes make them likely candidates for dropping out.

In an important refinement of the model, Bean and Metzner (1985) focused upon variables which have special effects upon non-traditional student persistence. The external environment has significant impact upon these students' persistence. Those environmental variables include finances, hours of employment, outside encouragement, family responsibilities, and opportunity to 


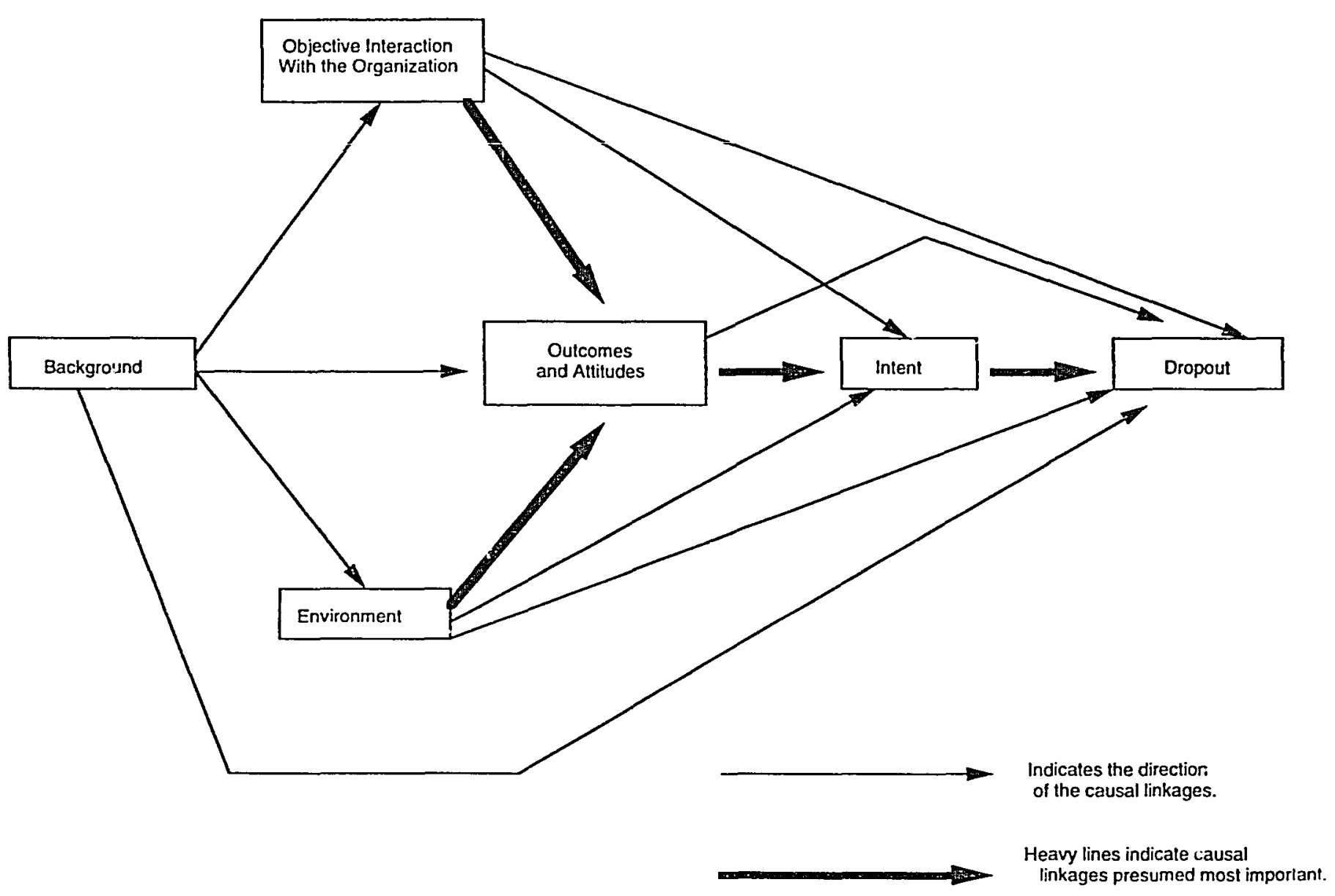

Figure 3 . Bean's model of student persistence. 
transfer. According to Bean, these external variables play an important role for non-traditional students, in addition to those internal environmental variables which affect traditional students.

Together these theoretical models provide the foundation for the conceptualization of the process of dropping out of colleges and universities, and potential frameworks for studying attrition. Bean (1982) noted that in using a particular theoretical approach for studying attrition, the purpose of the study must be clearly in mind. He stated that:

Studies of attrition commonly focus on four issues: What are the reasons students leave school? Which students are likely to leave this institution this year (or semester)? What effect are our programs and services having on attrition? What are the entry level characteristics of the students most likely to stay in school or to leave? (p. 31)

For Bean (1982) each of these questions called for a different approach. For example, in studying the first question, "Why do students leave school," either a longitudinal approach like Spady's (1971) or Tinto's (1975) or a synthetic approach like Bean's would allow for analysis of the different effects of several types of variables. In examining the effect of particular programs and services, the synthetic model would be most appropriate. Bean suggested in this instance that the institutional researcher would introduce variables related to student contact with particular programs and services 
under the category of "objective interaction with the organization." He noted that the influence of these variables on attrition could then be assessed without loss of statistical control over other factors which affect attrition.

Student Integration, Isolation and the Effect of Significant Personal contact Upon Student Departure: Findings from Previous Research

One of the variables cited by Bean (1982) as a form of a student's objective interaction with the organization, and a theme common to all of the models of student persistence, is the notion that a student's integration into the social and academic communities of the institution has a significant effect upon whether that student stays or leaves college. Spady $(1970,1971)$ identified this concept as congruence with the institutional community. Pascarella (1980) focused upon the importance of students' contact with faculty with their feeling of integration. And among the organizational variables affecting a student's "intent to leave" in Bean's model and "goal commitment" in Tinto's (1975) model, several of the most influential were those which precipitated integration: close friends, informal contact with faculty, and membership in campus organizations. 
Isolation

The converse of integration, isolation, is also

associated with student withdrawal. According to Tinto

(1993):

Departure also arises from individual isolation, specifically from the absence of sufficient contact between the individual and other members of the social and academic community of the college. Though isolation may be associated with incongruence, in that deviants are isolates as well, it arises independently among persons who are not different from other members of the college. Individuals who might otherwise find membership in college communities are unable to establish via intervening interaction with other individuals the personal bonds that are the basis for membership in the communities of the institution. (p. 56)

Paraphrasing the work of Pascarella and Terenzini, Tinto added that;

Voluntary withdrawal is much more a reflection of what occurs on campus after entry then it is of what has taken place before entry. And of that which occurs after entry, the absence of contact. with others matters the most. (p. 56)

In support of this, Husband's (1976) study found that voluntary leavers in a small, liberal arts college were much less likely than persisters to identify someone on campus with whom they had a significant relationship. Good grades held little satisfaction in the absence of personal contact with other institutional members. Isolation, absence of significant contacts and remoteness of faculty as causes for leaving were reported by Bligh (1977) as well. 
This notion of isolation as a root of departure, and the identification of contact with other community members as an effective means of preventing isolation has been supported by an extensive body of research. This research has focused upon interaction with peers and involvement with extracurricular activities, interaction with faculty, and, interaction with other campus staff members.

Interaction with Peers and

Extracurricular Involvement

Pascarella and Terenzini (1991) noted that given the theoretical justification for the role of social participation in the educational process "it is not surprising that substantial research has addressed the relationship between social involvement and persistence and educational attainment" (p. 391). This research clearly suggests that "the frequency and quality of students' interactions with peers and their participation in extracurricular activities are positively associated with persistence" (p. 391). Among the many examples of this evidence which they cite are the studies of carrol (1988) (positive peer group interaction is a predictor of freshman success among black students); Dukes land Gaither (1984) (students participating in a cluster program which required high rates of social interaction had higher rates of persistence than non-participants); Mallinckrodt (1988) (perceived social support was a predictor of persistence 
for black and white students); Nelson and Scott (1984) (non-persisters participated in activities less and were significantly less satisfied in their social life then persisters); Simpson, Baker, and Mellinger (1980) (non-persisters had significantly less social integration and fewer friends); and Vaughn (1968) (non-persisters participate in significantly fewer social activities). Significant evidence exists that peer contact and social involvement have a positive effect on educational attainment, as well. Hanks and Ecklund (1976) found that social participation had a positive effect upon educational attainment for both men and women in a national sample of college students. More recently Stoecker, Pascarella, and Wolfle (1988); Ethington and Smart (1986); and Pascarella, Ethington, and Smart (1988) found positive relationships between social involvement and attainment of the bachelor's degree, entrance into graduate school and attainment of doctoral degrees.

\section{Interaction with Faculty}

Studies of student non-classroom interaction with faculty and its effect upon student|persistence and educational attainment have been nol less prolific that those concerning peer contact. In a succession of studies, Pascarella and Terenzini (Pascarella \& Terenzini, 1976, 1977, 1979a, 1979b; Terenzini|\& Pascarella, 1978, 1980) consistently found that persistence to the sophomore 
year was positively influenced by students' non-classroom contact with faculty.

Non-classroom contact of students with faculty had a similar effect upon educational aspirations and educational attainment according to the literature (Gurin \& Epps, 1975; Hearn, 1987; Pascarella, Ethington, \& Smart, 1988; Pascarella, Smart, \& Ethington, 1986; Pascarella, Terenzini, \& Wolfle, 1986). Conversely, the absence of faculty contacts has been found to be related to student voluntary withdrawal, as well (Pascarella, Smart, \& Ethington, 1986).

The weight of this research leaves little doubt that student interaction with faculty members has a strong influence on whether they choose to stay in an institution and ultimately graduate, or go no to graduate school.

Student Interaction with other Non-Teaching staff

Despite what we know by experience and from anecdotal evidence (Vieira, 1991), there has been little formal research on the impact upon persistence of students as a consequence of contact with campus employees other than teaching faculty. This gap in our understanding remains despite the declaration of prominent researchers (Noel et al., 1985; Tinto, 1993) who state that almost every contact which students have with campus community members will have an effect upon student persistence. 
However, research which does examine the effect of non-instructional staff on persistence offers a promising glimpse at a potentially rj.ch resource for support of student persistence on campus. For example, Beal and Noel (1980) found that student interaction with non-teaching staff, particularly student service professionals, was strongly related to student persistence. Similarly, in a study which looked at the effect of a mentoring program which utilized both faculty and student service administrators, Miller and Brickman (1982) found that this interaction had a positive impact upon student academic performance and retention. Yet even these fail to address the impact of staff beyond those in professional service, or advising roles. While Bernotavicz and Clasby (1984) found that departmental secretaries play an important role in communicating information about policies and procedures and in projecting a positive image of the university, in general, the impact of student contacts with classified staff members on college campuses is ignored.

\section{Programmatic Facilitation of student Contact with staff}

Having established that isolation hastens voluntary withdrawal, and student contact with others (peers, faculty, and to a lesser degree non-instructional staff) positively affects student persistence and educational attainment, we turn to the question of how to facilitate 
this contact, particularly in the early transition stages of a student's experience on campus? Here again, there is a rich literature which describes these applications. Described by Tinto (1993)| as "early contact programs" (p. 165), he emphasized that early in the freshman year is the most important time to institute such programs. Beal and Noel (1980, p. 81) concurred that the first year is a critical transition period for students and recommend that institutions "front load" their best services and people during the freshman year. Some of the most common examples of these front loaded programs which promote student contact are new student orientation, academic advising, residence Iife programs and student activities, and mentoring programs.

\section{Orientation Programs}

orientation programs are the most common method for initiating early contact with students. According to Titley (1985) the purposes of these programs are: (a) to explain to students and parents the requirements of the institution; (b) to help students get the most out of programs and services; (c) to help students evaluate their interests, abilities, and values; (d) to encourage students' relationships with faculty and staff; and (e) to help students deal with the many transitional problems (e.g., psycho-social adjustment, study skills, roommates) which they face early in their academic experiences. 
Titley (1985) suggested that orientation programs generally fall into three basic time formats: summer programs (one to three days), fall programs (usually a week), and orientation courses (one term). Pascarella and Terenzini (1991) described these programs as an institutionalized attempt at early student socialization, and state that the evidence suggests that there is a statistically significant positive link between orientation programs and student persistence. The related research indicates that students who participate in orientation programs have higher rates of persistence (Bron \& Gordon, 1986; Forrest, 1985) and graduation (Forrest, 1982).

of particular note are those orientation programs described as orientation courses or freshman seminars as described by Upcraft and Gardner (1989). The goals and objectives of these "freshman year experience" courses vary by institution, but most often include introduction to the college environment, academic skill enhancement and knowledge, values exploration, career exploration, stress management, and critical thinking (Gordon, 1989). Typically occurring in small group settings, their very nature promotes peer interaction in addition to the opportunity to interact with faculty and staff. The effect of these courses upon student persistence has been well established. Included in the evidence 
supporting this effect is the evaluation of freshman seminar courses at the University of South Carolina (Fidler \& Hunter, 1989). Research conducted over a 14year period found that students taking the freshman seminar persisted at higher rates than non-participating students in each year of the program (these differences were statistically significant in 10 of those years). Another study found that this difference may extend to graduation rates as well. The findings of a seven-year longitudinal study of participating students found that students taking the course had a significantly higher graduation rate (Shanley, 1987, p. 421).

\section{Advising Programs}

Like orientation, academic advising has been found to be positively related to increased persistence and graduation (Forrest, 1982, 1985).

While students clearly benefit from the substantive information provided through academic advising, there is little doubt that they benefit from the relationships which are facilitated by these activities, as well. crockett (1985) described four advising delivery systems in which this occurs: faculty advising, professional staff advising, peer advising, and paraprofessional advising. According to crockett only a few campuses have formally established paraprofessional delivery systems. More often this type of advising occurs informally among 
secretaries, clerks and other staff. Paraprofessionals, he said, "do not possess the background, depth, and experience to deliver the full range of developmental advising. . . but (their) use as advisers has merit" (p. 252). For example, the organized use of paraprofessionals in advising can provide continuity, free professional staff for other work with students, provide a sense of contribution for the paraprofessional, and reduce costs.

In whatever mode, faculty advising or paraprofessional, no activity is cited more often as a means for improving student persistence (Beal \& Noel, 1980; Lenning, Beal, \& Sauer, 1980; Ramist, 1981).

\section{Residence Life and student}

Activities

The effect of residence life and student activities programs upon student persistence has long been well established. Once again the basis for the effect of these programs seems to lie substantially in their natural tendency to link students with peers, staff, and faculty. Astin (1977, 1984) characterized this linkage as "involvement" with various elements of the institutional environment. In developing his theory of "involvement" Astin found that student engagement with the institution, especially peers and faculty, has a significant positive effect upon student retention along with other educational outcomes. 
Not only does the mere fact of living in residence halls improve persistence and academic achievement (Astin, 1973, 1977; Chickering, 1974), but whom a student lives with, who the residence hall staff are, and what kind of environment is promoted are important as well (Upcraft \& Gardner, 1989). For example, evidence exists that when students are assigned to residence halls by major, academic achievement and persistence improve (Davison, 1964; Schroeder \& Freesh, 1977; Taylor \& Hanson, 1971). Similarly, Upcraft, Peterson, and Moore (1981) found that students who get along well with their resident assistant received significantly higher grades. More recently, living-learning residence halls, in which the educational program is brought into the hall, has been found to improve retention (Pascarella \& Terenzini, 1980; Whiteley, 1982) •

Student participation with extracurricular activities (student activities, co-curricular activities) is also positively associated with persistence (Pascarella \& Terenzini, 1991). Specific activities which enhance persistence include belonging to student organizations (Billson \& Terry, 1982), involvement in social activities (Jeanotte, 1982; Terenzini, Pascarella, \& Lorang, 1982), involvement in cultural activities (Winter, Mcclelland, \& Stewart, 1981) and using campus facilities (Churchill \& Iwai, 1981). Pascarella and Smart (1990) also found that 
males who participate in intercollegiate athletics were slightly more likely to finish a bachelor's degree than non-athletes.

But not all students can participate so readily in campus programs. Students who commute to campus participate less in extracurricular activities and are generally less involved with the campus than non-commuters, and therefore have a greater tendency to dropout than non-commuters (Astin, 1973; Chickering, 1974). According to Chickering and others (Harrington, 1972; Schuchman, 1974) this lack of involvement is due, in a great degree, to the many roles (family, home, work, community) which involve commuter students in addition to their roles as students. Understanding this, some institutions have created activities for commuters which integrate their social networks with those of the institution. Wilmes and Quade (1986) described a model for developing programming for commuter students in which "integration of outside support systems and significant others" is one of the most important goals for helping to establish links for commuter students. Though not as easily accommodated, commuters experience higher rates of persistence and educational achievement for many of the same reasons as non-commuters. According to Knefelkamp and stewart (1983),

Commuter students have a need for opportunities often associated with residence on campus, more 
time with faculty, more intensive peer

interaction time, and closer integration of

living and learning experiences. (p. 66)

\section{Mentoring Programs}

Another category of programs which is designed to increase student contact with institutional

representatives and reduce isolation are those programs which have been described as mentoring programs. While the notion of mentoring is not a new concept, it has gained much recent attention in business and education as a formal means by which individuals learn from, and receive guidance from, one more experienced, and usually older than themselves. According to Daloz (1986) "mentors have become a hot item" (p. 17). Beginning with the first Mentor, who appeared in the odyssey as a trusted guide and friend to Odysseus's son Telemakkos, Daloz described mentors as guides who lead us on the journey of our lives. Mentors, and the concept of mentoring have been further described and popularized by Levinson (1978) and. Sheehy (1976). Both described mentors and mentoring as an important relationship, the existence or absence of which, may have an important impact upon an individual's development. Levinson described the role of the mentor as host, guide, counsel, exemplar, and facilitator of the "Dream," the individual's vision of the future. Both Levinson and Sheehy believe that mentors, when they are 
available, play an important role in an individual's transition from one life stage to another.

The transition into college, to a new environment and culture, is the type of significant life transition, which Levinson (1978) and Sheehy (1976) described. A review of the literature on mentoring students in higher education is rich with the description of mentoring programs and reflects the understanding of the importance of this role. There are faculty mentoring programs; peer mentoring programs that target women, minorities, freshmen, graduate students and returning adults; programs that use community members; and programs that utilize the telephone for communication with mentees (Boyd, 1990). The purposes of mentoring are equally varied and include: improving student retention, increasing self esteem, increasing student involvement, educational experience, and decreasing isolation (Johnson, 1989). Without commenting on the success of the programs, Johnson cited six examples of typical mentoring programs:

1. Bowling Green State University: A mentor team of faculty, staff and peers co-teach a seminar designed to enhance students' relationship with the college, assist the transition from home to college, and to provide a contact for students both inside and outside of class.

2. Colorado State University: Minority freshmen are matched with ethnic minority faculty or staff, or faculty 
in their major, who interact with students in both structured and unstructured activities including dining out together, recreational activities, or participation in other campus activities.

3. University of California, Irvine: Students attend a pass/no pass general information course which includes topics like study skills, relationship skills, and substance abuse. In addition mentor/mentee relationships are fostered with faculty and staff (including the police chief, student affairs staff, and other non-teaching staff).

4. Notre Dame college of Ohio: students meet as individuals or in groups with mentors who help them set goals for social and intellectual growth and development. students are selected in their freshman year, pick a faculty or staff mentor, and are encouraged to continue in the program for the duration of their college experience.

5. Rensselar Polytechnic Institute: Students with low grade points during their first semester are assigned to a faculty member who is responsible for creating a relationship with the student and helping him or her to get involved in college. Mentors and students meet on a once a week basis.

6. Canisius College: Faculty and student aides act as mentors for freshmen and transfer students in order to: (a) improve their transition to college; (b) teach them 
new social; personal, and academic skills to enhance academic success; (c) enhance relationships between students, faculty and administration; and (d) develop a positive image of the college by students.

Each of these examples describes a different model of mentoring, but each is similar in its core purpose-to provide opportunities for student contact with institutional members. Tinto (1987) explained that the value of mentors is that they:

shepherd newcomers through the period of separation and transition to the life of the college, and assist in their eventual incorporation as participating members in the community of the college. (p. 147)

In the same vein, Johnson (1989) concluded that mere contact is important, but "the key to mentoring is caring" (p. 128).

Finally, Johnson (1989) suggested that there are several basic concepts that should be considered about mentoring programs:

1. Mentors are more than just teachers, they provide assistance through times of transition and individual development.

2. Mentors need not be exclusively faculty, but may include staff and mature peers.

3. Intrinsic rewards for mentors are most important, but extrinsic rewards should be developed as well.

4. Mentor programs must include training. 
5. Goals and structure for mentoring programs must fit the individual culture of the campus and its students.

6. Systematic evaluation for mentoring programs is essential.

7. Mentoring programs seem to be of special benefit to women and minorities.

8. Mentoring provides an opportunity to enhance freshman success, and to maximize the use of the skills and abilities of faculty and staff.

Another framework for mentoring programs had been provided by Murray (1991), a management consultant specializing in mentoring programs. In describing a mentor, she stated that while the role might include being a sponsor (a booster or advocate) and a role model (an individual inspiring emulation), being a mentor includes several other functions:

1. Providing information about the mission and goals of the organization.

2. Providing understanding of the organilzation's human resource philosophy.

3. Tutoring specific skills and behaviors related to effective organizational functioning.

4. Giving feedback on performance.

5. Being a coach for adding to skills and ability.

6. Being a confidant in times of crisis. 
7. Assisting the person baing mentored in career development.

8. Meeting at planned intervals to provide feedback and planning.

9. Agreeing to a conclusion of the relationship at the appropriate time.

10. Maintaining the relationship between the person being mentored and their natural boss. Murray suggested that there is the potential for positive and negative impacts upon the organization, the mentor, and the mentee as a result of a facilitated mentoring program.

For the organization, potential positive impacts include increased productivity, better communication, reduced costs, and motivation for senior personnel who act as mentors. Negative impacts might include frustration on the part of individuals who are mentored and for whom there is no organizational payoff, or who perceive there to be no organizational commitment for the program, lack of coordination with other personnel programs, and the cost of administering the program.

For the individual being mentored positive outcomes might include increased productivity, increased awareness and understanding of the organization, and ultimately increased success within the organization. Negative aspects for the person being mentored might include 
unrealistic expectations for promotion, damage to the relationship with a boss, and having a mentor who does not maintain commitments.

Murray (1991) pointed out that the positive aspects of mentoring for the mentor include increased self-esteem as a result of being chosen to mentor, a fresh perspective and revitalized interest in work, the potential for financial reward, and the opportunity to fulfill individual developmental goals by helping others. Mentors might find the experience to be negative if they feel pressured to participate, lack the necessary skills particularly in terms of coaching and feedback, lack time and/or institutional commitment to work with the mentee, no perceived reward, either intrinsic or extrinsic, and being mismatched with the mentee.

Like Murray (1991), Boston University professor Kramm (1988) defined the functions of mentors in the work setting. Sheldivided these into two categories: (a) career functions ("those aspects of the relationship which involve learning the ropes and preparing for advancement in an organization" [p. 22]) and (b) psychosocial functions ("those aspects of the relationship that enhance a sense of competence, clarity of identity, and effectiveness in a professional role" [p. 22]). Like the notion of student integration and its importance to retention cited in the models described earlier (Bean, 
1982; Pascarella, 1980; Spady, 1971; Tinto, 1975), Kramm stated that "psychosocial functions affect the individual's relationship with self and significant others both within and outside of the organization" (p. 32). It is this potential for individual integration with the institution or organization which hold promise for mentoring programs designed to affect student satisfaction and persistence.

While mentoring and mentor programs in higher education have been thoroughly described (Johnson, 1989; National Clearinghouse for Commuter Programs, 1985), support for the link between mentoring and academic success and persistence has not been well established. In a recent review of the literature on mentoring, Jacobi (1991) concluded that "empirical studies of the association between mentoring and academic outcomes are in short supply" (p. 515).

Jacobi (1991) examined literature which described the relationship between academic success, and both informal/ naturally occurring mentoring, and formal mentoring programs. In her examination she found only one study of natural mentoring which directly assessed its relationship to academic success. In this study (Erkut \& Mokros, 1984), the authors reported that all of the respondents could identify a professor who had an impact on them. However, the differences in student outcomes could not be 
attributed to the mentor relationship. Jacobi noted also that the definition of mentoring used in this study emphasized role modeling, almost to the exclusion of direct assistance with professional development or emotional support. She pointed to other related areas of research, especially those which described the impact of student contact with faculty (Astin, 1977; Pascarella \& Terenzini, 1977; Wilson et al., 1975) as providing indirect support for the hypothesis that mentoring promotes academic success.

According to Jacobi (1991), formal mentoring programs, designed specifically to promote academic success, are well described, but systematic evaluations of these programs are more rare. She cited Noe's (1988) study of a teacher/administrator program and cosgrove's (1986) study of a mentoring transcript program, as possessing the methodological rigor which others lacked. Noe (1988) examined a professional development program in which administrators were assigned to teachers as mentors. The results of this study indicated that the mentoring relationship provided psychosocial, but not career or vocational benefits. While Jacobi (1991) found Noe's study to be noteworthy, she noted that it is unknown to what degree it could be generalized to the university setting. 
While Noe (1991) focused upon the outcomes of teachers being mentored by administrators, Cosgrove (1986) focused more specifically upon undergraduates. In this study cosgrove looked at a program in which undergraduates were assigned to a mentor for the purpose of providing more information about university life, and assistance in choosing opportunities for extracurricular involvement. This study found that students who participated in the program were more satisfied with the university environment, and showed greater developmental gains than the control group. In discussion of the results, Cosgrove noted that overall satisfaction with the institution is thought to be positively associated with student retention (Astin, 1977). While this study provided some support for the value of mentoring programs, it did not attempt to measure the effect of the program upon academic success or retention.

In addition to the need for more methodological rigor in relationship to the study of the impact of mentoring in higher education settings, Jacobi (1991) suggested that there is also a need for more standardization in the definition of these programs, and more theoretical support to explain the proposed links between mentoring and academic success. She suggested four theoretical perspectives that might guide the development of the program and related research: (a) involvement in learning 
(Astin, 1977, 1984, 1993); (b) academic and social integration (Tinto, 1975, 1987); (c) social support (Cobb, 1976; House, 1981); and (d) developmental support (Chickering, 1969; Perry, 1970). In conclusion, Jacobi noted that while the belief in the value of mentoring programs is widespread, as exemplified by the implementation of mentoring programs over the last 10 to 15 years, "there is a critical need for more research about mentoring, especially as it applies to undergraduate academic success" (p. 1526).

Given this rich description, if not evaluation, of mentoring programs in the literature, it is somewhat surprising that there are no examples which utilize classified staff. This lack of attention may be an expression of the perception that these employees are already overburdened, and are increasingly being asked to do more, as higher education institutions cut budgets and downsize all across the country. Another explanation might be that these employees are not perceived to be sufficiently educated or competent to play this role.

At the same time, it could be said that individuals who work in classified positions act as mentors every day. In many aspects of their daily work they advise, guide, and care about students with whom they come in contact, as do the mentors in the examples cited earlier. These typical roles for classified staff, combined with aspects 
of the mentoring models described, provide the framework for the mentoring model to be tested in this study. The characteristics of the model instituted include Johnson's (1989) perspective that mentors in higher education settings need not only be teaching faculty, and that rewards for mentoring include intrinsic payback, but must include extrinsic rewards as well. It also includes the functions of interpreter, tutor, and guide for understanding the organization which Murray (1991) described as a function of mentor (what Kramm [1988] described as career functions). Finally, this mentoring model depends heavily on those mentor functions which Kramm described as psychosocial (role modeling, acceptance and confirmation, counseling, and friendship).

While it is intended that these roles of the mentor will have positive effects on the mentee, as Kramm (1988) suggested in her discussion of the functions of a mentor, there may be reciprocal benefits for the mentor as well. students may not be the only beneficiaries of this relationship. Indeed a review of the literature of job satisfaction and service quality suggests an interactive linkage between job satisfaction of classified service employees who work with students and the quality of their service and interaction with students. 


\section{Job Satisfaction}

As the earlier reviewed literature indicates, there is substantial evidence to support the belief/that student interaction and involvement with other campus|community members (faculty, staff and peers) leads to greater satisfaction and student persistence. This outcome in itself would seem to be sufficient to stimulate institutions to promote these relationships. But in fact, other positive outcomes may result from these interactions. There is much to suggest that the reverse of the equation may be true: that staff interaction and involvement with students may result in increased satisfaction on the part of these individuals las well. The literature reviewed hereafter attempts to uncover this symbiotic relationship, focusing especially on job satisfaction and how it interacts with the role of staff on campus and quality of service.

\section{Theories of Job Satisfaction}

Theories of job satisfaction have evolved along with, and in relation to, general theories of management. As managers and theorists sought to improve organizational productivity their focus was frequently upon making workers happy (Lawler, 1973). This "happy workers are productive workers" theme focusing upon the role which satisfaction has played on productivity, absence and 
turnover, has evolved more recently into an examination of the "meaning" of work for individuals and how that affects satisfaction.

Miles (1975) suggested a convenient framework for looking at this evolution of management theory. He suggested that there are three categories: traditional theory, human relations theory, and human resources theory (Table 1). Within this framework each category has a set of assumptions based upon human attitudes and beliefs, the policies that a manager might utilize, and the expected outcomes in relationship to worker satisfaction. Using this framework we can follow the progression of satisfaction theory from the belief that fair pay is sufficient to motivate productivity (with no thought to worker satisfaction), to the notion that work may satisfy the social, psychological, and physical needs of workers including motivating productivity, stimulating personal development, and increasing satisfaction.

\section{The Traditional Model}

Perhaps most illustrative of the Traditional Model, particularly in relationship to its focus on process rather than people, is Taylor's (1911) theory of Scientific Management. 
Table 1

The Evolution of Management Theory

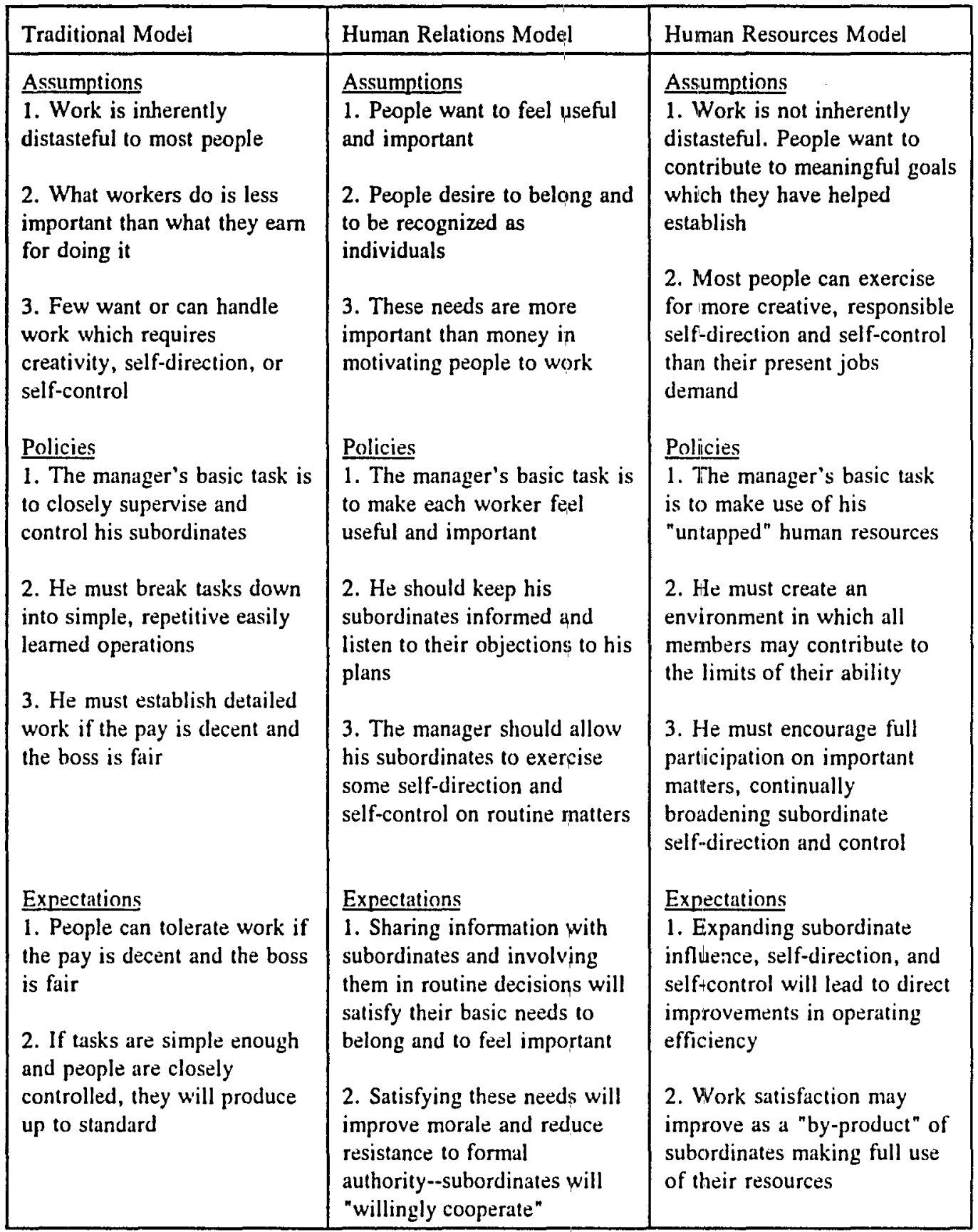


For Taylor (1911), management of an organization and people was best delivered through scientific analysis of the process, and mechanistic assignment of people to produce the output. His concept was to achieve ". . . the maximum prosperity for the employer, coupled with the maximum prosperity for each employee" (p. 9). Central to his theory was the principle that management's role was to direct and prepare the work, and for workers to accomplish the work at $100 \%$ of their output. In Taylor's model, workers had no natural tendency to wish to achieve. Rather, worker initiative could only be stimulated through the provision of "special incentives," including higher wages and promotions.

Locke (1976), a prolific researcher and industrial/ organizational psychologist, characterized the era of Taylor and others as the "Physical Economic School" with primary focus on the physical arrangements of the work, physical working conditions, and pay. The work of Weber (1947) was also characteristic of this school. Seeing the limitation of practical organization typical early in the century, Weber developed the bureaucratic model of organizations which had the following six dimensions (Bolman \& Deal, 1987): (a) fixed division of labor among participants, (b) hierarchy of offices, (c) a set of general rules that govern performance, (d) separation of personal property from official property and rights, (e) 
selection of personnel based on technical qualifications, and (f) employment viewed as a career by organizational participants.

As in Taylor's '(1911) work, Weber's (1947)

bureaucracy focuses upon the structure of work and minimizes the human dynamic. In both Taylor's and Weber's theoretical systerns authority and responsibility are rooted in positions and structures created through systematic analysis-the role of individual workers is only important insofar as they do, or do not, accomplish the tasks assigned to the position (Bolman \& Deal, 1987; Miles, 1975).

\section{Human Relations Model}

Despite pervasive support for the traditional model, there were theorists and managers who argued that while you might treat the organization like a machine "its human parts, along with its equipment, needed regular Iubrication" (Miles, 1975, p. 40).

Central to this shift in thought concerning the relationship of managlement to employee satisfaction and production, were the Hawthorne studies initiated in the early 1920s. Begun as a study of rest pauses, incentives on productivity and other working conditions, the focus of the study soon shifted to the attitudes of workers. What researchers discovered was that employees in a congenial work group, interacting with supportive managers, 
maintained or increased work productivity despite changes in working conditions. This research interpreted by Mayo (1933) and Roethlisberger and Dickson (1939), helped to shape research on job satisfaction.

Supported and stimulated by the Hawthorne studies, the Human Relations theory of management, the idea that employees would be satisfied in their work if they had benevolent supervisors and liked their fellow workers, would remain popular among managers and organizational theorists until the 1960s.

\section{Human Resources Model}

While the Human Relations movement did much to add to the understanding of people's needs for acceptance, status and recognition, the notion that people need more than praise and congenial relationships at work began to develop in conjunction with psycho/social constructs initially developed in the 1930s and 1940s. Most prominent among these was Maslow's Hierarchy of Needs. Maslow (1943) argued that human beings have innate wants and needs which affect an individual's behavior and development and that these occurred in ascending order from the basic needs of food, shelter, and clothing, to safety, love and self esteem needs, and finally to the highest and most intangible needs of self actualization or fulfillment (Figure 4). An individual's ascendancy in the hierarchy is developmental in that each level must be 
Maslow's Hierarchy of Needs

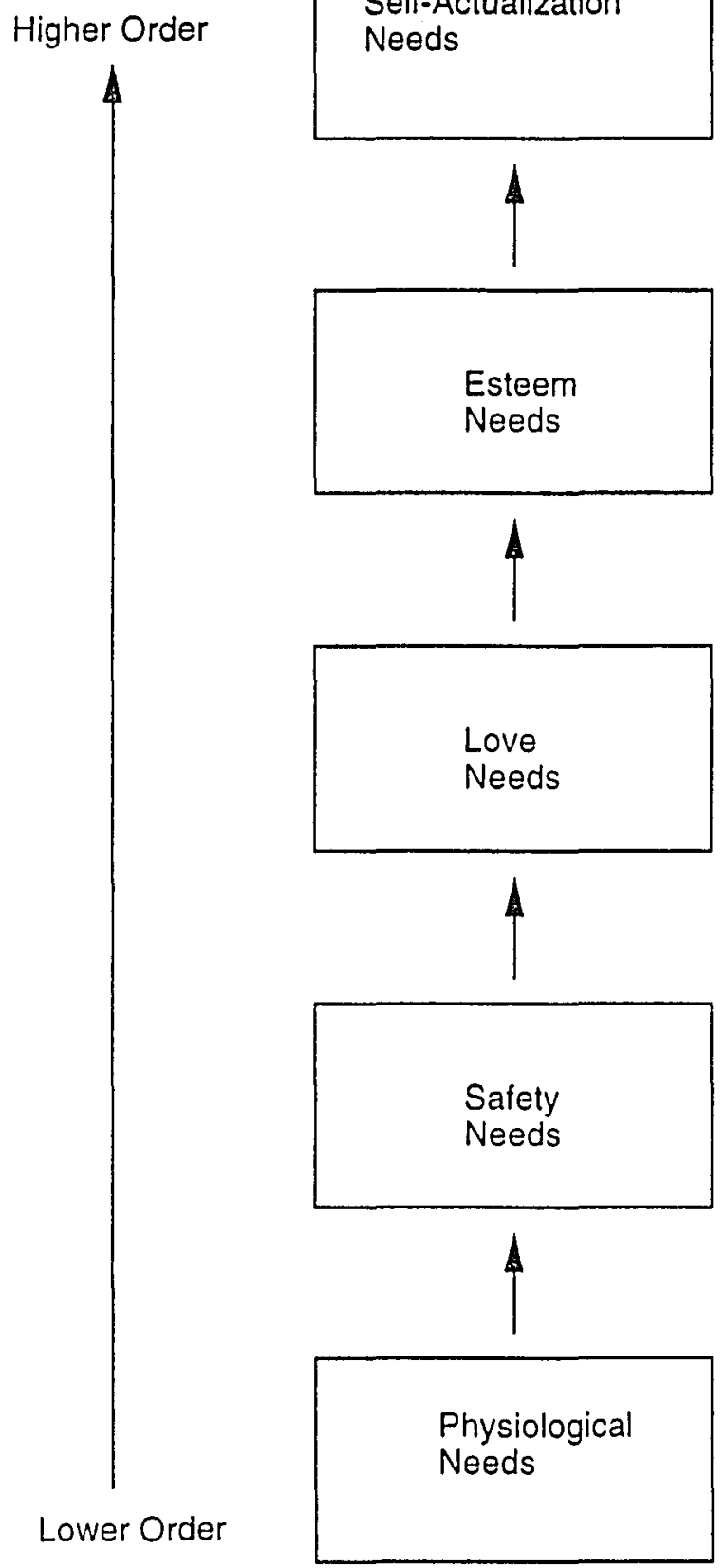

Figure 4. Maslow's hierarchy of needs. 
minimally satisfied before rising to the next level. While few ascend to the level of self-actualization, there is a natural inclination for individuals to strive for that level and to be productive in that pursuit. Put in the context of work, Maslow's hierarchy argued that job satisfaction might be stimulated by providing individuals opportunities to grow and develop in their job. Maslow's (1943) theory opened the door for many other theories of management which argued that the content (rather than the output) of the job, and an individual's opportunity to control that content, has a significant effect upon job satisfaction. The following are examples of theoretical constructs which fall within the Human Resources model:

\section{Lawler's Model of Facet} Satisfaction

Lawler (1973), an industrial and organizational psychologist, theorized that emotions, including satisfaction and dissatisfaction, result from an individual's perceptions of various facets of work (personal inputs, inputs of others, job characteristics, outcomes of work, of self, and others). For example, if equity is perceived between input to a job, the characteristics of the job, and ultimate reward for the job, an individual is likely to experience satisfaction. If equity between different facets of work is missing 
(e.g., the relationship of an individual's experience and education to the requirements of the job, and/or pay) an individual might experience dissatisfaction, or even guilt and discomfort. While Lawler's model looks at the satisfaction derived from particular facets of the job, he theorized that the combined feelings a worker has about all aspects of the job define overall job satisfaction, and that this will vary according to the importance of the factor to a particular individual.

\section{Locke's Value Theory}

Another industrial and organizational psychologist, Locke (1976), contrasted needs (objective elements which insure survival) from values (which are subjective and represent a person's desires). Locke summarized his theory as follows:

Job satisfaction results from the perception that one's job fulfills or allows the fulfillment of one's important job values, providing and to the degree that those values are congruent with one's needs. (p. 1,307)

He argued that job satisfaction (or any emotional response) is a product of a dual value judgement: the discrepancy between what an individual wants and what he or she is getting, and the importance of what is wanted to the individual. Importance of a particular element of the job also plays an important role in job satisfaction. If an element is unimportant, one's feeling about it will have little effect upon overall job satisfaction. 
Conversely, satisfaction with a particular job element of high importance may have a significant effect upon overall satisfaction.

\section{opponent-Process Theory}

Landy (1978), a professor of psychology at Pennsylvania State University, theorized that an individual's experience of satisfaction will change over time as a result of a mechanism (which he names an opponent process) which acts to provide equilibrium for an individual's emotional state. This mechanism acts as a damper to extreme emotional states (positive or negative) which might be damaging to the individual. It is this protection function which causes job satisfaction to vary between individuals. The theory has three components (primary emotion, opponent process, and stimulus) which interact as follows. A positive or negative stimulus is introduced, which causes an emotional response. After some threshold of time has passed, an opponent process is activated to bring the primary response under control. When the stimulus disappears the emotional response stops immediately, the opponent process continues and disappears more gradually. The theory also assumes that the strength of the opponent process increases each time it is activated. In this way, the same stimulus could have a different effect on individuals depending upon whether they had experienced it in the past. 
The theory implies that satisfaction may have a longitudinal perspective (dependent on whether it is measured during the stimulus or the opponent process), and that work itself may not be dissatisfying for employees. Rather, the opponent process may have become stronger, implying that any work-related stimulus can become boring.

\section{The Vitamin Model}

Another psychologist, Warr (1987), developed a model patterned after the way in which vitamins affect physical well being. Like various vitamins affect health, he identified nine elements of work which can affect satisfaction: money, physical security, valued social position, externally generated goals, variety, clarity, control, skill use, and interpersonal control. A minimum daily "dosage" of these elements will promote satisfaction, he suggested. However, too much of certain variables may have adverse effects including overload, stress, low concentration, achievement, lack of personal control, and overcrowding.

\section{Satisfaction as Attribution}

While not a formal theory, Landy (1989) described what he called an emerging position: satisfaction as attribution. Landy argued that satisfaction/ dissatisfaction is a feeling and therefore more attention should be paid to theories of emotion. He highlighted the 
theory of Schachter and Singer (1962) which suggested that an event in the environment causes arousal in the individual, and the individual in turn looks for cues in the environment to explain the arousal. The resulting emotion is dependent upon the person interpreting the clues. In thisi way the outcome (feeling of satisfaction or dissatisfaction) could be different for different individuals, despite the same circumstances of arousal. For example, job enrichment, an increase in the scope or breadth of job duties, is frequently a method for creating an individual's development and satisfaction. However, given the circumstances of the individual or the work group, the emotional outcome of job enrichment might be dissatisfaction (in an environment in which enrichment is seen as getting more work for the same pay). In this way, Landy (1989) argued satisfaction and dissatisfaction "become social and cognitive construction" (p. 22). He noted that the relationship of job enrichment to satisfaction from a cognitive perspective is particularly puzzling. Several studies (Caldwell\& O'Reilly, 1982; Marks, Mirvis, Hackett, \& Grady, 1986; Rafaeli, 1985) found that there was not a relationship between job enrichment and satisfaction. However a meta-analysis by Loher, Noe, Moeller, and Fitzgerald (1985) of 27 studies of the effects of enrichment upon satisfaction indicated that there was a substantial 
pasitive relationship between efforts to enrich jobs and worker satisfaction.

Along with cognition, Landy (1989) argued that satisfaction may well be attributed through personal disposition. He stated, "Some people are simply more satisfied with all aspects of their lives" (p. 466). Landy cited the work of Bandura (1986, 1987), O'Reilly and Caldwell (1981), and Pulakos and schmidt (1983) in support of this notion. All of these studies indicate that previously held personal beliefs or traits had more effect upon satisfaction/dissatisfaction than did the objective conditions of the job. Of special interest in this regard, was the study by Arvey, Bouchard, Segal, and Abraham (1987) in which $30 \%$ of the variance in job satisfaction of identical twins reared apart, could be attributed to genetic factors. Landy argued that the position of satisfaction/through attribution (cognitive or dispositional) is an important emerging trend worth further: study, which further adds to the richness and complexity of theoretical frameworks for understanding job satisfaction.

In addition to these theoretical perspectives, indiviclual studies have revealed much of what we know about the sources of job satisfaction. Three significant reviews of this literature have been undertaken by 
Herzberg, Mausner, Peterson, and Capwell (1957), Vroom (1964), and Locke (1976).

In the most recent of these, Locke (1976) estimated that more than 3,300 articles or dissertations had been published on job satisfaction. Categorized by their source, Locke divided these studies by: (a) events and conditions (which cause happiness/unhappiness or satisfaction/dissatisfaction and (b) agents (who are responsible for events and conditions). Landy (1989) synthesized the results of these studies and Locke's conclusions as described in Table 2. Because of the disparity of these studies, Landy concluded that they "tell us little about the nature of satisfaction" ( $p$. 470), but "they might represent a point of departure for a manager who would like to set about improving the satisfaction/ of his workforce" (p. 471).

Job Satisfaction and Productivity

A belief which is generally a fundamental corollary to the discussion of satisfaction in the workplace is that worker satisfaction promotes productivity. According to Iaffaldano and Muchinsky (1985), this assumption is implicit in our "organizational programs and policies, our research endeavors, and even in the expectations of those who review the satisfaction-performance literature" ( $p$. 271). 
Table 2

Synthesis of Job Satisfaction Research

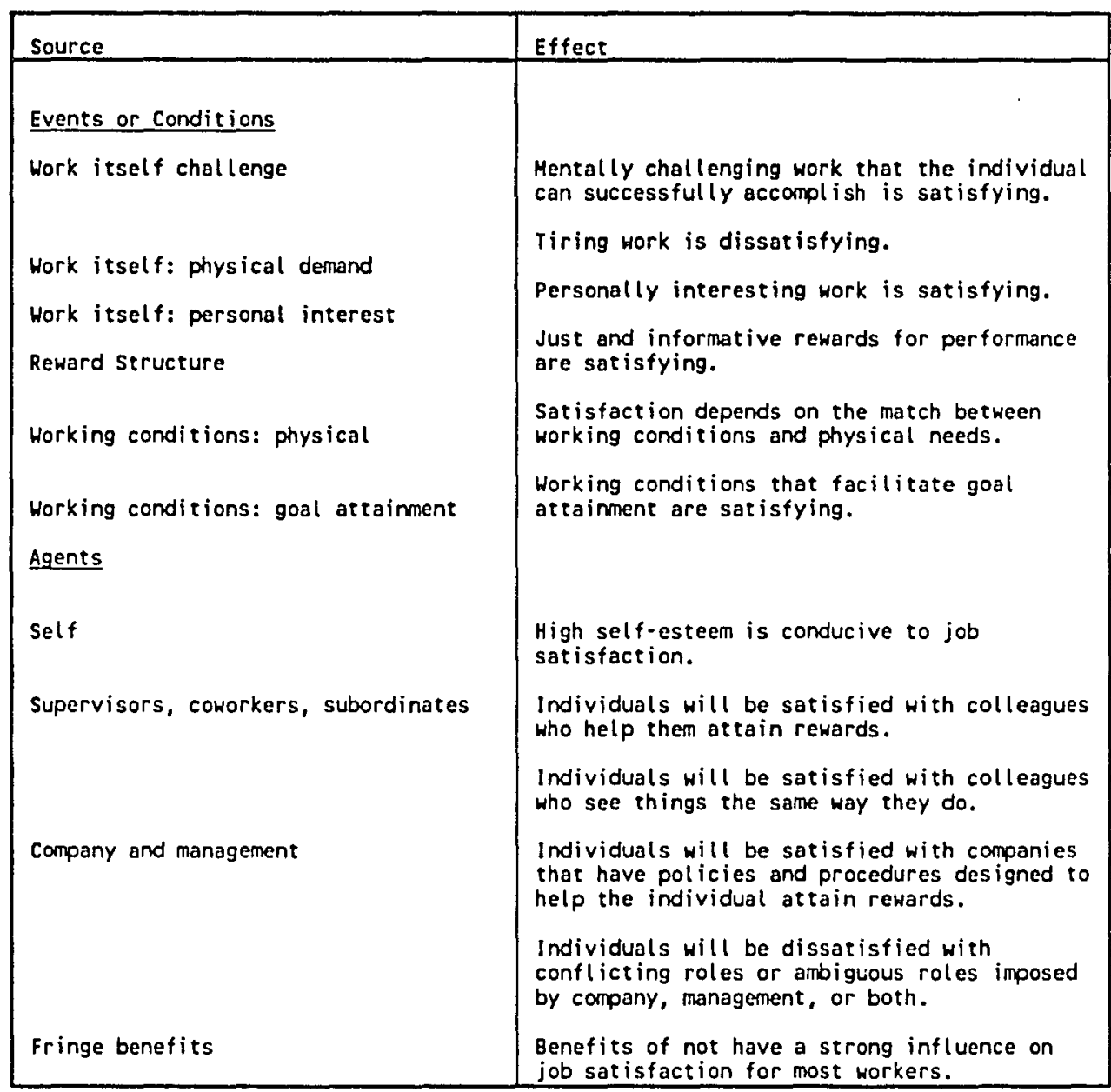

Despite this firm belief, until recently the connection between satisfaction and productivity (including quality service) has not been born out by an analysis of the literature. Similar to earlier reviews (Brayfield \& Crockett, 1955; Herzberg et al., 1957; Vroom, 1964), Iaffaldano and Muchinsky's (1985) meta-analysis of the related literature found that "satisfaction and 
performance are only slightly related to each other" (p. 271) despite our intultive notion that there should be a connection between these two variables. While they found no connection, they conclude that the importance of high satisfaction and high productivity in our society, and the belief that we may be able to design work which links the two, will continue to drive research which examines the satisfaction-performance l'ink.

Service Quality: A Product of staff Satisfaction, and a Tool for student Retention

While the intuitive link between job satisfaction and productivity seems to be elusive, recent studies in the literature of service quality seem to hold some promise that there is a link between the attitudes of employees and the perception of productivity defined as service quality.

Ulrich, Halbrook, Meder, Stuchlik, and Thorpe (1991) described this approach to/management of organizations as the merging of three streams of management thought: the quality movement (Deming, 1986), an awareness and dedication to customers (Albrecht \& Zemke, 1985; Peters, 1987), and a focus upon employees and strategies which secure increasingly scarce/human resources (Schein, 1985). They stated that:

The merging of these streams has begun. Managers are beginning to recognize that employee attachment--indicators of employee 
dedication, commitment, productivity and affective response to a company--may be a predictor of customer attachment--indicators of customer dedication, commitment, productivity, and affective response to a company. (p. 89)

According to Ulrich et al. (1991) there are three rationales for connecting employee and customer satisfaction:

1. The competitive rationale: As traditional sources of competition between organizations evolve toward parity (equal access to capital and technology, and common process features) managers must find new ways to differentiate their firms. Organizational practices which increase customer service, and meet customer expectations, increase the customer's perception of value in the organization and thereby, organizational competitiveness.

2. The psychological rationale: Where employees share mindsets or cognition about the goals and processes of an organization their attachment to the organization is likely to be high. Customers who come into contact with these shared mindsets are likely to be affected favorably by what they see. In this way, employee attachment may increase customer attachment.

3. The human resources rationale: If the shared mindset of employees increases their attachment, which in turn increases customer attachment and increased competitiveness, then practices (including HR practices) 
which influence shared mindset may play an important role. For example,

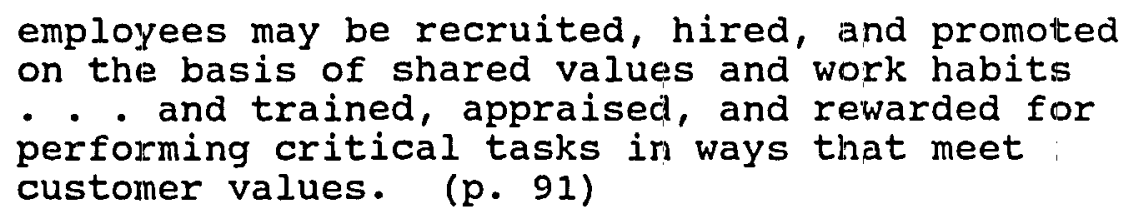

Figure 5 highlights Ulrich et al.'s (1991) basic premise that employee attachment may resilt in customer attachment and increased competitiveness and the rationale for creating systems and processes which|may increase that attachment. In support of his premise Ulrich presents three case studies "which suggest that employee and customer attachment are two sides of a coin and that increasing employee commitment may lead to increased customer commitment" (p. 102).

Other recent studies have also suggested support for this premise. Citing earlier literature: which found strong relationships between employee and customer perceptions and attitudes in relation to service practices and quality among bank branches, Turnow and wiley (1991) found strong, positive relationships between customer satisfaction, employee perceptions/attitudes of managerial practice (overall satisfaction with the company, and attitudes regarding organizational culture and climate) and organizational performance. Further, this study found that employees' perceptions of the organization's/culture for succes:s correlated highly with management practices, and that this in turn showed a substantial relationship to customer satisfaction with service. 
Premise and Rationale for Employee and Customer Attachment Basic Premise of Employee/Customer Attachment:

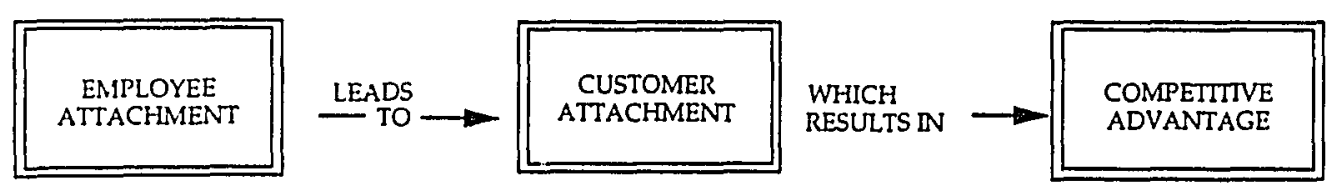

Rationale for Employee/Customer Attachment:

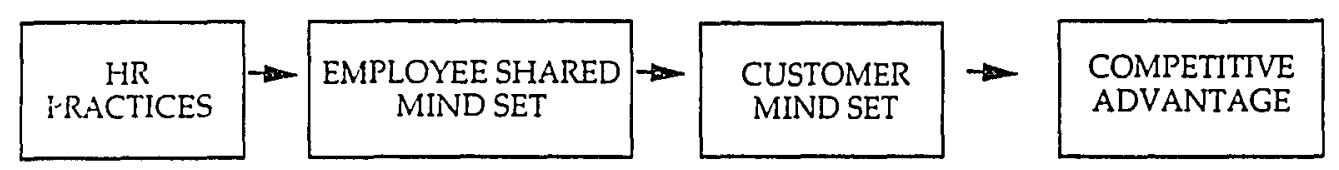

Fiqure 5. Premise and rationale for employee and customer attachment.

wiley (1991) found similar results in a study which examined employee opinions and customer satisfaction in more than 200 comparable retail stores. This study found a strong positive relationship between customer satisfaction and how employees describe key aspects of the store's work conditions and processes. In short,

the environment that management creates and reinforces for its employees is directly related to both the within-store experience of the customers, as well as their stated intention to return. (p. 123)

Further support for this link between customer satisfaction and employee job satisfaction was found in a study of employees and customers of an insurance organization. Looking at the relationship between customer satisfaction, job satisfaction and employees' self-perceived service capability, schlesinger and 
Zornitsky (1991) found that if employees feel good about the service they are delivering, they are satisfied in their jobs and their capability to provide good service, and that effort successfully directed at enhancing service capability also improves job satisfaction. They found also that this relationship increases as the tenure of employees increases. They stated that these findings imply that "focusing on activities that enable employees to better serve customers is generally the most significant service-related initiative an organization can make" (p. 149).

As this literature suggests, there is some reason to believe that job satisfaction might promote better service, which in turn might promote increased customer satisfaction. Translated into higher educational terms, job satisfaction in front-line classified employees might improve service quality, which could improve the satisfaction of students (customers) being served, which could ultimately improve student (customer) retention and satisfaction. In this way, job satisfaction may lead to student satisfaction. The foundations for these beliefs are grounded in the concept of quality management or TQM, which has as its center the concept of quality customer service.

Higher education has only more recently begun to embrace the concept of total quality management (TQM) that 
has so engaged business and industry for several years now (Carothers, 1992; Coate, 1991; Seymour, 1991, 1993). And though higher education has lagged behind the business sector, the involvement has been no less valuable. What colleges and universities are finding is that they can improve the manner in which their product (educational services) is delivered, and that the means for accomplishing this is through continued improvement of the product facilitated by the involvement and empowerment of the individuals who most directly provide the product. Sherr and Lozier (1991) summarized the foundation of this theoretical approach, now dubbed TQM, developed by Deming (1986), Juran (1988, 1989), and Crosby (1979) in five focused areas:

1. Mission and customer focus; Everyone in the organization is both a supplier and a customer of services. Service is provided to both external and internal customers. Having a focus on our customers requires that we know their needs and know whether they are being satisfied, so we can continue to satisfy them.

2. Systematic approach to operations; TQM requires systematic, not random, continuous improvement of the dimensions of quality. Any aspect of higher education, from the curriculum and advising, to payroll, purchasing and travel reimbursement, can benefit from predictable input. For example, consider teaching course $B$ that has a 
prerequisite of course A. If the instructor can count on students knowing material from course $A$, it will be much easier to teach course B, and educational quality will be improved.

3. Vigorous development of human resources; Continuous quality improvement requires continuous personal improvement. Development of human resources, therefore, is at the heart of improvement of organizations. Part of that development comes as a product of empowerment. Individual employees closest to the impact of a decision must be prepared and capable to make critical decisions and to take action.

4. Long-term thinking; Quality requires long-term thinking and foregoing short-term benefits for long-term well being. Organizational improvement does not occur overnight. The goals of continuous improvement and development of human resources are not achieved immediately require systematic and ongoing attention.

5. Commitment; Every employee must be involved and committed in order for a culture of quality to be created. It is not enough for a leader to demand that it will occur. Employees at all levels, especially where the service is provided, must support the effort to continuously improve.

These elements of TQM theory have profound implications for the notion that classified staff may 
affect the satisfaction and retention of students (customer satisfaction). As noted earlier, front-line classified staff have frequent interaction with students. If we agree with Tinto (1987) that every interaction has an effect on student retention, then frontline staff may be both suppliers and consumers of services designed to deliver the product--student satisfaction and retention. TQM theory argues that as suppliers they should: (a) participate in a systematic analysis of the effect of their interaction; (b) be empowered to act on the ideas and strategies they develop, and attempt to continuously improve their product; (c) focus on their customer and recognize that satisfying students is their job, not merely answering phones or processing paper; and (d) be provided with training to support and develop their service to customers.

TQM theory argues that the result of this style of management can improve customer service. Indeed, at least one educational consulting firm (Noel/Levitz) has developed a training program for staff members which links student retention to staff customer orientation (Tschohl, 1989). But it also supports the proposition that there are parallel positive effects upon the employees who participate in such a management framework. Juran (1988) argued that the methods of TQM (e.g., more self control, quality circles, consensus decision making, and job 
enrichment), are ways of managing employees which promote motivation, satisfaction, and growth as described by Maslow (1943) (Hierarchy of Needs), Herzberg (1966) (Motivation Hygiene Theory), and McGregor (1960) (Theory $\mathrm{X} /$ Theory $\mathrm{Y}$ ). In the same vein, seymour (1993) argued that the methods of TQM (training, empowerment) create Hawthorne-type effects which benefit both the employee and the organization.

Summary

This review has spanned a broad spectrum of Iiterature which describes both how organizations (especially colleges and universities) function and how people function within them.

As described earlier, student retention and success occur as a consequence of a complex interaction between the individual and the college, and are affected by even the simplest of day-to-day interactions with staff members (though this interaction has been studied the least). This literature review has also encompassed the theory of job satisfaction and motivation which suggests that these outcomes occur most often when employees have significant and fulfilling jobs, within which they have some control and responsibility for the outcome. And finally this review has examined a theory, or really a group of theories, TQM, which provides a method for pursuing 
quality outcomes, which acknowledges the importance of individual employees in accomplishing those outcomes, and which maintains that customer satisfaction cannot be fully attained without that input. Figure 6 attempts to portray how these theories may relate to support the general hypothesis that student interaction with staff members may produce and improve student satisfaction and retention, and staff satisfaction and motivation.

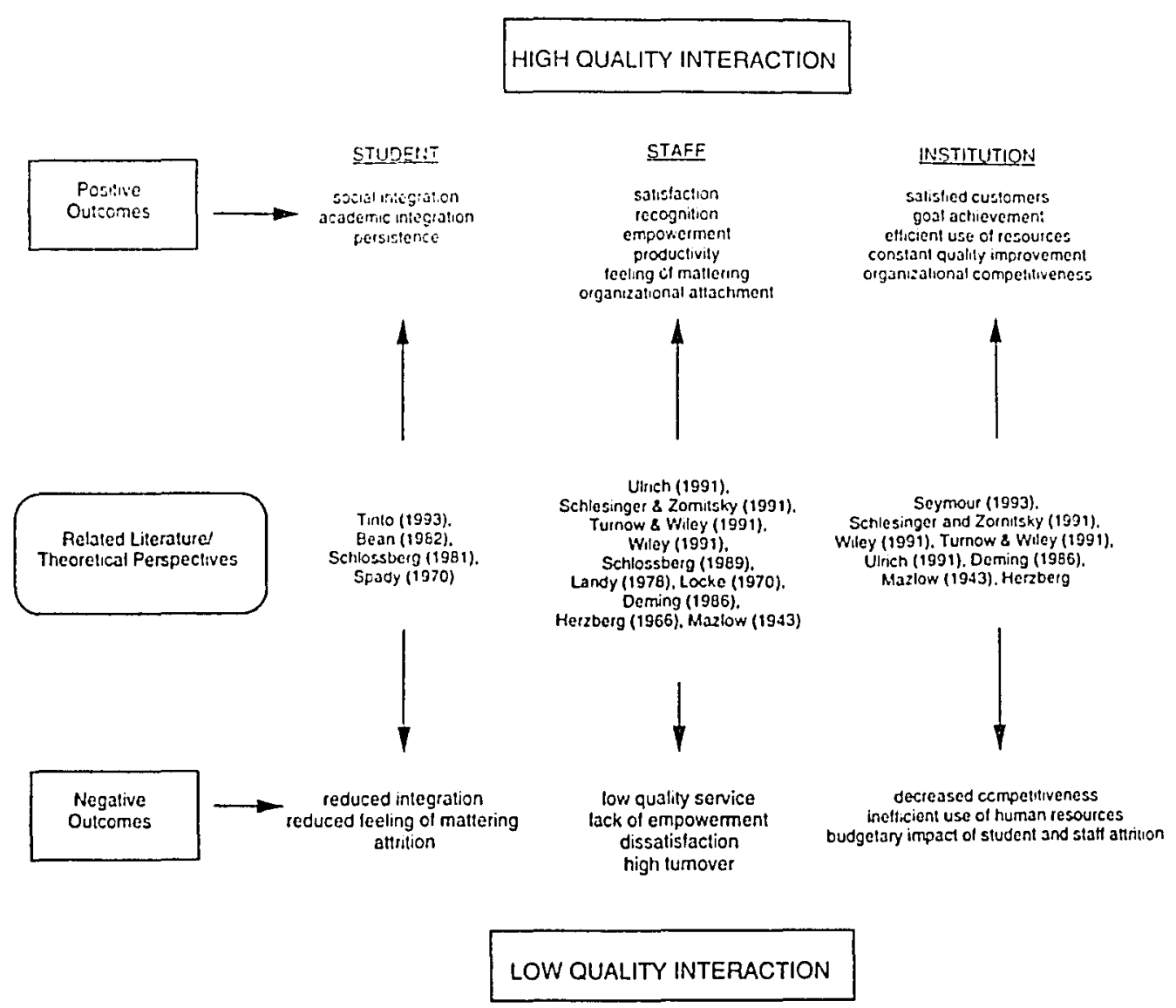

Figure 6. Student, staff, institutional outcomes, and related literature. 
As shown in Figure 6, the literature suggests that moving toward high quality interactions of students and staff, has the potential for positive outcomes for students, staff and the institution. Conversely, low quality interactions may result in negative outcomes. The literature has clearly shown the potential for the interaction of staff and students, but can we enhance the benefits by understanding the process better, or through more intentional approaches toward facilitating interaction in a higher education setting? The following chapter describes the methodology employed in this study which seeks to answer this question. 


\section{CHAPTER III}

\section{METHODOLOGY}

The purpose of this study was to explore the general hypothesis suggested by the literature that student interaction with front-line staff members affects student retention and satisfaction (Bernotavicz \& Clasby, 1984; Noel et al., 1985; Tinto, 1987), while at the same time having an effect upon staff job satisfaction (Miles, 1975), service quality (Carothers, 1992; Tschohl, 1989), and feeling of mattering between staff and students within the institution (Schlossberg et al., 1989; Vieira, 1991).

The study used a quasi-experimental design, in addition to personal interviews, to assess the effect of a planned intervention in which new freshmen, without prior college credit, are linked with classified staff members who will act as advisor/mentors during their first year in the university. The related research questions which will provide the focus for this analysis are:

(Student related questions)

1. Does student interaction with classified staff members, in a planned intervention, increase persistence to the second year? 
2. Within the framework of the experimental intervention, are there any factors that influence a student to persist or not to persist?

3. Does student interaction with classified staff members in a planned intervention increase the level of interaction with other members of the campus community (faculty, clerical staff, other staff, students)?

4. Does student interaction with classified staff members in a planned intervention during the first year in college increase the student's feeling of social integration or connectedness with the institution?

5. Does student satisfaction with the experience of interaction with classified staff members in a planned intervention increase student persistence to the second year?

(Staff related questions)

1. Does staff member interaction with freshman students as mentor/advisors in a planned intervention have an effect on their overall job satisfaction?

2. Does staff member interaction with freshman students as mentor/advisors in a planned intervention have an effect on their feeling of contributing to the educational mission of the institution (that they matter)? 
subjects

The subjects for this study were freshmen admitted Fall term of 1991 and front-line classified staff at Portland state University (PSU). Portland state University, located in Portland, $O R$, is a comprehensive university with more than 15,000 full- and part-time students.

\section{students}

students involved in this study were full-time freshmen, admitted Fall of 1991 who received no college credit prior to being admitted at portland state University. This group was chosen because: (a) the first year is thought to be the most important in which institutional action might be effective in increasing student persistence (Beal \& Noel, 1980; Tinto, 1993); (b) nationally this is the time during which this group experiences the single highest period of withdrawal (U.S. Department of Education, 1977); and (c) more is known about this group's rate of persistence at Portland state University (1995) (the site for the experimental intervention) than any other category of student.

Student subjects were initially chosen during Fall term from a random selection of 150 students provided by the Portland State University office of Institutional Research. This list was generally representative of the 
total group of freshmen, new from high school, without prior college credit: $52 \%$ were women, $48 \%$ were men, and 27\% were minorities. Each of these students received a letter soliciting their participation in the study, promising their anonymity, and a return postcard to indicate their willingness to participate. Within the first two weeks 31 students returned the card agreeing to participate. Seventeen more students agreed to participate as a consequence of receiving a follow-up phone call. This group of 48 (25 or $52 \%$ women, 23 or $48 \%$ men, 7 or $15 \%$ minorities), constituted the experimental student group. The numbers of men and women in this group were the same as in the original random sample for women (52\%) and men (48\%), but the experimental group contained fewer minorities (15\% vs. 27\%) .

Forty-eight more students $(26$ or $54 \%$ women, 22 or $46 \%$ men, 12 or $25 \%$ minorities) were randomly selected from the group of all freshmen beginning Fall 1991, and assigned to control group 1. The characteristics of this group were generally comparable to the experimental group with slightly more women ( $54 \%$ vs. $152 \%$ ), fewer men ( $46 \%$ vs. $48 \%$ ), and more minorities (25\% vs. 15\%). The control group had a higher entering high school grade point average (GPA) (3.36) than the experimental group (3.19). Students in both groups werelsent, and ultimately returned, informed consent forms, which explained 
confidentiality, anonymity, and their rights as subjects in the study.

A second control group (control group 2) which comprised all first time freshmen not participating in any part of the intervention, was created for purposes of comparison with control group 1 and the experimental group.

\section{Staff}

The other group of subjects selected for this study were front-line classified staff at Portland state University. Classified staff are employees whose jobs are among those classifications contained within the state of Oregon classified system. Those classifications include, clerical, skilled trade, and fiscal positions. Front-line classified staff are those who work in positions which provide direct service to students on a daily basis. For purposes of this study, front-line classified staff were defined as those within the secretarial/clerical classifications. This group of employees was chosen because: (a) among all classified employees they are most likely to have direct interaction with students on a daily basis; (b) interacting with students may be part of their specific job responsibility; and (c) many of these individuals have significant knowledge of the university either by virtue of their job responsibilities, or through knowledge obtained on the job. Also, as explained 
earlier, while the literature is clear regarding the impact of student interaction with faculty, and even with professional staff (e.g., counselors, advisors), there is little acknowledgment of any effect on the part of classified staff.

Among all classified staff within the university, 379 were in the secretarial/clerical category as of Fall 1990. Each of these individuals received a letter soliciting their participation in the study. I of this group, 52 agreed to participate in the experimental group (five were asked to be backups). These individuals were screened using personal knowledge of the researcher to ensure that all staff members working with students had the ability to be an advisor/mentor. Qualities which were considered were communication skills, employee attitude, and knowledge of the institution. No one was excluded as a consequence of this screening. In addition, another 48 staff members were selected to become the control group. An analysis of the two groups was conducted to insure that they were reasonably matched in terms of the type of positions held and number of years in service. Both the experimental and control groups were heavily weighted toward women, in keeping with the ratios existing among clerical/secretarial staff (approximately 10:1). Among the volunteer experimental group only one male participated, while four males were in the control group. 
Beyond their indication of a willingness to participate, and their membership in the defined employee category, there was no screening of the staff participants.

staff in both groups were sent and ultimately returned informed consent forms, which explained confidentiality, anonymity, and their rights as subjects in the study.

\section{The Experimental Intervention}

An experimental intervention (named staff-Link)। was conducted in order to attempt to assess the general question of whether student interaction with classified staff has an effect on their persistence and satisfaction, and a commensurate effect on staff's job satisfaction and feeling of contributing to the educational mission of the university. The intent of this intervention was to create a formal connection for students with staff members, through a structured opportunity for student and staff interaction which could be measured and studied.

The conceptual foundation for this intervention/ was based in the theory and literature of the central variables which were investigated: student retention and staff job satisfaction. With the goal of affecting student retention, the intervention was designed to increase student integration with the academic and social systems of the institutions as proposed by Tinto (1975). Tinto specifically suggested that mentor programs, like 
other early contact programs, be established during the first year in order to establish "the conditions which foster the integration of students" (p. 155). Unlike earlier investigations, this intervention tests this theory using classified staff.

Similarly, this intervention was supported by the theory of job satisfaction and the quality movement. Along with having a positive effect upon student retention, the literature of job satisfaction and service quality suggests that empowering staff to serve students (in this instance through a formal mentoring relationship), may result in increased job satisfaction and increasingly greater service quality (Albrecht \& Zemke, 1985; Schlesinger \& Zornitsky, 1991; Seymour, 1993; Ulrich et al., 1991).

Final program coordination took place during Fall term 1991. Review and approval of the study by the PSU Human Subjects committee was among the final arrangements necessary to conduct the intervention. Final approval for the study was received from the committee chair on December 20, 1991 .

Next, selection was made and participation by students and staff in the experimental groups was confirmed. In addition, all participants were asked to complete informed consent forms. Upon receipt of these, students and staff in the experimental groups received 
notification of the name of their advisor/advisee and a time frame in which to begin meeting. Prior to meeting with advisees, all staff members in the experimental group received training for their roles as advisor/mentors. Training was conducted by the researcher who is a long time university administrator, and two colleagues whose jobs involve academic advising and personal counseling, respectively.

In keeping with Tinto's (1975) theory, this training focused upon skills and information which would tend to foster the feeling of social and academic integration. Schlossberg's (1989) concept of mattering for adult learners also provided guidance for training staff members for being facilitator of integration. Originally conceived by sociologist Rosenberg (cited in Schlossberg et al., 1989), mattering is:

the beliefs people have, whether right or wrong, that they matter to someone else, that they are the object of someone else's attention, and that others care about them and appreciate them. ( $p$. 21)

This concept was integrated into all aspects of the training. Guided by these theoretical frameworks, they were informed that their role was: (a) to be a link to the university community, (b) to establish a helping relationship, (c) to be knowledgeable about campus resources, (d) to refer appropriately, and (e) to assist in general problem solving. They were also informed that 
they should not undertake: (a) academic advising, (b) career counseling, (c) psychological counseling, or (d) personal problem solving intervention for the student. In addition to this information, training included a brief description of the study, an overview of national and PSU retention statistics, and requisite skills training. The skills component included personal connection and interaction skills, problem solving skills, the "art of referral," and an opportunity to role-play interaction with their advisee. Advisor/mentors were provided with resource and referral sources across the campus for their use in assisting their advisee. Finally, advisor/mentors were provided with copies of advisor meeting log forms. They were asked to use these forms to record each meeting with their students. Information requested by these forms included the advisor name, date, length of meeting, subjects discussed, assistance and referral given, and a statement of comments, reflections or feelings that they had about their meeting.

The intervention began in winter term 1992 and continued through spring term 1992. While this timeframe did not allow the intervention to address those students who would dropout the first term (approximately one third of the total fall-to-fall dropout rate according to 10-year institutional averages), almost two thirds of those students who might be expected to dropout before the 
next fall continued their enrollment through winter term. It was determined that the numbers in the potential dropout pool which remained, and the time for conducting the intervention, were sufficient for testing the effects of the intervention.

Staff members and their assigned student advisees began meeting the first week of winter term. Staff members were asked to meet with their advisees at least a minimum of three times per term, and told that they could meet more often if they wished. In order to stimulate the process of interaction and integration, each staff member was provided with tickets which would allow/him or her and the student to have lunch together in the University food service facility three times per term. Staff members were asked to complete and return an advisor meeting log reflecting the experience of each meeting with their students.

The staff control group and student control groups 1 and 2 did not participate in any formal activity which linked them with other campus personnel or students.

$$
\text { Data Collection and Analysis }
$$

Data resulting from this intervention was collected and analyzed through both quantitative and qualitative means. This strategy for collecting the data results both from the phenomena being examined and from the perspective 
that using multiple methods is a means for strengthening the research design (Denzin, 1978; Patton, 1990). Patton described this strategy as triangulation and identified four basic types: (a) data triangulation--using different data resources, (b) investigator triangulation--using different investigators or researchers, (c) theory triangulation--using multiple viewpoints for interpreting data, and d) methodological triangulation--using multiple methodological approaches. For this study the approach was to use multiple methodological approaches, qualitative and quantitative, in order to more thoroughly collect the data which relate to the research questions.

\section{Data collection: Quantitative}

Methods

One of the primary questions being asked in this study was: "Does student interaction with classified staff members in a planned intervention increase their persistence to the second year?" The effect of this interaction upon student persistence was measured by comparing the number of persisters vs. non-persisters of the experimental student group to enrollment in Fall term 1992, with the number persisters vs. non-persisters in the control student group to enrollment in Fall term 1992. A chi-square analysis was used to determine if there was a significant difference between the groups. These results were also compared in the same way to the persistence 
rates of all other freshmen enrolled in Fall 1992 (control group 2).

In addition to this measurement, both the experimental and control student groups completed surveys at the beginning and at the end of the intervention (see Appendix A): Along with demographic data, these surveys included items designed to measure the students' feelings of connectedness to the university, the quantity of their interaction with campus community members, their attendance in precollege preparation programs, their intention to continue to the next year, and their intention to obtain a degree at Portland State University. For the experimental group, the post intervention survey also included items which assessed student satisfaction with the intervention. Responses to survey items were also correlated with student persistence.

Similar to the data collection concerning students, staff members in both the experimental and control groups completed surveys before and after the intervention (see Appendix B). The staff surveys items which measured the quality and nature of their interaction with students in general, their opportunity for and the personal reward experienced by working with students. Additionally, the experimental staff were ask:ed to respond to items which described their experience of working with their advisees, and how this affected their feelings about their jobs. 
Staff surveys also included the Work subscale of the Job Descriptive Index (JDI) (see Appendix C). The JDI (Smith et al., 1969) is perhaps one of the most well known and extensively used measurement of job satisfaction (Cook, Hepworth, Wall, \& Warr, 1981). Among its five subscales, the work subscale has been found to be "most closely associated with other measures of overall job satisfaction" (Cook, Hepworth, Wall, \& Warr, 1981, p. 52), and is the only subscale among the five which measures intrinsic rather than extrinsic job satisfaction (p. 58). The scale is composed of 18 items designed to measure satisfaction with work on the present job. Responses to the scale are Yes, Uncertain, and No. Because the authors suggest that Undecided is more likely an indication of dissatisfaction than satisfaction, they suggest that the scale be scored 3 (yes), 1 (uncertain) and 0 (no) rather than the traditional 3, 2, 1 scoring (Smith et al., 1969).

\section{Data Collection: Qualitative}

Methods

As described in the previous section, quantitative methods and measures were used to attempt to establish a relationship between the experimental intervention and student persistence, and the intervention and staff job satisfaction. While that data may give us some indication as to whether such relationships exist, it provides no guidance regarding the effect of the quality, and the 
experience of that interaction. This richer description may be achieved through qualitative methods. Blending research methods and data in this way may strengthen the research design and the validity of results (Denzin, 1978; Goetz \& Lecompte, 1984; Patton, 1990). Glaser and strauss (1967) argued that

in many instances, both forms are necessary--not quantitative used to test qualitative, but both used as supplements, as mutual verification - . as different forms of data on the same subject, which, when compared will each generate theory. (p. 18)

Taylor and Bogdan (1984) stated that "no method is equally suited for all purposes" (p. 43). For this study, it was determined that qualitative interviews/ were the most appropriate method to gain information concerning the experience and feelings of the students and staff participating in the intervention. Patton (1990) described three approaches to qualitative interviewing: (a) informal conversational interview, (b) interview guide, and (c) standardized/open-ended interview.

This study utilized the interview guide approach in order to achieve maximum flexibility while insuring that particular topic areas were covered. Patton (1990) described the interview guide approach as providing more structure through preparation of a guide consisting of topical areas to be covered. The interviewer is free then to fully explore a particular subject in a spontaneous manner, but is provided with the structure to insure that 
important subjects are covered. This approach can increasie the comprehensiveness of the interview, but can also reduce the comparability of responses because of flexibility provided to the interviewer. Also the "creative interviewing" advice of Douglas (1985), Goetz and Lecompte (1984), and Patton (1990) was essential in planning for, and actually conducting, the interviews-particularly in relationship to phrasing questions and establishing rapport with interviewees.

Topic categories for the experimental staff group includeld: (a) general feelings about work, (b) role of staff in working with students, (c) role of staff in the educational mission of the university, and (d) experience of working with an advisee in intervention.

Topic categories for the student experimental group included: (a) initial experiences of the university, (b) experiencing community and a feeling of connectedness and mattering, (c) expectations of the campus climate, (d) expectation and experience with classified staff, and (e) experience in the intervention.

Eight individuals from each group (student: experimental and control; staff: experimental and control) were selected to be interviewed. The number of interviews conducted was: students: control $=4$ (males: 1, females: 3); experimental = 6 (males: 2 , females:

4), Staff: control $=5$ (males: 1 , females 4); 
experimental $=9$ (males: 0 , females: 9). All

interviewees were informed of the purpose of the interview and the research, provided assurance of anonymity, and were informed of the need to tape record the session. Each interview was tape recorded and later transcribed.

The results of these interviews and other qualitative data, including the advisor meeting logs described earlier, were analyzed using the grounded theory method as developed by Glaser and Strauss $\mid(1967)$. This method uses the strategies of theoretical sampling and constant comparative analysis to develop theory directly from the data. According to Glaser and strauss the constant comparative analysis combines the process of coding of qualitative data, with ongoing analysis of the datia and theory generation. This occurs in four stages: (a) coding and comparing incidents or data; (b) integrating categories created though the first stage by continued comparison of incident and refinement of the properties of categories; (c) delimiting the theory through the discovery and reduction to more generalized terminology, and fewer and more general categories; and (d) writing the theory as a result of the themes!wich emerge from constant comparison and winnowing of categories.

Glaser and strauss (1967) combined this with the process of theoretical sampling, which they describe as data collection for generating theory "whereby the lanalyst 
jointly collects, codes, and analyzes his data and decides what data to collect next and where to find them in order to develop his theory as it emerges" (p. 45). Through the grounded theory method, researchers do not set out to prove theories but to create theories that "fit" and "work" :

By "fit" we mean that the categories must be readily (not forcibly) applicable to and indicated by the data under study; by "work" we mean that they must be meaningfully relevant to and able to explain the behavior under study. (p. 3).

If conducted properly, this method will yjeld a theory with four important properties: (a) it will fit the area in which it is to be used, (b) it will be understandable by laymen working in the area, (c) it will be general enough to apply to many different types of situations, and (d) it will allow the user to have sufficient control to manage change in their environment as the theory is applied.

\section{Data Analysis}

Using these data collection methods, the following analyses were conducted, and the resulting data utilized to answer the primary research questions. 
Student Related Analyses

Research Question \#1: Does student interaction with classified staff members in a planned intervention increase persistence to the second year of college?

Question \#1 analyses.

1a. Student Persistence and non-persistence of the experimental group and control group 1 were compared using the chi-square test. This comparison was conducted to determine whether any significance may be attributed to the observed differences between the persistence of the experimental and control groups.

1b. Student Persistence and non-persistence of the experimental group and control group 2 (the cohort of all other freshmen, Fall 1991 without prior college credit) were compared using the chi-square test. This comparison was conducted to determine whether any significance may be attributed to the observed differences between the persistence of the experimental groupland all other students not participating in the intervention, in order to further investigate the effect of the intervention.

1c. Student Persistence and non-persistence of the control group 1 and control group 2 were compared using the chi-square test. This comparison was conducted in order to validate the control group and to further investigate the effect of the intervention. 
Research Question \#2: Are there any other factors that affected persistence or non-persistence among all students participating in the study?

Question \#2 analyses.

2a. A chi-square was used to examine the relationship of several variables to persistence. These variables included demographic data (gender, high school GPA, race), attendance at New student orientation and/or the university survival course (IST 199), intention to enroll, and intention to obtain a degree. Other variables which were examined included student interaction with other community members (Research Question \#3), and student response to items which identify their feeling of connectedness or integration with the university (Research Question \#4).

2b. Those variables found to be significantly related to persistence were then included in a Multiple Regression analysis to determine their contribution to the prediction of variance in persistence, and their rank order.

2c. A chi-square analysis was conducted to determine whether there are significant differences between the groups in those variables found to predict variance in persistence. 
2d. Interviews with students in both groups were qualitatively analyzed to identify factors which contribute to persistence.

Research Question \#3: Does student interaction with classified staff members in a planned intervention increase the level of interaction with other members of the campus community (faculty, clerical staff, other staff, students)?

\section{Question \#3 analyses.}

3a. Chi-square and ANOVA were employed to examine responses to post test survey items relating to interactions with community members $(2 a-2 h)$ in order to determine whether there was a difference between the groups in whether they interacted, and to what degree.

3b. Qualitative interviews with students were also analyzed in order to examine student interaction with other community members.

Research Question \#4: Does student interaction with classified staff members in a planned intervention during the first year in college increase the feeling of social integration or connectedness with the institution?

Question \#4 analyses.

ANOVA was employed to determine whether there were significant differences between the groups in responses to several post intervention survey items (Post Survey Question $1, a-k$ ) related to student feeling of connection 
and integration with the university. This analysis was conducted to compare the differences in interaction between the groups.

$4 \mathrm{~b}$. The effect of student interaction with classified staff members on students feeling of social integration or connectedness with the institution, was also assessed through the qualitative analysis of interviews conducted with a sample of individuals from the experimental and control student groups.

Research Question \#5: Does student satisfaction with the experience of participating in a planned intervention increase student persistence to the second year?

Question \#5 analyses.

5a. ANOVA was employed to examine the differences in response to items related to satisfaction with the experimental intervention (post survey question 8 , experimental groups only)between those students who persisted and those who did not.

5b. Qualitative interviews of students who participated in the experimental intervention were analyzed to examine the satisfaction of subjects who participated in the intervention.

\section{Staff Related Analyses}

Research Question \#6: Does staff member interaction with freshman students as mentor advisors in a planned 
intervention have an effect upon their overall job satisfaction?

\section{Question \#6 analyses.}

6a. ANOVA was lemployed to analyze staff responses to survey items related to job satisfaction (staff post intervention survey questions 8 and 14). This analysis was conducted to determine whether there was any significance difference in job satisfaction between the experimental and control groups.

6b. The effect of the experimental intervention upon job satisfaction was also assessed through the qualitative analysis of interviews conducted with a sample of individuals from staff experimental and control groups.

Research Question \#7: Does staff member interaction with freshman students as a mentor/advisor in a planned intervention have an effect on their feeling of contributing to the educational mission of a college (that they matter)?

\section{Question \#7 analyses.}

7a. ANOVA was employed to examine responses to survey items (staff post intervention survey question 8 , a-d) which identified staff feeling of mattering and feeling of contributing to the university mission. This analysis was conducted to determine whether there is any significance difference between the response of the experimental and control groups. 
7b. The effect of the experimental intervention upon staff members' feeling of contributing to the university mission (that they matter) was also assessed through the qualitative analysis of interviews conducted with a sample of individuals from the staff experimental and control groups.

\section{Summary}

This chapter has outlined the methodology used in this study. This included a description of the experimental intervention, its subjects, and procedures. The procedures by which data concerning this intervention were collected and analyzed have also been described. Chapter IV describes the results of that analysis. 
CHAPTER IV

RESULTS OF THE STUDY

Introduction

This study explores the general hypothesis suggested by the literature that student interaction with front-line staff members affects satisfaction, the feeling of mattering and ultimately student persistence, while simultaneously having an effect upon staff job satisfaction, service quality, and feeling of mattering among staff. This hypothetical relationship between students and staff was investigated through the creation and analysis of a quasi-experimental intervention linking staff and students, and through interviews which sought to better understand the experience which students and staff had in the intervention, and in their regular day-to-day interactions.

This chapter first presents descriptive data concerning the subjects of this study. Second, this chapter presents analyses of both quantitative data derived from subjects before and after the intervention and qualitative data from subsequent interviews. Analyses are organized by the research questions posed earlier and 
are divided between questions felating to students and questions relating to staff.

\section{Characteristics of Subjects}

subjects for the study were freshmen, new from high school, and classified staff working in a variety of administrative, academic, and service departments at the institution. Students and staff were selected from randomly generated lists. Subjects from both the student and staff experimental groups agreed to participate as part of the intervention. Subjects in the control groups received and returned surveys only.

\section{students}

The gender and race of students in both groups were generally representative of all students in the institution (Table 3 ). Both groups had more women than men, reflecting the institutional distribution of $51.3 \%$ Female and $48.7 \%$ Males. However, the control group had a slightly higher percentage of females and lower percentage of males.

Like gender, the race of students in both groups closely reflected the institutional distribution among undergraduates for the same time period: Black (2.7\%), Asian (8.2\%), Hispanic (2.7\%), Native American (1.7\%), and White $(68.5 \%)$. The main differences were the larger percentage of Asian students, the absence of Native 
American students in both groups, and the absence of Hispanic students in the control group. Here again, relatively small numbers in the groups account for seemingly large differences in the distribution.

Table 3

Gender, Race of student subjects

\begin{tabular}{|c|c|c|c|c|}
\hline & \multicolumn{2}{|c|}{ Experimental Group } & \multicolumn{2}{c|}{ Control Group } \\
\hline & $\underline{N}$ & $\%$ & $\underline{N}$ & $\%$ \\
\hline Gender & & & & \\
\hline Female & 23 & 57.5 & 29 & 63 \\
\hline Male & 17 & 42.5 & 17 & 37 \\
\hline Total & 40 & 46.5 & 46 & 53.5 \\
\hline \hline Race & 3 & & & \\
\hline Black & 4 & 10.8 & 11 & 25.6 \\
\hline Asian & 1 & 2.7 & 0 & 0 \\
\hline Hispanic & 29 & 78.4 & 31 & 72.1 \\
\hline White & 37 & 46.3 & 43 & 53.8 \\
\hline Total & & 8.1 & 1 & 2.3 \\
\hline
\end{tabular}

Similarly, the enterting high school GPA for students in both groups was reflective of the mean for all new entering freshmen during the same year $(\underline{M}=3.08)$ though higher for both groups (see Table 4). 
Table 4

High School GPA of student subjlects

\begin{tabular}{|c|c|c|c|c|c|c|}
\hline & \multicolumn{3}{|c|}{ Experimental } & \multicolumn{3}{c|}{ Control } \\
\hline & $\underline{\mathrm{M}}$ & $\underline{\mathrm{sd}}$ & $\underline{\mathrm{N}}$ & $\underline{\mathrm{M}}$ & $\underline{\mathrm{sd}}$ & $\underline{\mathrm{N}}$ \\
\hline High School GPA & 3.19 & 0.53 & 39 & 3.36 & 0.42 & 46 \\
\hline
\end{tabular}

\section{Staff}

Demographic data related to staff subjects included years worked in the institution, education, highest degree, the primary function of their department, and their primary work. Most of the subjects within the staff groups were females, though one male participated in each group. This reflects the predominance of women, and the relative absence of men, in front-line classified service positions in the institution.

staff subjects had significant experience working in the institution as shown in Table 5 . For both groups, the mean number of years worked was more than eight.

Table 5

Years of Work and Education of Staff

\begin{tabular}{|c|c|c|c|c|c|c|c|c|c|}
\hline & \multicolumn{3}{|c|}{ Experimental } & \multicolumn{3}{|c|}{ Control } & \multicolumn{3}{|c|}{ Total } \\
\hline & $\underline{\mathrm{M}}$ & sd & $\underline{\mathrm{N}}$ & $\underline{M}$ & $\underline{\text { sd }}$ & $\underline{\mathrm{N}}$ & $\underline{M}$ & $\underline{\text { sd }}$ & $\underline{\underline{N}}$ \\
\hline $\begin{array}{l}\text { Years Worked at } \\
\text { University }\end{array}$ & 8.7 & 6.5 & 42 & 8.4 & 6.5 & 39 & 8.6 & 6.5 & 81 \\
\hline $\begin{array}{l}\text { Years of School } \\
\text { Attended }\end{array}$ & 14.9 & 2.4 & 43 & 14.5 & 2.5 & 40 & 14.7 & 2.5 & 83 \\
\hline
\end{tabular}


The educational levels and diegrees earned were similarly high. The mean number of years of education for both groups was more than 14 , most subjects having pursued some level of education beyond high school (Table 5). This is reflected in the degree attainment among staff (Table 6). More than $40 \%$ of both groups reported that they held a Bachelor of Arts or Bachelor of Science degree. When associate, master's, and doctoral degrees were included, more than $60 \%$ of the experimental group, and more than $57 \%$ of the control group had received a degree beyond the high school diploma or GED.

Table 6

Degree Attainment of staff

\begin{tabular}{|l|c|c|c|c|c|c|}
\hline & \multicolumn{2}{|c|}{ Experimental } & \multicolumn{2}{c|}{ Control } & \multicolumn{2}{c|}{ Total } \\
\hline & $\underline{N}$ & $\frac{\sigma}{8}$ & $\underline{N}$ & $\frac{\sigma}{8}$ & $\underline{\mathrm{N}}$ & $\frac{8}{6}$ \\
\hline $\mathrm{HS} /$ GED & 13 & 30.2 & 17 & 41.5 & 30 & 35.7 \\
\hline $\mathrm{AA}$ & 8 & 18.6 & 5 & 12.2 & 13 & 15.5 \\
\hline BA/BS & 20 & 46.5 & 17 & 41.5 & 37 & 44 \\
\hline Master's & 1 & 2.3 & 1 & 2.4 & 2 & 2.4 \\
\hline Doctorate & 0 & 0 & 1 & 2.4 & 1 & 1.2 \\
\hline Other & 1 & 2.3 & 0 & 0 & 1 & 1.2 \\
\hline \hline Total & 43 & 51.2 & 241 & 48.8 & 84 & 100 \\
\hline
\end{tabular}

The primary functions of the departments in which staff worked reflected the diversity of institutional classifications and the settings in which staff encounter students: academic, student service, administrative 
support, and other support (Table 7). The distribution of primary departmental functions of staff was generally representative of all institutional units, though the experimental group was composed of more individuals working in student service settings (33.3\%), while the control group had more individuals working in administrative and academic support (36.8\%).

Table 7

Primary Functions of staff Subjects' Departments

\begin{tabular}{|l|c|c|c|c|c|c|}
\hline & \multicolumn{2}{|c|}{ Experimental } & \multicolumn{2}{c|}{ Control } & \multicolumn{2}{c|}{ Total } \\
\hline & $\underline{\mathrm{N}}$ & $\%$ & $\underline{\mathrm{N}}$ & $\%$ & $\underline{\mathrm{N}}$ & $\%$ \\
\hline Academic & 5 & 11.9 & 9 & 23.7 & 14 & 17.5 \\
\hline Student Service & 26 & 61.9 & 8 & 21.1 & 34 & 42.5 \\
\hline Administrative Support & 11 & 26.2 & 14 & 36.8 & 25 & 31.3 \\
\hline Other Support & 0 & 0 & 7 & 100 & 7 & 8.8 \\
\hline \hline Total & 42 & 52.5 & 38 & 47.5 & 80 & 100 \\
\hline
\end{tabular}

The primary type of work of the subjects reflects the high numbers of classified employees involved in clerical and administrative positions within the institution (Table 8). The majority of both groups indicated that their work was clerical or administrative. More than $70 \%$ classified staff in the institution fall into this category. 
Table 8

Staff Subjects' Description of Work

\begin{tabular}{|l|c|c|c|c|c|c|}
\hline & \multicolumn{2}{|c|}{ Experimental } & \multicolumn{2}{c|}{ Control } & \multicolumn{2}{c|}{ Total } \\
\hline & $\underline{\mathrm{N}}$ & $q$ & $\underline{\mathrm{N}}$ & $q$ & $\underline{\mathrm{N}}$ & $\frac{q}{6}$ \\
\hline $\begin{array}{l}\text { Clerical/ } \\
\text { Administrative }\end{array}$ & 31 & 72.1 & 39 & 95.1 & 70 & 83.3 \\
\hline Managerial & 5 & 11.6 & 0 & 0 & 5 & 6 \\
\hline $\begin{array}{l}\text { Professional/ } \\
\text { Technical }\end{array}$ & 7 & 16.3 & 1 & 2.4 & 8 & 9.5 \\
\hline Pther & 0 & 0 & 1 & 2.4 & 1 & 1.2 \\
\hline \hline Total & 43 & 51.2 & 41 & 48.8 & 84 & 100 \\
\hline
\end{tabular}

Presentation of the Results

Results of the analyses are organized in accordance with the research questions posed for this study and are presented in two parts: (a) student analyses and (b) staff analyses. (Note: all probabilities have/been rounded to $\mathrm{p} \leq .001$ )

Student Analyses

Research Question 1: Does student interaction with classified staff members in a planned intervention increase persistence to the second year of college?

In order to attempt to assess the effect of student interaction with front-line staff members on student persistence, an experimental intervention was conducted. This intervention was developed both to test a specific method for affecting student retention, and to act as an 
experimental setting through which to gain insight into an activity that occurs naturally as students and staff interact on a daily basis. The effect of the intervention on the persistence of subjects to the second year is analyzed through the use of chi-square to compare the rates of persistence between the experimental group (who participated in the intervention), control group 1 (who filled out surveys only), and control group 2 (all other freshmen admitted the same Fall term).

The results of these analyses (Table 9), indicate that students in the experimental group persisted at the rate of $82.9 \%$. This rate was slightly higher, but not significantly higher than the rate of control group 1 (78.3\%). There was a significant difference ( $\mathrm{p} \leq .05)$, however, between the experimental group and control group $2(65.3 \%)$. Finally, control group 1 also persisted at a higher rate $(78.3 \%)$ than did students in control group 2 (65.3\%) though the difference was not significant.

The differences found here are particularly notable in that the rate of control group $2(65.3 \%)$ is higher than the mean rate of fall-to-fall persistence (58.5\%) for all freshmen from 1986 to 1991 [Portland State University (PSU), 1995]. Thus, despite a persistence rate for all other freshmen (control group 2) above what might be expected, the persistence of control group 1 was higher, 
and the persistence of the experimental group was significantly higher.

Table 9

Comparison of Group

Persistence Rates

\begin{tabular}{|l|c|c|c|c|c|c|}
\hline & \multicolumn{2}{|c|}{ Experimental } & \multicolumn{2}{c|}{ Control 1 } & \multicolumn{2}{c|}{ Control 2 } \\
\hline & $\underline{\mathrm{N}}$ & 8 & $\underline{\mathrm{N}}$ & $\frac{8}{8}$ & $\underline{\mathrm{N}}$ & $\frac{8}{8}$ \\
\hline Persisters & 34 & 82.9 & 36 & $7 \mathrm{~B} .3$ & 352 & 65.3 \\
\hline Non-persisters & 7 & 14.1 & 10 & 21.7 & 187 & 34.7 \\
\hline Total & 41 & 100 & 46 & 100 & 539 & 100 \\
\hline & $\mathrm{Chi}-\mathrm{Sq}$ & $\underline{\mathrm{p}}$ & & & \\
\hline Experimental-Control 1 & 0.3 & $\mathrm{n} . \mathrm{s}$. & & & \\
\hline Experimental--Control 2 & 5.31 & $\mathrm{p} \leq .05$ & & & \\
\hline Control 1--Control 2 & 3.18 & $\mathrm{n} . \mathrm{s}$. & & & \\
\hline
\end{tabular}

These differences suggest that the intervention did have an effect on the experimental group, especially when compared to control group 2 (students who were not involved in the intervention at all). While control group 1 received no intervention other than a request to complete surveys about their experience, it may be that this act alone contributed to their relatively high rate of persistence. This may suggest that any attention paid to students by the institution or its staff may have a positive effect upon persistence. 
Research Question 2: Are there any other factors that affected persistence or non-persistence among all students participating in the study?

Research Question 2 was posed for the purpose of better understanding the factors which contribute to persistence and the degree to which these factors contributed to the differences in persistence between the experimental group and control group 1 .

Quantitative analysis: Research question 2 . The quantitative analysis conducted for Research Question 2 examined several factors related to the intervention and a student's first year experience to determine whether any of these factors seemed to influence student persistence. Control variables were included in this analysis to determine whether any significant factors were unevenly distributed between the groups. Several dependent variables were included to determine whether the intervention had any effect upon factors deemed to contribute to persistence.

The control variables included demographic variables (gender, high school GPA, race), attendance at new student orientation, and enrollment in the university survival course (IST 199). The dependent variables included intention to enroll, intention to obtain a degree, student interaction with other community members (Research Question 3), and student responses to items which identify 
their feeling of connectedness or integration with the university (Research Question 4).

Among these variables, five were found to be significantly related to persistence (Table 10). The significant variables included one control variable (Gender), and four dependent variables (intention to enroll next fall, intention to get a degree at PSU, it is easy to meet people at PSU, and feels attached to a teaching faculty member). These factors were then included in a multiple regression analysis to determine their contribution to the prediction of variance in persistence. and their rank order (Table 11).

As indicated, two variables ("intention to get a degree from PSU," and "it is easy to meet people") were excluded from the regression analysis for lack of contribution to the variance. However, three variables did contribute almost $30 \%$ ( $\underline{R}-$ Square $=.2908)$ to the variance in persistence: gender, "feels attached to a teaching faculty member," and "intend to continue enrollment during fall." It is especially notable that "feels attached to a teaching faculty member" was first and contributed $14 \%$ of the variance by itself. Gender contributed $.0750 \%$, and "intend to enroll in the fall" $.0715 \%$, respectively. 
Table 10

Factors Relating to Persistence

\begin{tabular}{|c|c|c|c|c|c|c|c|}
\hline & & \multicolumn{2}{|c|}{ Persist } & \multicolumn{2}{|c|}{ Not Persist } & \multicolumn{2}{|l|}{1} \\
\hline & & $\underline{N}$ & $\%$ & $\underline{\mathbf{N}}$ & $\%$ & Chi-Sq & D \\
\hline \multicolumn{8}{|l|}{ Sex } \\
\hline \multicolumn{2}{|l|}{ Female } & 37 & 71.2 & 15 & 28,8 & 9.11 & 0.003 \\
\hline \multicolumn{2}{|l|}{ Male } & 33 & 28.8 & 1 & 2.9 & & \\
\hline \multicolumn{8}{|l|}{ Intend to enroll next fall } \\
\hline \multicolumn{2}{|l|}{ Yes } & 63 & 87.5 & 9 & 12,5 & 9.86 & 0.002 \\
\hline \multicolumn{2}{|l|}{ No } & 6 & 50 & 6 & 50 & & \\
\hline \multicolumn{8}{|l|}{ Intend to get PSU degree } \\
\hline \multicolumn{2}{|l|}{ Yes } & 56 & 88.9 & 7 & 11.1 & 6.83 & 0.009 \\
\hline \multirow[t]{3}{*}{ No } & & 12 & 63.2 & 7 & 36.8 & & \\
\hline & \multicolumn{2}{|c|}{ Persist } & \multicolumn{3}{|c|}{ Does Not Persist } & & \\
\hline & \multicolumn{2}{|c|}{$\underline{M} \quad \underline{s d} \quad \underline{N}$} & \multicolumn{3}{|c|}{$\underline{M} \quad \underline{\underline{s}} \quad \underline{N}$} & \multicolumn{2}{|l|}{ F-value $\mathrm{D}$} \\
\hline $\begin{array}{l}\text { It is easy to meet } \\
\text { people at PSU }\end{array}$ & \multicolumn{2}{|c|}{$\begin{array}{lll}2.68 & 0.65 & 69\end{array}$} & \multicolumn{3}{|c|}{$\begin{array}{lll}2.31 & 0.70 & 16\end{array}$} & \multicolumn{2}{|l|}{$4.02 \quad .048$} \\
\hline $\begin{array}{l}\text { Feel attached to faculty } \\
\text { member }\end{array}$ & \multicolumn{2}{|c|}{$\begin{array}{lll}2.71 & 0.79 & 69\end{array}$} & \multicolumn{3}{|c|}{$\begin{array}{lll}0.93 & 0.77 & 16\end{array}$} & \multicolumn{2}{|l|}{$12.58 \quad .001$} \\
\hline
\end{tabular}

Table 11

Factors Which Contribute to Persistence

\begin{tabular}{|c|c|c|c|l|}
\hline \multicolumn{5}{|c|}{ Multiple Regression Analysis } \\
\hline Step Entered & Mult R & R-Squared & R-Sq Change & Variable \\
\hline 1 & .3800 & 0.1444 & 0.1444 & $\begin{array}{l}\text { feels attached to a teaching faculty } \\
\text { rnember }\end{array}$ \\
\hline 2 & .4683 & 0.2192 & 0.075 & gender \\
\hline 3 & .5395 & 0.2908 & 0.0715 & $\begin{array}{l}\text { intends to continue enrollment } \\
\text { during fall term }\end{array}$ \\
\hline
\end{tabular}


All of these variables were then analyzed to determine whether|there were significant differences between the experimental and control groups. The result of that analysis indicated that there were no significant differences in gender between the groups, suggesting that this, along with other control variables, did not contribute to the difference in persistence noted between the experimental and control groups. There were also no significant differences between the groups in the variable "intend to enroll next fall." Finally, the variable "feels attached to a teaching faculty member" was found to be significant at $\mathfrak{p} \leq .05$. This outcome suggests that not only was this variable identified as a factor affecting persistence among lall subjects, the tendency to "feel attached to a teaching faculty member" seemed to be enhanced for those students in the experimental group.

Qualitative analysis: Research question 2. The analysis of interviews with students from both groups also provides some insight into factors which relate to persistence. Most notable was the difference between student expectation, and their ultimate realization of the campus environment, and the dissonance which that differential caused. In this regard, Tinto (1993) noted that integration with the social and academic life of the institution is an important contributor to persisterice.' He also stated that integration may not occur where there 
is a mismatch or lack of congruence between the intellectual and social orientation of the student and the institution. The degree of student congruence was explored through a discussion of student expectation of the institutional environment.

When asked what they expected when they came to the university, students in both groups unanimously agreed that they expected the institution to be large and impersonal. For most students, the first term experience exceeded their expectation, and indeed, was more than they had bargained for. This feeling was best exemplified by the experience of one woman. Having begun the Fall term after her senior year in high school, she stated "I had a real hard time with just being one of the crowd and not being known for me anymore." "I felt real lost and lonely," she said. "It's really hard to meet people here because a lot of the Freshman classes are very large and it is real hard to get to know people in those kinds of settings." Another student said "I expected to be like a name, instead of a number." Yet another student felt "isolated" when commuting back and forth from home. "That really doesn't build any sense of community . . what I thought college would be partly about."

This impression of the institution as an impersonal environment was not differentiated by student attendance at new student orientation. While all students had 
attended orientation, none indicated that attendance had prepared them for their first term experience or served to connect them to the institution in any way. one student noted that for her it had the opposite affect by raising expectations of a more connecting environment than what she experienced during the first term. When asked about her experience she replied:

\begin{abstract}
Yeah, I thought it (orientation) was great. Somebody is going to help me. . all these people coming to talk about student government and the bookstore and helping you get through your first term at least. They approach you really helpful and excited about starting a new school year. Getting all these freshmen in and advising them, showing them how to fit in, then (when the term began) it was kind of like "OK" that was your two hours.
\end{abstract}

Perhaps the largest gap in students' feelings of integration with the institution (at least academically) related to their expectation of direction. Simply put, most students were accustomed to, and had come from an environment in which they were told how to register, what to take, and what to study. Conversely, they were now moving into an environment in which personal choice and direction was more the norm, and in which little external direction or advice was offered or available. Students were surprised and somewhat confused by this difference. One woman said:

I came onto campus . . I was like what do I do? I said "OK" who is going to help me get my classes? When I was in high school, we always met with our counselor whenever we wanted to meet with them. And they would say we need to 
do this, this, and this. Well, my personal experience I never ever up to maybe last month, had anyone sit down with me and plan my class schedule.

Another woman stated, "I really did think that somebody would say 'you need to do thisi and this.' That wasn't the case." Yet another student said "I think we should hook everybody up with some kind of advisor that is trained and can give you the information you need. So at least you have one connection."

This expectation and perceived need for assistance was common among students interviewed. At the same time, while they perceived this need, they did not have preconceived notions as to who should provide this assistance. Students indicated that they had no preference regarding who should provide this information (faculty, staff or students) as long as, in the words of one woman, "it was professional."

Expectation of the institutional |experience was clearly influenced by input from both|peers and parents. While most students generally agreed that they expected the institution to be large and impersonal, some students also said that the quantity and quality of connection was less than what friends and family had, or were experiencing on other campuses (usually private and liberal arts institutions). One student remarked upon "the different programs [at another institution] where you could make connection with staff members on campus, and 
also students." Another talked about a friend at a small liberal arts institution who "talked about the instructors like they were best friends," and how "some of the instructors invite him over for dinner." "There is no way the teachiers on campus will do that here," he said. Another student lamented missing the experience of living on campus and "away at school." "My dad went to an ivy league school" she said. "We just can't afford it. . . I guess it wasn't [for] me."

These qualitative data suggest that the expectations which students bring with them, and the way in which the institution meets, or does not meet that expectation may influencelpersistence. Experience comparable to expectation seems to contribute to satisfaction and connection. If a student expects an environment which is supportive and service oriented, realizing that type of environment will likely enhance persistence. Conversely, if a student expects a supportive environment, or comes from that type of environment, and experiences instead, unmatched lexpectations and unmet needs, this will likely contribute to dissatisfaction and confusion--conditions which work against persistence.

Research Question 3: Does student interaction with classified staff members in a planned intervention increase the level of interaction with other members of 
the campus community (faculty, clerical staff, other staff, students)?

Quantitative analysis: Research question 3 . Here again, the literature suggests that student commitment and ultimately persistence may be affected by the degree to which the student feels involved in the institution, and that the institution is committed to them, as exemplified by their experience interacting with community members (Astin, 1993; Cabrerra, Nora, \& Castaneda, 1992; Tinto, 1993). In order to examine the differences in interaction with other community members between the experimental and the control group 1, chi-square was used to compare the responses of subjects on the post intervention survey to items related to interaction with|community members.

The results of this analysis (Table 12) indicate that significantly more subjects among the experimental group than among the control group had interactions with teaching faculty ( $\underline{\underline{p}} \leq .001)$, clerical staff ( $\underline{\mathrm{s}} \leq .001)$, "other" staff $(\underline{p} \leq .001)$ and with students $(\underline{p} \leq .017)$. Whether this increased interaction came about as a part of the activities of the intervention, or resulted from the effect of the intervention, is unclear and is probably not as important as the fact that there was more. What seems to be suggested is the simple but powerful notion that involvement and integration, may foster more involvement and integration. 
Table 12

Student Interaction with other Community Members

\begin{tabular}{|c|c|c|c|c|c|c|}
\hline & \multicolumn{2}{|c|}{ Experimental } & \multicolumn{2}{|c|}{ Control } & \multirow[b]{2}{*}{$\mathrm{Chi}-\mathrm{Sq}$} & \multirow[b]{2}{*}{$\underline{p}$} \\
\hline & $\underline{\mathrm{N}}$ & $q$ & $\underline{N}$ & $\frac{8}{6}$ & & \\
\hline \multicolumn{7}{|c|}{ Faculty } \\
\hline Yes & 40 & 100 & 28 & 62.2 & 18.99 & 0.001 \\
\hline No & 0 & 0 & 17 & 37.8 & & \\
\hline \multicolumn{7}{|c|}{ Clerical } \\
\hline Yes & 39 & 97.5 & 7 & 15.6 & 52.3 & 0.001 \\
\hline No & 1 & 2.5 & 38 & 84.4 & & \\
\hline \multicolumn{7}{|c|}{ Other staff } \\
\hline Yes & 39 & 91.7 & 8 & 17.8 & 54.45 & 0.001 \\
\hline No & 1 & 2.5 & 37 & 82.2 & & \\
\hline \multicolumn{7}{|c|}{ Students } \\
\hline Yes & 40 & 100 & 39 & 86.7 & 5.74 & 0.017 \\
\hline No & 0 & 0 & 6 & 13.3 & & \\
\hline
\end{tabular}

To further test this question and the impact of the intervention, an ANOVA was performed in order to examine differences in the quantity of interactions anong those who indicated that they had interactions with community members. This analysis did not show any significant differences between the experimental and the control group. If students interacted with community members, they seemed to do so at about the same rate.

Qualitative analysis: Research question 3. Analysis of interviews with students who participated in the intervention provides some information related to why 
these students were more likely to have interactions as indicated by the quantitative analysis.

Those most satisfied with the relationship seemed to focus upon the sense of connection which the relationship gave them. In describing this relationship one student said that being directly involved with a staff member at PSU was a very positive experience for her.

It was extremely helpful. to know her when I got started. I didn't know what to do. You naturally feel Imore comfortable and have more connection because you know that person.

For this student, knowing one person made her feel "comfortable" enough to make connections with others. This necessary "comfart" level was echoed by others, and may help to reinforce student interaction with other community members, if not to cause it. It may be that interacting with one person allows a student to reach a threshold comfort level, after which it is easier to interact with others' on campu's.

This response helps to explain the finding that interacting with one community member (in this case staff) may stimulate interabtions with other community members.

Research Question 4: Does student interaction with classified staff members in a planned intervention during the first year in college increase the feeling of social integration or connecledness with the institution?

Quantitative analysis: Research question 4. Several items in the survey administered to students after the 
intervention were designed to identify their feeling of social integration and connectedness as a consequence of experiencing or not experiencing the intervention. Analysis of Variance (ANOVA) was used to examine the differences between the experimental group, and control group 1 in response to these items (Table 13).

The result.s of these analyses indicate that for eight of the items the experimental group was significantly more in agreement with these statements than control group 1 . Significantly more students in the experimental group felt "personally connected to PSIU," felt "comfortable at the institution," thought that it was "easy to meet people," felt "attached to staff," that "staff cared," and that they knew "where to go for help." Conversely, for three of the items the differences did not reach the level of significance. There were no significant differences in how students felt about whether faculty or other staff cared about them or whether they felt attached to a faculty member though the mean score for each of these items was higher for the experimental group than for the control group.

These results |suggest that the experimental group had more positive feelings about their relationship with the institution and institutional members. But despite being higher, the mean scores for the experimental group left some room for improvement. While the mean response of the experimental group iwas above "agree" for all items which 
were significantly different from the control group 1 response, in none of the responses did the mean scores rise to the level of "strongly agree." Moreover, in those responses where the differences were not significant, the mean score did not reach the level of "agree" for the control or the experimental group.

Qualitative analysis: Research question 4. Analysis of interviews both with students who did experience the intervention, and those who did not, provides insight into the process by which the feeling of connectedness or integration may be stimulated or retarded through interaction with classified staff.

As indicated earlier, students who participated in the intervention generally responded that they felt a sense of connectedness with their staff link advisors and that their experience was generally very positive. They commented that they were "nice," that they "enjoyed" meeting with them, and that they appreciated that someone cared enough about students to "volunteer" for such an effort. Those most satisfied with the relationship seemed to focus upon the sense of connection that the relationship gave them. In describing this relationship, one student described her experience of working with her staff link advisior: 
Table 13

student Feeling of Connectedness

\begin{tabular}{|c|c|c|c|c|c|c|c|c|}
\hline & \multicolumn{3}{|c|}{ Experimental Group } & \multicolumn{3}{|c|}{ Control Group } & \multirow[b]{2}{*}{ F-value } & \multirow[b]{2}{*}{$\underline{\mathbf{p}}$} \\
\hline & $\underline{\mathrm{M}}$ & $\underline{\mathrm{sd}}$ & $\underline{N}$ & $\underline{\underline{M}}$ & $\underline{\text { sd }}$ & $\underline{\mathbf{N}}$ & & \\
\hline I feel personally connected to PSU & 3.15 & 0.36 & 40 & 2.47 & 0.59 & 45 & 40.43 & .001 \\
\hline I feel comfortable & 3.18 & 0.45 & 40 & 2.69 & 0.67 & 45 & 15.15 & .001 \\
\hline It's easy to meet people & 2.78 & 0.48 & 40 & 2.47 & 0.79 & 45 & 4.62 & .035 \\
\hline Teaching faculty members care about students & 2.74 & 0.59 & 39 & 2.67 & 0.57 & 43 & 0.29 & .591 \\
\hline Clerical staff members care about students & 3.13 & 0.33 & 40 & 2.51 & 0.63 & 45 & 30.64 & .001 \\
\hline Other staff members care about students & 2.58 & 0.55 & 38 & 2.55 & 0.66 & 44 & 0.06 & .806 \\
\hline $\begin{array}{l}\text { There are many opportunities for me to be } \\
\text { involved }\end{array}$ & 3.03 & 0.48 & 40 & 2.62 & 0.72 & 45 & 9.04 & .004 \\
\hline $\begin{array}{l}\text { I feel attached to at least one teaching faculty } \\
\text { member }\end{array}$ & 2.75 & 0.74 & 40 & 2.40 & 0.89 & 45 & 3.82 & .054 \\
\hline I feel attached to at least one clerical staff member & 3.10 & 0.38 & 40 & 1.89 & 0.71 & 45 & 91.93 & .001 \\
\hline I feel attached to at least one "other" staff member & 2.70 & 0.61 & 40 & 1.89 & 0.72 & 44 & 30.88 & .001 \\
\hline $\begin{array}{l}\text { I feel that I know where to go for help when I } \\
\text { have a problem }\end{array}$ & 3.33 & 0.53 & 40 & 2.42 & 0.82 & 45 & 36.04 & .001 \\
\hline
\end{tabular}


It was extremely helpful to know her when I got started. I didn't know what to do. She kind of directed me along to someone I could talk to and I would go into the [institutional] office. I could connect with them because I know somebody there and a friendly face. And that is always helpful wherever you go if you recognize someone in that place or environment. You naturaliy feel more comfortable and have more connections in there because you know that person.

Echoing this sentiment, another student said it was nice to "have a face that you recognize, someone to say hello to."

The potential for both increasing and decreasing the feeling of connectedness through interacting with frontline staff is also exemplified by the experience of those students who did not experience the intervention, but who interacted with staff on a daily basis. Students generally had strong opinions related to this subject. For many students the experience of interacting with classified staff was highly positive. Regarding her experience one woman said:

They [secretaries] have always been the ones that I have met with and [they] have always been helpful. I know the secretary in [institutional] office... . I am always talking with her. She is really great. And the secretary in the [institutional] office. They will direct you where you need to go or can give you any inside information about what is happening, just little things. I have never had any problems!

Another student stated "They can make or break the place. If they feel good about the institution then the 
students will feel good about it too. Especially if they are interacting positively "

In this same vein, another student noted that the attitudes of classified staff members had an effect upon his attitude. He said:

I would get lost in the hallways, and I would say I am looking for this person or that department. They would say "oh you have come to the right place and it's right down the hall." To have a smile on your face in the afternoon because of the secretaries is |pretty nice.

other students found their rellationship with classified staff members to be less positive. "They can be very intimidating," said one student.

When I was going into the [institutional] office and working on my application, It was very intimidating. I remember thinking I would never let myself feel this way. I am always thinking they are not going to make me feel bad. They are not going to make me feel like I have done something wrong.

Another student indicated that her experience with interacting with staff members was/limited after a negative experience. She said:

The only people I had to deal with are at the School of [school name] and I have actually had some trouble there. The one individual was not very helpful, but she didn't seem to be helpful to anyone. I felt like they thought it was a burden to point someone in the right direction. No one asked if there were any questions or anything they could do for youl. It was "here is your ID, see you later." I haven't been there since. It has kind of turned me around from seeking advisors from the school of [school name]. Which is kind of hard because that is where I want to go. 
Another student said she felt like "sorted mail. . You go to this office and fill this out. They say you have to fill this out then send you to another office." No one office, she felt, treated her in an integrated way, as "one person."

At least one student saw both the positive and negative aspects of interactions with staff members. In describing her experience she stated that they can act like "gatekeepers" limiting students" access to information. Or, they can help to facilitate a student's "understanding of the organization structure of the institution." She also suggested that students would appreciate and perhaps better utilize the service of staff if they perceived that the institution did. She stated that "when students understand the University appreciated those people, then they will appreciate them a lot more."

These responses support the survey responses of students who participated in the intervention--that students who have positive interactions with staff feel more connected. They also suggest that the reverse may be true, that negative relationships may contribute to reducing a student's feeling of connection with the institution. This analysis also suggests that feeling connected may be a result of a multitude of student interactions with staff, faculty, with other students, and sometimes with external communities. None of these 
interactions may by themselves cause persistence, but each contributes to a web of connection embracing individual students.

Beyond the specific effect of the intervention on students' feelings of integration and connection, it is important to better understand what made a difference in terms of their feeling connected, and what the source of these feelings was. At the time of these interviews, as students began their second year, most felt as if they were connected to the institution in ways which began to give them a sense of being in a community. At the beginning of their experience at the institution, however, their feeling of connectedness was much different. For most, there was no feeling of community, of connectedness, of joining with others in a common endeavor.

Students generally attributed this lack of a community feeling to the lack of interaction with other students. One woman described the environment as "antisocial." She said:

I guess I expected more interaction with people, basically the people in my classes. People come in, during a class I don't talk either, but if you get there 15 to 20 minutes before hand and I would say "hi" to the person sitting next to me and they would look at me like I was some kind of possessed person. Like it was awful; like I was going to attack them or something. I just wanted to get to meet some people. Not just coming and going. It's really hard to get used to because nobody will have anything to do with anybody else. 
One student said she felt isolated because she still

lived at home:

commuting to and from school everyday and then just going to your classes and going home. That really doesn't build any sense of community, what I thought college would be partly about.

Another student similarly attributed her lack of feeling of community to living off campus and commuting. When asked if there was a sense of community at the institution she said "not for me. . I could see how it could be for other people that get involved in clubs. A lot of my problem is that I do leave campus pretty much at noon." Another student agreed with this sentiment. He said, "I pretty much come here and then go home. So there isn't a lot of time for that [interacting with other students]."

One woman said that the institution was both "friendly and unfriendly." She said:

In class among the people you know, the friends, the teacher, it feels friendly. But then you go outside of that and around to the other places and you're dealing with other people, maybe it doesn't feel quite as friendly.

When asked about their sense of community on campus, none of the students among the control group I. suggested that either faculty or staff made any significant contribution to that feeling. Instead when they conceived of community it was in relationship to association with other students. This was best exemplified by the reaction 
of one student who explained her conception of community

on campus. She said:

I think the faculty and staff have a lot to do with it, but I think that students have even more. You are going to react with the people that are in you classes a heck of a lot more than you would professors or secretaries in the office. Because I am surrounded by students all the time and very rarely, have there been times when I see my political science teacher in the hall. I will stop and talk to him or whatever, but year-around you see students so much more and their attitude and their experiences affect you a lot more than the faculty would.

While most students sensed a lack of community on campus, by the beginning of their second academic year almost all of them had made connections with some individual or group which they described as contributing to their feeling more comfortable, and more closely associated with the institution. While the outcome of these connections was similar (they make students feel more satisfied with their university experience) the variety of ways in which students indicate that they make this connection is striking.

The most common form of connection mentioned by students was establishing significant relationships with a group of other students. One student felt connected once she had established a group of friends who were not her high school friends. Dissatisfied at first associating with only people whom she knew, she felt more connected after meeting new people. She said: 
I happened to meet a girl in my math class and there was another guy that was in another one of my classes that knew her from another class. And that was like, oh, three people. Not bad. Some of her friends that she went to high school with I met them. We got about ten people. Somehow or another we would go out after school and bowling was a ritual on Thursday afternoons. But we got to be good friends and that was the best part. I guess it is still important to me because I have met other people outside of high school. . I have a base.

Conversely, another student felt connected through

his old friends. He said:

I have my two best friends here so we are always able to help each other out. We plan our classes at the same time so we can find a parking space and car pool together down here. We usually meet and have lunch together. We live within two blocks of each other so it's easy for us to plan. I have met and made new friends through my friends from high school.

Another student established her "base" of friends through a class they were taking which was designed to introduce them to the university. She explained:

Yeah, I think really in the first year where I really got to know people the best. It was in [course name] because we were all in the same boat, we were all beginning college. We were experiencing the same type of things and in some cases people were living on campus. They were experiencing life away from home for the first time and being in college for the first time.

It was through this beginning that she gained the skilis which allowed her to make friends in other classes as well.

While connecting with other students was common, it did not always happen naturally or easily for the students 
interviewed. One student explained the process of her connecting with people:

Oh, I think it was last summer when all of my friends were coming home from school and they would say "Oh, I am going to miss this person or that person." I thought "mmh, there is really not that many people at [institution name] I would miss." I said "that is not right. I am going to be here for four years, I should make some connections." So in september I thought I was going to say "hi" to people and meet people. I made it my purpose to find friends and meet people and go out of my way to say "hi." And now everybody says "hi, hi, hi" and you know everybody and it makes you feel like "yeah somebody really knows me here."

While connecting with peers was most common for

students, some also found connection with faculty, and staff. One student who described her experience as otherwise lacking in connection, remarked that her connection was through a campus faculty organization which gave her a scholarship.

I have a scholarship from the [institutional] association and their members are related to the School of [school name]. I talk to them and they are really nice people and they are giving me advice and stuff. It was just that one experience.

Another student significantly constrained by time, found the institution to be "very isolating socially." She said:

I found the teaching staff to be remarkable; I would say in all sincerity I have never had an instructor that didn't feel like they had a personal investment in my success. I have had just wonderful experiences. I have never had an instructor even in incredibly large classes that didn't know my name and that didn't make an effort if I indicated I needed help or something 
like that. . that didn't make an effort to make sure that everything was fine.

Another student said that her staff link advisor

provided the same kind of close connection for her. She said:

It was extremely helpful to know her when I got started. I didn't know what to do. She kind of directed me along to someone I could talk to and I would go into the [institutional] office. I could connect with them because I know somebody there and a friendly face. And that is always helpful wherever you go if you recognize someone in that place or environment. You naturally feel more comfortable and have more connections in there because you know that person.

Another student found his connection through student organizations. One said,

I don't know how to say it but working in [student organization name] I learned a lot and it was a great experience and that is why I am coming back into it. You meet a lot of people and that sort of thing.

While most students found a sense of connection oncampus, at least one student found her sense of connection off-campus. When commenting on her close connections in her apartment and at work, she said:

I did that on purpose. I didn't want to be entirely involved in school. I wanted to have my own realm, because I wasn't sure what I wanted to experience here in a sense. So I just kept everything open. The building I live in nobody goes to school in that building. Really young kids with purple hair. I enjoy that because I like to have people around me that are different.

Finally, another student found that she not only did not miss the feeling of connection, she believed that she 
may have benefitted from that experience. When asked if she missed the feeling, she said:

A little bit, but my personality is such that I don't miss it that much. When I started here, I learned a lot of independence because of that and I think that is good. I am able to go places by myself and be able to function by myself which I had never done before. It was always you had four friends with you or your teacher was telling you what to do or whatever. So I don't know that I missed it. . . I missed it in the first place but it helped me gain something else. But now that I know I can do things by myself, I want to do things with other people too.

These data suggest that there is no one single mode of feeling connected for students. Some students find this feeling in relationship to their experience with faculty. Some students who participated in the intervention found this feeling with their staff link advisor. Many students related the feeling of connection to their interaction with peers. One student's feeling of connection was supported by their interactions with their external community. None of these connections seem to promote persistence in and of themselves. Rather, they suggest a web of connection which each student weaves for themselves, each strand supporting the other and enhancing persistence. Similarly, a weak or missing strand (lack of connection or negative interactions with community members) may inhibit persistence. 
Research Question 5: Does student satisfaction with the experience of participating in a planned intervention increase student persistence to the second year?

Quantitative analysis: Research question 5. An ANOVA was used to examine items on the post test which asked those participating in the experimental intervention to rate their experience. In general, the responses of the persisters were more positive, though the differences between groups did not rise to the level of significance on any of the items (Table 14).

students who persisted agreed that "their advisor was well informed," that their advisor "referred them to others when appropriate," that their "staff link advisor cared about them as a person," and that they "would recommend that other students have a staff link advisor." In contrast non-persisters agreed only with the statement "my staff link advisor was helpful" and "my staff link advisor cared about me as a person."

While lacking statistical significance, the generally positive nature of these responses provides some evidence that there is a relationship between satisfaction with the experience of the intervention and persistence. This is especially true when viewed from the perspective of the significant difference in persistence between students who participated in the intervention and those who did not participate at all (control group 2). 
Table 14

Persistence and Satisfaction with Experimental Intervention

\begin{tabular}{|l|c|c|c|c|c|c|c|c|}
\hline & \multicolumn{3}{|c|}{ Persisted } & \multicolumn{3}{c|}{ Did Not Persist } & \\
\hline & $\underline{M}$ & sd & $\underline{N}$ & $\underline{M}$ & sd & $\underline{N}$ & F-value & $\underline{2}$ \\
\hline $\begin{array}{l}\text { My staff link advisor } \\
\text { was well informed }\end{array}$ & 3.06 & 0.35 & 33 & 2.83 & 0.41 & 6 & 2.06 & .160 \\
\hline $\begin{array}{l}\text { My staff link advisor } \\
\text { was helpful }\end{array}$ & 2.97 & 0.59 & 33 & 3.00 & 0.58 & 7 & 0.02 & .902 \\
\hline $\begin{array}{l}\text { My staff link advisor } \\
\text { helped me to solve } \\
\text { problems related to my } \\
\text { attendance }\end{array}$ & 2.94 & 0.70 & 33 & 2.43 & 0.53 & 7 & 3.25 & .079 \\
\hline $\begin{array}{l}\text { My staff link advisor } \\
\text { referred me to others at } \\
\text { PSU when appropriate }\end{array}$ & 3.03 & 0.47 & 32 & 2.71 & 0.49 & 7 & 2.54 & .119 \\
\hline $\begin{array}{l}\text { Meeting with my staff } \\
\text { link advisor was a } \\
\text { valuable use of my time }\end{array}$ & 2.85 & 0.57 & 33 & 2.86 & 0.38 & 7 & 0.00 & .970 \\
\hline $\begin{array}{l}\text { My staff link advisor } \\
\text { cared about me as a } \\
\text { person }\end{array}$ & 3.18 & 0.64 & 33 & 3.00 & 0.58 & 7 & 0.49 & .490 \\
\hline $\begin{array}{l}\text { I would like to continue } \\
\text { my relationship with my } \\
\text { staff link advisor }\end{array}$ & 2.55 & 0.67 & 33 & 2.29 & 0.76 & 7 & 0.84 & .365 \\
\hline $\begin{array}{l}\text { I would recommend that } \\
\text { other students have a } \\
\text { Staff link advisor }\end{array}$ & 3.03 & 0.53 & 33 & 2.71 & 0.49 & 7 & 2.11 & .155 \\
\hline
\end{tabular}

Qualitative analysis: Research question 5. That the intervention was a positive experience for students is supported both by what students experienced and what they wished more of in their interactions with their staff link advisors. As expressed by qualitative analysis the experience of students with their staff link advisors was 
deemed to be generally positive. They commented that they were "nice," that they "enjoyed" meeting with them, and that they appreciated that someone cared enough about students to "volunteer" for such an effort.

Those most satisfied with the relationship seemed to focus upon the sense of connection that the relationship gave them. As noted earlier one student said of this relationship that knowing a staff member at PSU directly was a very positive experience for her. "It was extremely helpful to know her when I got started. I didn't know what to do. You naturally feel more comfortable and have more connections because you know that person." Another student said it was nice to "have a face that you recognize, someone to say hello to."

In terms of the substantive assistance which students experienced as a consequence of their relationship, the response from students participating in the intervention mirrored that of students interaction with staff in general . . for some it was very helpful, and yet for others it could have been even more helpful. A few students were assisted by their advisor cutting red tape or providing general assistance. Many wanted more. One student summed up that sentiment in this way: "It was very pleasant and I enjoyed it, but I can't really say that it is, as I look back on it, that it really made a difference." While this individual felt a connection to 
her advisor, she felt that they should have had more of an agenda "about things they wanted to tell you," or "where you should go if you need help."

This sentiment was echoed by other people participating in the intervention. One student said "it's good that people talk, but it should be more, it should be more lucrative." By "Iucrative" he explained he meant more information, especially academic information. "It would have been nice to have more information.. . if she would have been a psychology major (his major) it would have been different."

These data suggest two important points. First, though they felt the relationship could have been improved or "been more," students clearly expressed some level of satisfaction with this intervention. In fact the perspective that the intervention could have been more is itself a positive response. Students did not indicate that the relationship was bad, or negative, or not worthwhile. Rather, they focused upon its value to them if it were made better. In this way these qualitative data support the results of the quantitative data. second, though these data do not suggest a clear link between satisfaction with the intervention and persistence, they do suggest that the manner in which students and staff interact and the relationships which result from that interaction, contribute to an environment 
which enhances the conditions for persistence, or erode that environment. As suggested by the quantitative analyses, this relationship does seem to make a difference.

\section{Staff Analyses}

Research Question 6: Does staff member interaction with freshman students as mentor advisors in a planned intervention have an effect upon their overall job satisfaction?

Quantitative analysis: Research question 6. The effect of the intervention upon job satisfaction of staff was assessed through the employment of an ANOVA. This analysis examined the response of subjects to two items in the survey of experimental and control staff groups. First, both groups were asked to respond to the statement, "Overall, I am very satisfied with my job." For the experimental group this rating included their experience as a staff link advisor in the intervention. The control group did not have this experience.

The response of subjects to the statement suggests that the intervention had a positive effect upon job satisfaction (Table 15). The mean score of the experimental group $(\underline{m}=3.95)$ reflected their strong agreement with this statement and was significantly higher than the mean score $(\underline{m}=3.0)$ for the control group ( $\mathrm{p} \leq$ $.001)$. 
Table 15

\section{Mean Scores of Overall Job \\ Satisfaction}

\begin{tabular}{|l|c|c|c|c|c|}
\hline \multicolumn{7}{|c|}{ Post surveys only } \\
\hline & $\underline{\underline{M}}$ & $\underline{\mathrm{sd}}$ & $\underline{\underline{N}}$ & F-value & $\underline{\underline{\mathrm{p}}}$ \\
\hline Experimental Group & 3.95 & 0.21 & 43 & 78.6 & 0.001 \\
\hline Control Group & 3 & 0.67 & 41 & & \\
\hline
\end{tabular}

To further examine this question, an ANOVA was conducted to compare pre and post survey scores of iboth groups related to the statement "overall I am very satisfied with !my job." This comparison also suggested a relationship between job satisfaction and the intervention. For the control group there was no | difference between the pre and post ratings of overall job satisfaction. Prior to beginning of the intervention, the control group indicated that they were in general agreement $(\underline{m}=3.0)$ with the statement. Their response in the post intervention survey was unchanged ( $\underline{m}=3.0)$. Conversely, for the experimental group the rating of overall satisfaction significantly increased ( $\underline{\underline{ }} \leq .001)$ from a mean of 3.38 in the pre intervention survey to a mean of 3.95 in the post intervention survey.

The second part of the survey which assessed job satisfaction was the Work Scale of the Job Descriptive Index (JDI), a scale composed of 18 items designed to measure overall job satisfaction. Responses to these 
items yielded an overall mean score for the scale for comparison of the experimental and control group (Table 16), and comparison to national norms (Table 17). An ANOVA was conducted to make this comparison. Here again, the mean score of the experimental group $(\underline{m}=43.9)$ was significantly higher $(\underline{p} \leq .001)$ than that of the control group ( $\underline{m}=31.1)$, indicating a higher level of job satisfaction among experimental group subjects than among the control group.

Table 16

Pre and Post Survey Mean Job Satisfaction scores

\begin{tabular}{|l|c|c|c|c|c|c|c|c|}
\hline & \multicolumn{3}{|c|}{ Pre Survey } & \multicolumn{3}{c|}{ Post Survey } & \\
\hline & $\underline{\mathrm{M}}$ & $\underline{\mathrm{sd}}$ & $\underline{\mathrm{N}}$ & $\underline{\mathrm{M}}$ & $\underline{\underline{\mathrm{d}}}$ & $\underline{\mathrm{N}}$ & F-value & $\underline{\mathrm{p}}$ \\
\hline Experimental Group & 3.38 & 0.63 & 39 & 3.95 & 0.21 & 43 & 30.89 & 0.001 \\
\hline Control Group & 3 & 0.67 & 41 & 3 & 0.67 & 41 & 0 & 1.00 \\
\hline
\end{tabular}

Table 17

Mean Scores of the JDI work Scale

\begin{tabular}{|l|c|c|c|c|c|}
\hline & $\underline{M}$ & $\underline{\mathbf{s d}}$ & $\underline{\mathrm{N}}$ & F-value & $\mathrm{D}$ \\
\hline Experimental Group & 43.9 & 7.16 & 42 & 43.23 & 0.001 \\
\hline Control Group & 31.1 & 10.34 & 41 & & \\
\hline
\end{tabular}

An ANOVA was also employed to compare the differences between pre and post JDI scores for the experimental and control groups. The results of this analysis also supported the finding of a higher level of job 
satisfaction among experimental subjects. The scores of the experimental group significantly increased ( $\underline{P} \leq .0001$ ) from a mean of 36.0 on the pre survey to a mean of 43.9 on the post survey. At the same time, control group scores on the JDI actually decreased from a pre survey mean of 31.6 to a post survey mean score of 31.1 (Table 18).

Table 18

Pre and Post JDI Scores

\begin{tabular}{|l|c|c|c|c|c|c|c|c|}
\hline & \multicolumn{3}{|c|}{ Pre Survey } & \multicolumn{3}{c|}{ Post Survey } & & \\
\hline & $\underline{\mathrm{M}}$ & $\underline{\mathrm{sd}}$ & $\underline{\mathrm{N}}$ & $\underline{\mathrm{M}}$ & $\underline{\mathrm{sd}}$ & $\underline{\mathrm{N}}$ & F-value & $\underline{\mathrm{D}}$ \\
\hline Experimental Group & 36 & 9.27 & 41 & 43.9 & 7.16 & 42 & 18.63 & 0.001 \\
\hline Control Group & 31.6 & 10.24 & 36 & 31.1 & 10.34 & 41 & 0.05 & 0.8197 \\
\hline
\end{tabular}

Finally, the mean JDI scores of the experimental and control groups were compared to national JDI norm scores (Table 19). Here again, the data provides a strong indication that the intervention had a positive effect upon staff job satisfaction.

At every level, the experimental group's post survey score was above national norms, having begun below the norms in the pre intervention survey. For the control group, the post survey scores of satisfaction rose above the national norms only in the 1st percentile (Table 19). It is also interesting to note that the pre intervention scores for the experimental group were much higher than the pre intervention scores of the control group. This 
difference prior to the intervention suggests that merely being chosen to participate in the study exerts some positive influence upon job satisfaction.

Table 19

Comparison of Mean Scores to JDI National Norms

\begin{tabular}{|c|c|c|c|c|c|}
\hline Percentile & 1985 Norms & Expe & ntal & contro & \\
\hline & & Pre & Post & Pre & Post \\
\hline 99 & 52 & 52 & & & \\
\hline 95 & 51 & 52 & 53.7 & 46 & 45 \\
\hline 90 & 49 & 47 & 51 & 43.6 & 43 \\
\hline 85 & 46 & 45 & 51 & 42 & 43 \\
\hline 80 & 45 & 44 & 51 & 41.6 & 42 \\
\hline 75 & 45 & 44 & 51 & 40 & 41.5 \\
\hline 70 & 43 & 42 & 49 & 37.9 & 37.4 \\
\hline 65 & 42 & 41 & 48.9 & 37 & 36 \\
\hline 60 & 42 & 40 & 46 & 36.2 & 34 \\
\hline 55 & 41 & 39 & 45 & 34 & 33 \\
\hline 50 & 39 & 38 & 44 & 33.5 & 33 \\
\hline 45 & 37 & 36 & 43 & 33 & 30 \\
\hline 40 & 37 & 35 & 43 & 31.6 & 30 \\
\hline 35 & 34 & 34 & 43 & 30 & 30 \\
\hline 30 & 33 & 31 & 42 & 19.1 & 26.2 \\
\hline 25 & 31 & 28 & 39.75 & 23 & 23.5 \\
\hline 20 & 29 & 27 & 37 & 19.4 & 21.4 \\
\hline 15 & 26 & 23 & 36 & 17.55 & 16.3 \\
\hline 10 & 23 & 22 & 34.6 & 14.7 & 14.2 \\
\hline 5 & 18 & 17 & 28 & 11.85 & 12.1 \\
\hline 1 & 9 & & & & \\
\hline
\end{tabular}


This strong evidence for a relationship between staff interaction with students and staff joblsatisfaction is supported by the qualitative analysis of interviews with staff members.

Qualitative analysis: Staff research question 6. As might be expected, the experience of working with their staff-link advisee was different for every person. For some it was the one most fulfilling work experiences they had ever had in a work setting. For others it was no different from their daily routine. Some felt they had made a big difference in the experience of their student. Others felt like their student did not need much help. Most were anxious to continue with this type of program. Only one person said she would probably decline if asked to participate in a similar activity. Overall, none of the staff members indicated that this was a negative experience for them, and most of them said it was very positive.

For those individuals most satisfied with this experience, the feeling of connection and mattering to their student made the most difference. They enjoyed having an opportunity to get to know students on a deeper level, and to provide them with support which had value. One staff member said:

I felt like I really made a connection with her and really got to know some of her fiears. I like to connect because when you learn more about an individual's personal concerns, then 
you can go a step further. If you don't go beyond, you don't learn the fears beyond what that person is talking about. When you are able to do that, when you are able to go beyond, you can address the whole issue.

Another staff member explained that it was like:

the same feeling that you get from volunteer work . . it's like you're being able to give something of value of yourself to someone else, and in turn you are getting that same thing back from the other person, hopefully.

Enjoying this feeling of mattering, several staff members said that they appreciated the opportunity to have personal responsibility for "one person . . their student." One staff member said "it was formal and there was one person that I would call or talk to, my person." Echoing this sentiment another staff member said, "that's right, that was mine, my person. Not connected to my job and what I do here." Another staff member said she enjoyed the opportunity to get to know her student on a "one-to-one" basis.

Support for the finding that the intervention had an effect upon job satisfaction is substantiated by the description of staff members' day-to-day interaction with students, and what role that plays in job satisfaction.

In addition to their experience in the intervention, staff members were asked to describe whether the ways in which they provided service to students on a daily basis were satisfying, and how it was satisfying. With one exception, those interviewed characterized service to 
students as their most satisfying job-related activity and their reason for working in the institution. "There are times," one woman said, "that the only sense of accomplishment I feel in my job is when I do help students." "Helping students" was not a one dimensional activity for those interviewed. Satisfaction with their interaction with students seem to fall into three categories: (a) through the provision of direct service within the framework of their specific responsibilities, (b) general assistance and referral, and (c) academic advising. Whatever the category, "helping students was," said one staff member, "the bottom line."

For most staff members serving students through their specific joib responsibilities was most satisfying. One individual stated simply that she loved her job because it allowed her to "inspire and connect." Another staff member was more detailed in describing her satisfaction. She said: |

I really think the biggest satisfaction comes from dealing with the students especially in our office. It takes some students a lot, of course, to walk in the door and being, at least in the afternoon, the first person they talk to can be extremely important because I can make or break their day with our office. If I happen to be a snooty wench they can walk out that door - . But I feel for every student that comes in there that they came for a reason and they wouldn"t be coming into [office name] if they didn't want something. So my satisfaction comes from making them feel as comfortable as I can. And seeing lots of times a physical reaction to me, they either smile or they calm down a little bit if they are agitated. Some people come in 
with tears. I kind of just work with them on an individual basis. I tell them "It looks like you are not feeling real well" and offer some Kleenex. And when I see that person kind of feels a little bit better, that gives me satisfaction over the long term. Sometimes a person comes in crisis, big heavy stuff is happening to them. And then over the course of time you see a person who has just blossomed into a healthy happy student, and it is strange not to see this child if she was not crying. Now every time I see this student she would smile and give a greeting. And that makes it worthwhile. I really enjoy that. I love being there for that contact. You know, to be that person that makes a difference.

In addition to providing direct service related to their job, other staff members noted that their satisfaction came from those opportunities to help outside of their specific job responsibilities. This usually took the form of the evolution of naturally developing mentor/ advisor roles by which they provided general assistance and referral. Noting that it was "the fun part of the job," one staff member said, oftentimes I form a bond with them [students]. It is true if you talk to someone more than three times you get to know them, they start calling you rather than anyone else on campus.

Several staff members indicated that this role of providing general assistance and being a mentor contributed greatly to their job satisfaction. One person explained in this way.

oh, sure I feel special. They come and they ask me questions. I feel special. Or they show me a picture of their niece or nephew. They give a lot to me. That makes a difference on days when I can't get anything done and [supervisor's 
name] gets pesky about something we should have taken care of weeks ago.

Even though this interaction was most satisfactory for her personally, she also saw how this relationship might benefit the university.

I don't think of them as being long-term friendships, but I think of them as being long term friendships for (the institution). They are people who will go on and really do something besides being career students . . or miserable or struggling.

A third category of service to students mentioned by staff was academic advising. Several individuals, especially those who worked in academic departments, indicated that academic advising was an informal (if not underground) role of departmental secretaries in academic departments. Though very satisfying, it was frequently undertaken with some reluctance for fear of being caught doing something outside of their role, or worse, giving bad information to a student. This concern however was counterbalanced by the pressure which staff felt to provide assistance for students who could not find it elsewhere and the fact that they "they are on the firing line right there in front." "You get tired of saying no," said one staff member.

They [secretaries] are there to help students. I feel students deserve it. You feel guilty sending them off. I know at least five departments where the secretaries just pitched in and did it. When I am really sure, and they are general questions I will answer those questions, but other secretaries actually have 
the student sit down and go over the transcripts.

Another staff member was less reticent about undertaking advising. He said:

I do a lot of advising. I mean all of the secretaries told me when I first started here. you are not supposed to be advising. You are not supposed to work registration. You are not supposed to give tests. And if you do all of these things they (the faculty and administration) will be all over you like a blanket. And you will be doing all of these things that are busy work that you shouldn't|be doing. This is the faculty's responsibility. Well, but that erodes as you get involved with the students and you get involved with your faculty and if there is give and take in the staff situations. The faculty knows that.

In the same vein another staff member said, "What are you going to do? When a student wants information about a program - . are you going to kick them out and say go talk to your advisors?"

In all of these ways staff members found satisfaction in their work and their interaction with students. They felt like they were not just doing a job, but making a contribution to the mission of the institution. This data suggests that staff members found that satisfaction through the intervention, and also that the same elements which promoted satisfaction in the intervention, promoted satisfaction through their daily work.

overall, these data were highly supportive of quantitative findings which suggested that there was a relationship between the intervention and staff job 
satisfaction. None of those interviewed found it to be a negative experience. Most of those interviewed found it to be empowering and inspiring, and an acknowledgment of the importance of their work. Finally, all of the subjects interviewed felt that with further refinement, a program like the intervention could be made even more valuable for staff and students.

Research Question 7: Does staff member interaction with freshman students as a mentor/advisor in a planned intervention have an effect on their feeling of contributing to the educational mission of a college (that they matter)?

Quantitative analysis: Research question 7. Staff members' feeling of contributing to the educational mission of the institution, and that they matter, was assessed through the analysis of response to several items on the survey. These items examined their satisfaction with opportunities to interact with students, their ability to see consequences of their helping student, and their perception of contributing to the educational process. Table 20 summarizes this analysis.

First, it should be noted, that all of the subjects, experimental and control alike, were in general|agreement with most of these items. Except for the items|"my daily work provides me with opportunities to help students" ( $\underline{m}=$ 2.95), and "I am able to clearly see the consequences of 
my helping students" ( $m=2.97)$, the mean responses of the control group were above the 3.0 mean level, indicating their agreement. But despite this general agreement, the mean scores of the experimental group were significantly higher for each item, as indicated by an ANOVA conducted to compare the scores.

Table 20

Comparison of Mean Feeling of Contributing
Scores by Group

\begin{tabular}{|l|c|c|c|c|c|c|c|c|c|}
\hline & \multicolumn{3}{|c|}{ Experimental } & \multicolumn{3}{|c|}{ Control } & & \\
\hline & $\underline{\mathrm{M}}$ & $\underline{\underline{\mathrm{sd}}}$ & $\underline{\mathrm{N}}$ & $\underline{\mathrm{M}}$ & $\underline{\underline{s d}}$ & $\underline{\mathrm{N}}$ & F-Value & $\underline{\mathrm{D}}$ \\
\hline $\begin{array}{l}\text { My daily interaction with students in my work } \\
\text { role is very satisfying. }\end{array}$ & 3.77 & 0.48 & 43 & 3.02 & 0.69 & 41 & 33.17 & 0.001 \\
\hline $\begin{array}{l}\text { My daily work provides me with opportunities } \\
\text { to help students. }\end{array}$ & 3.49 & 0.7 & 43 & 2.95 & 0.63 & 41 & 13.55 & 0.001 \\
\hline $\begin{array}{l}\text { I am able to clearly see the consequences of my } \\
\text { helping students. }\end{array}$ & 3.7 & 0.6 & 43 & 2.97 & 0.82 & 41 & 24.89 & 0.001 \\
\hline $\begin{array}{l}\text { My daily work is an important part of the } \\
\text { educational process. }\end{array}$ & 3.67 & 1.57 & 43 & 3.1 & 0.66 & 41 & 18.44 & 0.001 \\
\hline $\begin{array}{l}\text { I am satisfied with the opportunities to help } \\
\text { students which my job provides. }\end{array}$ & 3.65 & 0.61 & 43 & 3.0 & 0.69 & 41 & 17.95 & 0.001 \\
\hline
\end{tabular}

Like previous analyses, this data suggests that the intervention had a positive impact upon the experimental group. At the same time, it once again seems to suggest that any acknowledgment of the importance of staff in this role, has a positive effect upon their self perception and satisfaction.

To further examine the effect of the intervention, an ANOVA was conducted to compare the pre and post 
intervention mean scores of the experimental and control groups (Table 21). This analysis provided further substantiation of the effect of the intervention. For all items accept for "My daily work is an important part to the educational process," the post survey mean scores of the experimental group significantly exceeded the pre survey scores.

Table 21

Comparison of Pre and Post Intervention Mean Satisfaction Scores: Experimental Group

\begin{tabular}{|l|c|c|c|c|c|c|c|c|}
\hline & \multicolumn{2}{|c|}{ Pre Survey } & \multicolumn{3}{c|}{ Post Survey } & & \\
\hline & $\underline{M}$ & $\underline{\text { sd }}$ & $\underline{\mathrm{N}}$ & $\underline{\mathrm{M}}$ & $\underline{\underline{\text { sd }}}$ & $\underline{\mathrm{N}}$ & F-Value & $\mathrm{z}$ \\
\hline $\begin{array}{l}\text { My daily interaction with students in my } \\
\text { work role is very satisfying. }\end{array}$ & 3.29 & 0.68 & 41 & 3.77 & 0.48 & 43 & 3.77 & 0.001 \\
\hline $\begin{array}{l}\text { My daily work provides me with } \\
\text { opportunities to help students. }\end{array}$ & 3.3 & 0.78 & 43 & 3.49 & 0.7 & 43 & 1.36 & 0.246 \\
\hline $\begin{array}{l}\text { I arn able to clearly see the consequences } \\
\text { of my helping students. }\end{array}$ & 3.09 & 0.81 & 43 & 3.7 & 0.6 & 43 & 15.46 & 0.001 \\
\hline $\begin{array}{l}\text { My daily work is an important part of the } \\
\text { educational process. }\end{array}$ & 3.67 & 1.64 & 43 & 3.67 & 0.57 & 43 & 0 & 1.00 \\
\hline $\begin{array}{l}\text { I am satisfied with the opportunities to } \\
\text { help students which my job provides. }\end{array}$ & 3.12 & 0.76 & 43 & 3.65 & 0.61 & 43 & 12.86 & 0.001 \\
\hline
\end{tabular}

For the coritrol group the reverse was true (Table 22). Post survey mean scores were lower for every item. These data suggest that in addition to being more satisfied with their jobs, the experimental subjects who participated in the intervention were more likely to be satisfied with their role and opportunities for interaction with students, to see the consequences of that 
interaction, and to feel that their work was an important part of the educational process.

Table 22

Comparison of Fre and Post Intervention Mean Satisfaction Scores: Control Group

\begin{tabular}{|l||c|c|c|c|c|c|c|c|}
\hline \multicolumn{1}{|c||}{} & \multicolumn{3}{|c|}{ Pre Survey } & \multicolumn{3}{c|}{ Post Survey } & & \\
\hline & $\underline{\mathrm{M}}$ & $\underline{\mathrm{sd}}$ & $\mathrm{N}$ & $\underline{\mathrm{M}}$ & $\underline{\mathrm{sd}}$ & $\underline{\mathrm{N}}$ & $\mathrm{F}$-Value & $\mathrm{p}$ \\
\hline $\begin{array}{l}\text { My daily interaction with students in } \\
\text { my work role is very satisfying. }\end{array}$ & 3.16 & 0.64 & 38 & 3.02 & 0.69 & 41 & 0.8 & 0.3753 \\
\hline $\begin{array}{l}\text { My daily work provides me with } \\
\text { opportunities to help students. }\end{array}$ & 3.39 & 0.67 & 41 & 2.95 & 0.63 & 41 & 9.39 & 0.003 \\
\hline $\begin{array}{l}\text { I am able to clearly see the } \\
\text { consequences of my helping students. }\end{array}$ & 3.15 & 0.71 & 39 & 2.97 & 0.72 & 41 & 1.24 & 0.2696 \\
\hline $\begin{array}{l}\text { My daily work is an important part } \\
\text { of the educational process. }\end{array}$ & 3.38 & 0.63 & 40 & 3.1 & 0.66 & 41 & 3.73 & 0.0569 \\
\hline $\begin{array}{l}\text { I am satisfied with the opportunities } \\
\text { fo help students which my job } \\
\text { provides. }\end{array}$ & 3.23 & 0.62 & 40 & 3.1 & 0.58 & 41 & 0.91 & 0.3433 \\
\hline
\end{tabular}

Qualitative analysis of interviews conducted with staff members from both groups provides additional insight into this phenomenon.

Qualitative analysis: Research question 7. As strongly suggested by the quantitative data, staff members who participated in the intervention, seemed to experience job satisfaction as a consequence of the interaction. Analysis of interviews with participants suggests that the roots of that satisfaction grow largely from the intervention's facilitation of staff members feeling of empowerment, of their ability to make a difference for 
students, and of their opportunity to contribute in this way to the educational mission of the institution.

The words of one staff member encapsulated the feelings of many:

It made me feel great. Because this student came to me. She wasn't going anywhere else. She was coming to me. It was empowering for me because I had to do some homework and I had to know what to do. So that made me feel good about the fact that I had to stretch a little bit, it is a stretch to make time, it is a stretch to find out that maybe there are a lot of things you don't know, and you have to find out because this person needs to know this. And I think that what really made me feel good is knowing that I played a part in hopefully making this process just a little bit easier for this student.

For her, job satisfaction resulted from making it "easier" for the student, for making a difference in that students experience in the institution.

Though most staff members involyed in the intervention echoed this sentiment, somel staff members noted that they could have made a larger contribution through the intervention had their advisee needed more assistance. For them the concept of the intervention was a good one. What needed to be changed or refined was the way in which students were selected for the relationship. These individuals wanted to make more of $\mid$ a difference. Therefore, they wanted to work with individuals who needed significant help, not just occasional advice.

The experience of participating in the intervention also had some important and related sideleffects which 
contributed to their feeling of mattering within the institution. For some staff members the experience of connecting with their student promoted and stimulated more connection with other staff members and the institution. One staff person described this phenomenon in this way:

Everybody that did it in our office was really thrilled. We would all get together and say "what's yours like, what yours like." It did give us more of a feeling of community because we were doing something different. And I felt that was a real connection to the land outside of us. It gave staff members a real boost for a while.

Staff also noted that through the intervention they had an opportunity to connect with, and be in contact with people from all over campus on an ongoing basis-an experience they did not always have. This increased connection occurred through the training provided before the intervention which brought people together from across the institution who do not normally work together, but who share common responsibilities. It also promoted an ongoing relationship across organizational units as advisors consulted and made referrals to each other as they assisted their advisees. This connection with others in a common endeavor linked to the core goal of the institution also helped to contribute to the feeling that they made a difference.

Here again, staff experience of interaction with students outside of the intervention corroborated and supported the experience of the subjects who participated 
in the intervention. Analysis of routine interaction with students strongly suggests that staff job satisfaction may be at least partly connecteil to the opportunity to serve students well, and make a difference for them educationally.

As noted earlier, Ulrich et al. (1991) suggested that there is a psychological rationale for the notion of linking employees with customer satisfaction and quality service. Where employees share mindsets or cognitions about the goals and processes of the organization, their attachment to the organization is likely to be high and in turn, customer attachment will be high. In order to better understand that mindset on the part of staff, individuals (experimental and control) were asked how they thought their regular role contributed to the mission of the institution, and conversely, how they felt others perceived their contribution.

From their response it is clear|that staff feel they are not just here to do a job, but rather to be part of the educational process. This sentiment was stated directly and forcefully by one staff $/$ member:

I am an education secretary. I / have worked grade school, high school, nursing residency training programs, and $\|$ the institution]. And the few times I have worked in other settings, I have not been happy. I have job hunted [as a consequence of layoffs] a long time and some of those places, I don't know what I would have done if they had asked me to come. Because I couldn't have stood that. They are selling 
insurance or they are selling farm machinery or something that seems so totally unrelated to me.

similarly, another staff member said that she could

work no where other than an institution of higher education.

You have learning; you have lots of information being passed on. The whole atmosphere of the institution of higher education is completely different than private business. I would rather be here or at another University or college then any place else.

Sounding more like a faculty member than staff member, another individual felt that the university environment and mission were conducive to her need to "inspire and connect." She said:

I think as human beings, our nature is to connect with individuals and to nurture, and we need an environment that allows us to do that. And I don't think you can get a better place then the University. You need a place that provides growth and development. I think that is why people come to an institution like this in the first place to apply for a job. Instead of applying at an insurance company, I applied where I felt my values existed and think people do that automatically when they come to [the institution].

Another staff member corroborated this feeling. "I

think that is why people work here. We like that stimulus [of the educational environment] and the opportunity to be exposed to new knowledge or to take classes."

As strongly as staff felt about being contributors to the educational mission, they felt that this was a role that was not acknowledged by the university. When asked if the institution valued or acknowledged the contribution 
of classified staff members to the educational mission one staff member said "I don't think they do that. I mean I don't think they think about it. For them to understand the value of why we are in that institution, I don't think that they recognize that." When asked what the institution would be like if the institution knew the contribution of staff, one person interviewed thought that things would "change immensely." She said:

People who respect each other's values respect each other. And they may not always recognize it in that in that person until it is shoved into their faces. And I don't think that as an institution we can take the time, or do take the time to recognize other people's values.

This sentiment was echoed by all individuals interviewed, each describing this status in slightly different terms. One individual said that classified staff members were considered "throwaways . . disposable people." Other terms which those interviewed used to describe their perception of how they were viewed by the university included "second class citizens," "peons," "unimportant," "invisible," "ghost people" and finally as "slaves." One staff member even likened the university to "a prison, or an army or any other socially structured institution. The students are the prisoners, the faculty are the overseers and the classified are trustees" who, he said, have power by virtue of their relationship between faculty and students, but who are never wholly trusted by 
the faculty. One individual explained the result of these feelings:

\begin{abstract}
Sure, if the person behind the desk doesn't feel that their role is important I cannot imagine them treating a person that comes up to them with respect and dignity and the courtesy they deserve, because they are not getting it. Real easy! If it is not recognized as being of importance then what kind if enthusiasm am I going to bring to that? Hey, the person who signs my check doesn't give a rip of what I am doing out here. Somehow work harder? Yeah, why work harder at being service oriented when they don't care.
\end{abstract}

Acknowledging this lack of congruence between how they viewed their contribution to the educational mission of the institution and how it was viewed by faculty and administration, some staff were angry, some were philosophical about it, but most were just resigned to the condition.

These data strongly support the finding that staff member interaction with students in the intervention had a positive effect upon their feeling of making a contribution to the university. Both the experience of staff in the intervention and staff in their daily interaction with students provide clear evidence of the existence of this relationship. At the same time, it is equally clear that the positive effects of that relationship may be eroded if they are not acknowledged. For individuals in the intervention, the attention paid to them as part of the activity, seemed to be sufficient to promote satisfaction as a consequence of contribution. 
For individuals not in the intervention, who felt unacknowledged for their contribution, satisfaction was not automatically forthcoming.

Other findings: Staff. Along with supporting the findings that staff interaction and service to students increase job satisfaction and a feeling of contributing to the educational process, interviews with staff members provided significant insight into what contributed to, and what detracted from the promotion of quality service and interactions. In this regard, Ulrich et al. (1991) suggested that another rationale for connecting employee satisfaction to customer satisfaction is the human resources rationale.| Within this framework, improving the conditions, policies, and procedures that play a role in creating shared values and goals, is central to the achievement of the outcome of creating an environment for service and satisfaction for employees and customers. staff members interviewed, both from the intervention and control groups, had very specific suggestions as to what improved the envifonment for service and what spoiled that environment.

Perhaps the most mentioned contributor to the service environment was the notion of empowerment. Staff members expressed empowernent as the ability and authority to take significant action on one's own as a product of support from their supervisor or the institution. Most often this 
feeling of empowerment emanated from, or was a product of what occurred in the department, rather than aativities organized by the university in general. For many staff members, having a supportive boss who conferred a feeling of respect and trust, and who valued staff members, helped to empower staff to providel better service. One staff member explained this feeling this way:

Yeah, you are, doing it because you like it and you want to make that gift you are sharing. You want to put yourself out. You are contributing to the learning process by what you contribute to the learning atmosphere in your realm.

The concept of empowerment was closely linked to the idea of teamwork and the feeling that staff, faculty and administration each, no matter what their title, educational. degrees or pay level, make an important contribution to the team. One individual described this support in the following way:

I feel that I have a lot of respect from all the people. You asked me about the university in general. I feel like my department people appreciated my work and respect my work. I can see that and that is reflected in my evaluations. He [her supervisor] is really happy with what I do. And that is a good feeling. He trusts me a lot and gives me all of these things to do and I think that is a good experience for me. If someone isn't happy at the place where they are, they are not going to be friendly. You can go to some departments and some of them are very helpful, very kind, and some are awful. They say "you have to go to this place or that place." I think it makes a big difference when you walk into an office and you find a friendly atmosphere where people are willing to help. In my department we are all treated equally. I don't feel that faculty feel like they are better. We get information about 
everything, and we know exactly what is going on.

Another staff member described his conception of teamwork:

After six years I began actually to relax and function as a member of the team instead of thinking of myself as an outsider. I am sure it had more to do with my attitude than theirs but I began to participate a little more willingly. It's a tight little band and it's nice to be part of that group. We party together and go on the field trips and they encourage me to go. over the years the sharing of students has formed bonds. They don't tell me often to my face but I am a functioning part, and they need me and are scared that I might ever get laid off.

Staff who felt empowered and part of a team were also more likely to mention that service to students was a formal part of their job description. In turn, they were more often evaluated, and ultimately rewarded, on that basis, among others.

While empowerment was identified as a condition which supported service, a lack of individual empowerment was also identified as something that worked against service to students. Talking about this gap, one staff member said:

I don't think the staff have power. I don't think they are given the power and because of that, because they are powerless, they react toward students requests in a manner that puts them off. Because they know they can't do it. I think if we empower those people to have the capability to do it, they will go beyond that power. I don't think staff people are given that power. Can we empower people to go to the edge of limitations . . to step out of that nice comfortable zone to make the institution 
one that allows them to do that? It has to come from the top.

Explaining how it made her feel, another staff member said, "it's hard to be [age] and powerless." When asked if she felt empowered to make change on campus she explained that she felt she had to hide her efforts to make change. She said:

I have to sneak it in. I have to sneak in change because I like to problem solve. I am working with people who have been at their jobs an average of 30 years. They have tried what they could think of at that time and in almost anything I bring up as a possible solution, they shoot down. So the only way to do that is to have them ignore the problem and me sneak in a solution. So that is very frustrating. I am not normally manipulative. So it makes me feel bad if I do get success. Because I didn't do it directly and the adult way.

Reward was also mentioned as an element which affected service. While for many individuals student appreciation was sufficient reward, for others monetary rewards were important. Expressing this sentiment, one staff member said:

It wouldn't have to be a whole lot more money. It could take just a little bit of money to be shown that you are recognized as being, as having more responsibility and having capabilities of handling those responsibilities, and that this is valuable to us. We are going to pay you more.

In addition to empowerment and rewards, training stood out as institutional activity which supported service. In fact staff members indicated that increased customer service demanded more training. One staff 
member's words reflect the feeling of most staff members interviewed:

Having the credentials is what people need to do a good job. If you are asking classified staff members to do more, they need to be trained to do it. They need to be told here is how we want to reach out. The student comes to the counter and says I know what to do and you say, "oh, that is too bad," or can we train them to say "here are the resources that are available to you."

Another staff member suggested that cross training would support service by allowing staff members to learn about each others areas, and thereby provide better service in their own job, and to be available to fill in other areas if this would help to serve students better. Several other staff members suggested that a profitable strategy would be to concentrate service training, and service specialists, in those departments where there is high student contact, and where the quality of that contact is particularly important for students. Others suggested that service to students needed to be stressed during orientation for new classified employees as a form of training for staff.

Finally another element of support for service mentioned by staff was informal assistance networks created by the staff themselves. While each was slightly different, staff members described these networks as having the common patterns of good communication, quick 
response, accuracy, and a breadth of information. Said

one staff member:

the department secretaries talk to each other. Then you become friends with other departments like [department name] and [department name] and you use those contacts to serve students.

Another staff member said:

Well, I just call until I get the right answer. You know, there are certain people that I know I can talk to. I know I can talk to [name] in[departmental office], or [name] in [departmental office]. I can talk to [name] in the [institutional] department. I can call [name] in [institutional department]. And if $I$ don't know the answer I will call (name). After being here a little while you begin to feel things out and you know there are a few people who will share with another staff member that they wouldn't share with a student. There are a few faculty that are a little more giving and bending and pliable then others.

While many aspects of the institution were supportive of service to students, there were also significant conditions within the institution which worked against support for service.

This lack of feeling of support for service and service providers was most often attributed to the sense that the institution was very hierarchical, and that staff were on the bottom of that hierarchy. This affected staff members' perceptions of themselves, their jobs, and ultimately how they treated students. One staff member said:

Oh yeah, that hit me like a ton of bricks when I first started working here at [the institution] over seven years ago. There is definitely a hierarchy. They [faculty and staff] are totally 
separate in fact. And it is still that way. It is still there. For example, some of the faculty in the other departments, it might take years before they would even speak to me.

This perception of hierarchy extended beyond faculty and staff relations to staff to staff relations as well. For example, service staff felt lower on the hierarchy than academic staff. Also, individuals who worked in upper level administrators offices (Dean, Vice Provost, Vice Presidents, Provost) were perceived to be higher in the hierarchy and have more clout than those who did not.

closely related to this notion of a hierarchy was the feeling of segregation which staff felt, especially from faculty and administration. One staff member noted that there was a "caste system," citing benefits which accrued only to faculty and administrators, and events which staff did not enjoy. In the same vein, another staff member noted that she felt segregated in terms of her ability to participate in institutional events. She said:

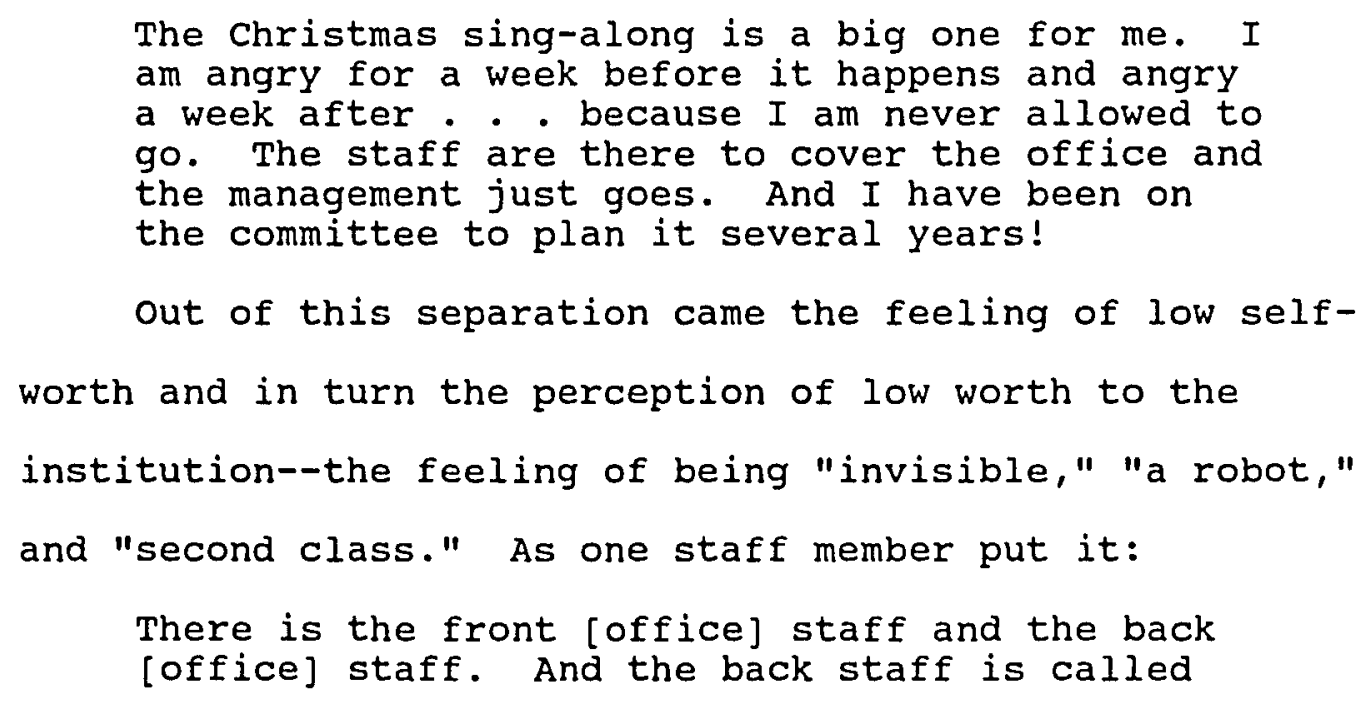


the professional staff. Well I am just as professional as anybody. That causes some grief sometimes for the people up front who have to take a lot. If somebody wants to holler at them (the professional staff) I get it. I smooth it over. Then if there is a staff retreat or something only those folks go. It means you're not important. You're not an important part of the organization.

Not only did they feel segregated from faculty and staff, some staff members felt that staff members were isolated from one another and that isolation was an inhibitor of good service. One staff member said:

The way classified people are managed on this campus is largely by isolating them in their own units. So that if the [institutional department] wants to put on a program in the school of [school name] auditorium, they are told "no" because they are not part of the school of [school name]. That kind of isolation cuts down this cooperative feeling. They don't feel a part of each other, they feel a part of their unit and so they don't extend themselves to the rest of the campus.

Said another staff member, "it is difficult with as many people as we have and as many problems as there are now. I think one of the biggest problems we have is the lack of communication just between departments."

This same staff member pointed out that isolation breeds another condition which works against a service environment, a condition she called "territoriality" of information. This was confirmed by several staff members. Expanding on the lack of communication between staff, one person said:

There are people over here in the [department name] department, they are not going to share 
information with anyone else. And you have the School of [school name] and they are not going to share any information. There should be a way of sharing information. Rather than "this is mine, why do you want to know about it." As long as I am the only one that knows it, I have a job. I hear that all the time.

Another staff member described how this phenomenon works :

They ask key questions; we all do it. Well, that is what happens when a person walks up to a desk in an office. They ask key questions. They are not generally known questions. They are questions the person sitting there uses to exclude everyone except those they feel they are there to serve. "If you are not a [major name] major don't ask me that question.. . If you are not a graduate student seeking more classes in [graduate program] you are talking to the wrong secretary." People feel that they are gatekeepers for their areas. They react like bulldogs at the front door and that is where the whole campus gets broken up into little segments. It just stops every thing, students and everyone else on the campus.

In this way, territoriality was perceived to reduce service, both by constricting the flow of information, and by eroding relationships between service providers.

Finally, it was also suggested that budgetary resources also had an effect upon a department's and an individual's ability to serve. It was noted that recent funding cuts, and staffing cuts had strained staff members' abilities to provide good service. One staff member said:

I think most staff members, myself included, really want to help the students in the best way they can, but we are also being pulled in other directions. [We are] overworked primarily, because of the cutbacks, not being able to add 
to our staff to really do a good job, the best job that we could.

These findings have significant bearing upon the results of analyses presented earlier. Earlier findings suggest that student interaction with staff may have positive effects upon persistence, and staff interaction with students may have positive effects upon satisfaction. These results indicate that those positive potential outcomes may be enhanced or diminished as a consequence of institutional culture and human resources policy and practice. 


\section{CHAPTER V}

\section{CONCLUSIONS, LIMITATIONS, IMPLICATIONS FOR RESEARCH, AND RECOMMENDATIONS \\ FOR PRACTICE}

\section{Introduction}

This study examined the general hypothesis that student interaction with front-line staff members in higher education settings has an impact upon the student experience, and ultimately, their persistence in colleges and universities. This study also examined the reciprocal hypothetical premise that this same interaction has an impact upon staff job satisfaction, and service quality. In order to provide a framework for the examination of these questions, this study reviewed several bodies of literature. First, in order to better understand why students stay and why students dropout, the literature and theory of student persistence were reviewed. This included a review of the research related to specific factors which are suggested to be theoretically linked to student persistence, including student integration, isolation, the effect of personal contact upon student persistence, and programmatic facilitation of student contact. 
The literature review also examined the other half of this relationship--the effect upon staff. Beginning with the theoretical frameworks of job satisfaction, this review included the linkage between satisfaction, productivity, and service quality, and the theoretical perspectives of Total Quality Management, and service quality, applied to the higher education setting.

Taken as a whole, there is much in this literature to suggest that there is a potentially symbiotic relationship between staff and students which could result in positive outcomes for students, staff and higher education institutions themselves.

In order to test the hypothesis that such a relationship exists, a quasi-experimental intervention was instituted which linked staff and students in an advising/ mentoring relationship. The outcome of this intervention was analyzed through the administration of pre and post surveys which examined the general experience of the interaction of students with stafe, along with the specific experience of the intervention. Surveys were also administered to staff and student control groups in order to better examine the effect of the intervention. In addition to this data, qualitative data were developed through interviews of staff and student subjects from both the experimental and the control groups. 
These data sources were then analyzed using quantitative and qualitative methods in order to assess the specific effect of this intervention, along with the more general effect of the day-to-day interaction between staff and students. The following conclusions have been drawn from those analyses.

Conclusions

Conclusion \#1

Formally linking students with staff in a mentoring/ advising relationship has a positive effect upon student persistence to the second year.

This conclusion was supported by both quantitative and qualitative data which resulted from the study. Though the experimental group persisted at a slightly higher rate $(82.9 \%)$, than control group 1 (78.3\%), their persistence rate was significantly higher ( $\underline{p} \leq 0.05$ ) than control group 2 (65.3\%) which was not involved in the intervention at all. It is also important to emphasize that this difference was achieved within the context of the mean persistence rate of freshmen who were not involved in such activities (control group 2) being much higher than normal. By comparison, the mean rate of freshmen for the six years prior to the intervention was 58.5\%. While it could be argued that the high retention rates of all groups were related to the unusually high 
retention rates of freshman students this year, this does not explain the significant differences between control group 2 and the experimental group.

The conclusion that there was a positive effect upon persistence is also supported by other data which suggested that the intervention helped to'create conditions which enhance persistence for students. First, students who participated in the intervention were more likely to interact with other community members. The experimental group's response to survey items related to student interaction with faculty staff, other staff and peers, were significantly higher $(\mathrm{D} \leq 0.05$ ) than that of control group 1. Second, significantly more students in the experimental group felt "personally connected to PSU," felt "comfortable at the institution," thought that it was "easy to meet people," or felt "attached to staff." Both of these results suggest the establishment of conditions which have been well documented as contributors to persistence. These conditions, the reduction of isolation and the increase of contact with peers (Carrol, 1988; Dukes \& Gaither, 1984; Mallinckrodt, 1988), staff (Beal \& Noel, 1980; Bernotavicz \& Clasby, 1984; Miller \& Brickman, 1982) and faculty (Gurin \& Epps, 1975; Hearn, 1987; Pascarella, Ethington, \& Smart, 1988; Pascarella, Smart, \& Ethington, 1986; Pascarella \& Wolfle, 1985) have been attributed to persistence in all types of 
institutions, including commuter and two-year institutions (Neumann, 1985; Pascarella, Smart, \& Ethington, 1986).

Another condition for persistence which seemed to be positively addressed by the intervention was students' feeling of "fit" or congruence with the institution. Qualitative data from the interviews suggested that students felt a significant lack of fit as they began their institutional experience. This feeling was especially characterized by students expression of a lack of support by the institution, particularly in contrast to environments which they were just leaving. The feeling of mismatch or incongruence resulted from leaving an environment in which there was an expectation for significant guidance from others, and entering an environment in which the individual is expected to guide and be responsible for themselves. This same incongruence was expressed regarding students feeling of leaving a community of peers and teachers in which they felt important and well known, and entering a community in which they were relatively unknown.

Arguably, students should have understood the nature of the institution they were entering. However, data suggest that they did not. To the extent that the intervention provided some assistance and attention and a sense of community, this incongruence was diminished. Tinto (1987) suggested that almost any institutional 
action has an effect upon persistence, whether you plan it or not. In this instance a planned and purposeful activity had a positive effect upon students.

In concluding that the intervention had a positive effect upon persistence, it is not assumed that the intervention was the sole cause of student persistence. Tinto (1993) suggested that persistence results from a complex interaction of institutional and personal actions which act upon student intentions and commitments and ultimately upon departure decisions. Along with other factors, this activity involved the process of students establishing a sense of integration with the institution during the critical first year. Like other possible institutional actions (Upcraft \& Gardner, 1989) this strategy seemed to help ease the transition for students and to help ensure their persistence at least to the second year.

\section{Conclusion \#2}

Certain factors related to the student experience seem to contribute to persistence more than others. Along with other findings, this study validated previous research in the identification of certain variables as having a particular impact upon persistence. These variables included sex, intention to enroll the following term, and interaction with a faculty member. 
That gender was significantly related to persistence was at first puzzling. Men and women were not treated differently in the study, and the ratio of men to women reflected the slightly larger number of women in the population in general. If anything, one might have expected women to persist at a higher rate then men, instead of the reverse. However, related literature (Tinto, 1993) seems to suggest that the effect of gender is probably not so much related to the intervention as it was to the difference in the experience of women during their first year in general as compared to men. Studies by stage (1989a, 1989b) provide particular insight into this difference. In a study looking at student motivation and commitment to attend college, stage (1989a) found that gender and social integration were linked to academic integration. Specifically, women who were socially integrated were significantly more likely to be academically integrated and ultimately more likely to persist (1989a). In another study, stage (1989b) found that there was a reciprocal effect between social integration and academic integration. For women the more socially integrated they were, the more academically integrated they were after one year. Given this evidence, the setting of this study in an urban institution where there may be less social integration, may alone account 
for the effect of gender upon persistence of students in the intervention.

student intention has also been found to be predictive of persistence and degree completion. Rodgers and Pratt (1989) found a significant relationship between intention to continue at an institution and persistence. Like Tinto (1987), they noted that intention does not explain persistence by itself, but rather that other factors (e.g., academic integration, social integration) tend to work in concert with student commitment.

While intention was significant in explaining persistence of all students, the intervention did not seem to play a role in changing a student's intention to persist or not to persist to the second year as there was no significant difference between the groups. It may be that the time period of the intervention was too short to show such a relationship.

A more likely explanation is that institutions have little ability to actively manipulate student intention by itself. Moreover, and as Tinto (1987) argued, student intention is a variable to be served rather than changed by institutions. Students may come to an institution initially with the intent to depart or their goals and intentions may change. For Tinto it is the "paradox of institutional commitment" that institutions which are truly committed to the educational success of their 
students will be as equally committed to encouraging students to leave if their intents or needs cannot be fully served, as they are committed to having them stay. Tinto (1987) described this institutional commitment as the "sum effect of personal commitments which link the individual to representatives of the institution-students, faculty and staff" (p. 184).

Finally, among all variables found to be related to student persistence, student contact with faculty may have received the most attention. Generally speaking, the more students have an opportunity for positive contacts with faculty outside of the classroom, the greater their persistence (Gurin \& Epps, 1975; Hearn, 1987; Pascarella, Ethington, \& Smart, 1988; Pascarella, Smart, \& Ethington, 1986; Pascarella, \& Terenzini, 1977; Pascarella \& Wolfle, 1985). Conversely, the absence of faculty contacts has been found to be related to student voluntary withdrawal, as well (Pascarella \& Terenzini, 1977).

Not only did contact with faculty seem to have an effect upon persistence, students in the experimental group seemed to have more of it. significantly more subjects among the experimental group than among the control group indicated that they had interactions with teaching faculty during the year $(\mathrm{p} \leq .001)$. This occurred even though these interactions were not the primary purpose for the intervention. 
There are at least two possible explanations for this result. First, staff members who participated in the intervention were trained to refer students to other appropriate community members, including faculty, for assistance and information. The difference in contact may be due to this referral. A more likely explanation is that contact stimulates more contact. As students worked with their staff advisors they gained competence (they knew where to go) and confidence (they felt more comfortable going there). As students learned from, and felt comfortable with a staff member, this helped them to feel less isolated and more confident about interacting with other community members.

\section{Conclusion 3}

The positive effect of students interaction with

staff in the intervention did not stem from social integration or intellectual integration themselves, but in helping to create the conditions for integration.

Theoretical propositions (Bean, 1982; Pascarella \& Terenzini, 1980; Spady, 1970; Tinto, 1993) have suggested --and a significant body of research (Munro, 1981; Pascarella, 1980; Pascarella \& Terenzini, 1977, 1983, 1991; Stoecker, Pascarella, \& Wolfle, 1988; Terenzini \& Pascarella, 1977) has demonstrated--that social integration (student interaction with other members of the 
educational community) is a critical element in the process of student persistence.

The importance of social and intellectual integration was supported by this study. Qualitative findings suggested that at the beginning of the second year students who expressed a feeling of integration and a sense of community responded that the feeling resulted from the experience of interaction with peers. Quantitative results suggested that interaction with faculty made a significant difference in student persistence. What role then did student interaction with staff play?

It was expected that the social components of this intervention would be at least equally important as the service role (information, assistance, administrative support) which students experience with staff. This did not prove to be true. Quantitative and qualitative findings suggested that students in the experimental group felt more "connected to the institution" and had more contact with community members, but staff were not seen as the primary objects for that connection and communication. Rather, staff involved in the intervention tended to play the role of facilitators of those conditions.

Students felt that their advisors were "nice" and they "liked" their interaction, but what they expected was help. This help took the form of referral to both 
academic information and resources, and to social and extracurricular resources. Staff were not necessarily viewed as participants in these activities as much as guides for students. In this way, this study seemed to support other research which identified faculty and peers as primary actors upon student persistence. However, it also suggested that integration may be facilitated by the action and interaction of staff.

While persistence may be more directly related to the interaction between students and peers and students and faculty, these may be less frequent or may be of lesser value without the effective and efficient facilitation of the interaction by staff. If faculty and peers are the engine which drive the persistence vehicle, staff may be regarded as the lubricant.

Conclusion \#4

The day-to-day service interaction between staff and students contributes to conditions which affect student persistence both positively and negatively.

Along with focusing upon the experience of students and staff in the intervention, this study looked at the daily interaction between students and staff and how that affected the experience of students. A student's experience of service through interaction with staff members was either very good or very bad, but never neutral. Students did have a perspective on the value of 
this interaction and it did have an impact, both positively and negatively.

Probably the most obvious benefit of this interaction was the substantive assistance and service that staff provide. Especially in an urban setting where students are involved in multiple roles, time is a particularly important and finite quantity. In this context especially, staff are perceived as important service providers. That service includes information and assistance related to the office they represent, referral to other offices and campus resources, and not infrequently academic advising, especially in academic departments.

Data indicate that some staff view providing academic assistance (advising) as an important responsibility of their job while others are uncomfortable providing any information which might be construed as academic advising. Students, however, often do not differentiate between staff and faculty in their expectation of who can provide them with basic assistance. If they cannot have immediate access to a faculty member to answer a question, they expect the staff member to be able to assist them, at least with the provision of simple information. This expectation varies across departments.

In the best of these interactions students receive timely and direct service. Staff are knowledgeable 
experts in their service area and provide current information related to their area of expertise. When outside of that sphere of expertise, staff refer accurately and follow up to ensure that the student was served.

Along with these substantive contributions, staff contribute to students' experience simply by their demeanor. Positive, pleasant, supportive, service oriented staff, contribute to what Noel, Levitz, and Saluri (1985) described as a "staying environment." Again, when time is a finite resource, especially in urban institutions, positive service interactions support and contribute to a student's experience.

This student/staff interaction can also have the opposite effect of eroding a student's relationship with the institution. For each student in the study who had a positive interaction with a staff member, there was one who had a negative interaction. Separate from the intervention, some students perceived some staff as rude, controlling, and intimidating. others found some staff members to be misinformed or lacking in knowledge. One student in particular noted that they quit seeking information from a crucial campus department because of feeling mistreated by the staff.

In a world in which quality service is rapidly becoming the standard, inadequate, incompetent and 
unfriendly service stands out. Taken as a part of the contribution toward the experience of students and ultimately their persistence, negative experiences cannot help but diminish the social and intellectual integration with an institution/which a student might otherwise enjoy.

\section{Conclusion \#5}

Staff participation in formalized activities designed to promote student success, also promotes job satisfaction.

Just as the results suggested that the intervention had an impact upon student persistence, the results related to staff strongly support the proposition that participation in formalized activities in support of students promotes job satisfaction for staff. Just like their faculty colleagues, staff in the intervention wanted to make a difference for students, and when doing so they were more satisfied with all aspects of their jobs.

This increased level of job satisfaction was noted in every measure of satisfaction resulting from the study. First, when asked about their overall job satisfaction at the conclusion of the intervention, there was a significant difference $(\mathrm{p} \leq .05)$ between the mean scores of the experimental group $(\underline{m}=3.95)$ and that of the control group $(\underline{m}=3.0)$. Moreover when the differences between the pre and post scores of the same measure were compared, there was a significant increase for the 
experimental group ( $\mathrm{p} \leq 0.001)$, and no increase for the control group.

Along with this general measure, both staff groups completed survey questions which included the work subscale of the Job Descriptive Index. Here again, results indicated that individuals in the experimental group were more satisfied with their jobs then those in the control group. The mean satisfaction score of experimental group $(\underline{m}=43.9)$ was significantly higher $(\underline{p} \leq 0.001)$ then the mean score of the control group $(\underline{m}=31.1)$. And just like the measure of "overall job satisfaction" there was a significant increase ( $\underline{p} \leq 0.001)$ in the pre to post survey JDI scores of the experimental group. This difference was not observed, however for the control group.

Finally, in order to place these measures of satisfaction in context with those found elsewhere, the mean JDI scores of the experimental and control groups were compared to national norms available for the Work subscale of the JDI. Here again, the results indicate that the experimental group was more satisfied with their jobs at the conclusion of the intervention than the control group. At every level, the experimental group's post survey score was above national norms, having begun below the norms in the pre intervention survey. Conversely, for the control group the post survey scores 
of satisfaction rose above the national norms only in the 1st percentile.

These results validate earlier research in business organizations which has suggested that the opportunity to provide quality service has a positive impact upon job satisfaction (Schlesinger \& Zornitsky, 1991; Turnow \& wiley, 1991; wiley, 1991).

other aspects of the intervention seemed to promote job satisfaction, in addition to the specific effect of the experience of staff working with their advisee. For many of the staff members involved in the intervention, the opportunity to participate itself was an acknowledgment by the institution of their importance in the mission of the institution. Staff also gained satisfaction through the opportunity to step out of their daily work routine, and to learn new skills connected to this role. While being somewhat peripheral to the intervention, these aspects of the staff experience played an important role in their job satisfaction.

\section{Conclusion \#6}

Beyond a positive effect upon job satisfaction, the intervention engendered other positive outcomes for staff and the institution.

For many staff members the context of the intervention helped to foster an increase in communication with co-workers in their department and in other 
departments. This occurred as staff members in the same office discussed their experiences and provided assistance and insight for each other in this endeavor. This also occurred on a broader institutional level. First, staff members were provided with the names of institutional contacts who could provide direct assistance and referral as they needed for/their advisee. This connected staff with individuals with whom they might otherwise not have had contact. Second, and perhaps more important, they were connected with each other. This experience connected staff members across institutional boundaries of administrative structure and hierarchy unlike almost any other experience which staff had. Many staff members had the experience of meeting other colleagues for the first time, or interacting with staff form other departments for the first time. In these ways, both inter-office and intra-office communication and relationships were improved.

This connection was designed to assist staff in the work of the intervention, but more likely had long term effects of improving ongoing campus relationships, as well. As institutions increase in size and complexity, as tradition and hierarchy continue to separate staff, and as human resources shrink, vehicles such as this which increase communication and connection have enormous potential for improving institutional performance. 
Conclusion \#7

Job satisfaction for classified employees in

university settings is enhanced through the opportunity to contribute to student success offered by their day to day interaction with students.

The results of this study indicate that the experience and feelings of staff involved in the intervention is mirrored by the daily unplanned interaction of staff with students--opportunities to contribute to the student experience and the educational mission have a positive impact upon staff satisfaction. Both quantitative and qualitative results support this conclusion.

First, as noted earlier, though the experimental group was statistically more satisfied, the measures of job satisfaction of staff in the control group did not indicate dissatisfaction. For example, when asked about their overall satisfaction, the mean score of the control group indicated that overall they "agreed" that they were satisfied $(\underline{m}=3.0)$. This may be related to the good feelings engendered simply by the recognition resulting from the request for participation. It is more likely that this general satisfaction is related to the feelings which staff associate with the role of helping students generally. 
These feelings are also apparent in the mean scores of the control group related to the "feeling of contributing" to the educational mission (Table 18). While they did not rise to the high levels of agreement of the experimental group, the mean scores of the control group were generally in the "agree" range (3.0 or above).

Along with these scores, the qualitative results from both the experimental and control groups support the proposition that the opportunity to interact meaningfully with students has a positive impact upon staff job satisfaction.

These results demonstrated, among other things, that for most staff, working at the University was more than just a job. Many $\mid$ chose to work in an educational institution because they perceived themselves to be "educators," and because this experience gave them the opportunity to "inspire and connect" with students. These osportunities generally occurred through the following activities: (a) direct service to students related to their job, (b) naturally developing advisor/mentor relationships in which they provided general advising and referral, and (c), academic advising.

A highly educated group, staff indicated that they chose specifically to work in educational settings, because of the environment and mission. They saw themselves as specialists who understood educational 
institutions and students. Their choice of careers and institutions was not accidental, but rather was based upon their interests and experience. The opportunity to have an impact upon the student experience played an important role in their choice to continue at the institution and their feeling of satisfaction.

Conclusion \#8

Though a few staff felt differently, overall, staff did not feel that they were valued or acknowledged for. their contribution to the institutional mission and the experience of students.

The feelings and experience of staff were fairly consistent. Generally, they felt like "second class citizens." The terms they used to describe how they felt they were perceived by faculty and administrators included "ghost people," "peons," "slaves," "trustees," and "robots." Though some individuals did feel valued by their direct supervisor, they also tended to fell devalued by faculty and administration outside of their unit.

This feeling of second class citizenship was contributed to by what staff perceived to be a very hierarchical organization, with the faculty and administration clearly on the top, and themselves on the bottom. This hierarchical feeling was characterized by a feeling of disrespect, lack of empowerment, and perception of segregation. 
This feeling of second class citizenship did not reduce the personal feeling of satisfaction or contribution of all staff. Some individuals seemed to find this internally, if not receiving it from external sources. However, it was clear that various institutional actions could help to support this feeling, or at least not contribute to its erosion.

\section{Conclusion \#9}

Certain conditions promote or detract from an environment in which staff are more likely to provide good service, thereby promoting student success and their own satisfaction.

Various aspects of institutional action and inaction in relationship to staff, help or hurt the environment for service. While the results of the study suggested that staff felt the environment for service was more often being impeded by institutional inaction, the identification of activities which could improve service was also made clear.

Staff identified a number of contributors to job satisfaction and good service including empowerment, teamwork, personnel policies and connection with other staff. This list of contributions is led by the feeling of empowerment. Staff felt empowered when their input was sought concerning significant responsibilities, when they were entrusted to accomplish meaningful outcomes, and when 
they were delegated appropriate responsibility by their supervisor. Staff felt especially empowered in relationship to their ability to have an impact upon the student experience.

closely linked to empowerment, another contributor: was the feeling of teamwork within an institutional unit. Staff felt more satisfied when they felt they were part of a team in which all members, whatever their job classification (faculty, staff, administration), made meaningful contributions to the institutional mission. Another important aspect of teamwork, was mutual acknowledgment of individuals' contributions.

staff also felt that the way in which human resources policies were administered had an effect upon service and satisfaction. Staff felt supported for their work when service was reflected specifically in their job descriptions, and when evaluation and reward were based upon that criteria, along with others. Good service and satisfaction were also stimulated when training opportunities and other Human Resources initiatives reflected the importance of quality service. Staff fecognition programs were particularly important in this regard.

Finally, good service was stimulated by staff themselves through the creation of their own service networks. Staff who had established a strong network of 
other employees of all types--whom they could call upon for assistance and information--felt more competent to provide quality service. The establishment of these networks had the added side effect of causing staff members to feel that they were part of a larger team all working toward a common goal.

But just as these actions could improve the environment for service, other actions wear away that environment. Leading the list of impediments to service was the feeling of staff that they were considered to be at the bottom of the institutional hierarchy of important actors. This feeling, was reflected by the derogatory terms which they used to describe how they were perceived by faculty and administration (e.g., peons, robots, slaves). Whatever internal satisfaction staff felt, was easily eroded by the feelings they got from others. Even if a staff member felt their own supervisor was supportive, most often they felt that they were not perceived the same way by others outside of their institutional unit.

Related to hierarchy is the effect of a feeling of segregation on the part of staff. This feeling results from staff's perception that access to benefits and institutional activities are different for different employee groups. Perceived differences between staff and faculty and administration related to flexibility in terms 
of time off, and access to certain social events were the most frequent examples given of this segregation. Staff felt that faculty and administrators could come and go as they pleased, while their own schedule was strictly constrained. They also felt excluded from some university events because the expectation was that staff would not attend because their schedule was not flexible. In addition to segregation from faculty and administrators, service was impeded as staff felt isolated from one another. Size, increasing complexity, and shrinking resources join to limit interaction among the staff. This is true within institutional units, but is especially notable across administrative structural boundaries across the university.

Compounding this isolation is the problem of territoriality of information. Frequently, staff in departments limit or make access to information difficult for students and other staff. Staff perceived this phenomenon as a consequence of individuals with little authority and control, using what limited leverage they had to make themselves feel more important.

Reciprocal to what stimulates good service, the lack of a feeling of empowerment also reduces service and satisfaction. Lack of trust, lack of authority over meaningful work and the lack of ability to determine how 
work is accomplished, all contributed to a low feeling of empowerment.

Finally, reduced resources, human and otherwise, place a strain on the service system. At some point, even the motivated staff members, empowered by the most enlightened supervisors, reach their limit. As reductions in staff and budgets occur through downsizing and limitations on appropriations, service improvement must ultimately reach a level beyond which continuing advances cannot occur.

\section{Limitations of the study}

There are four main limitations to the study which must be addressed. First, it must be noted that though every attempt was made to randomly assign subjects to groups, given the design of the study it was impossible to ensure that the final selection was random. Students and staff subjects were asked to participate from randomly drawn lists, but their ultimate participation was dependent upon agreement to participate in the intervention (experimental groups), or fill out a survey (control groups). It is possible that individuals who volunteered for participation might have been more motivated to change in the direction promoted by the intervention, or might have other characteristics that affect the results of the study. In particular for staff, 
part of this motivation could have resulted from the researcher's institutional status as a senior-level administrator or a long-term work relationship with the researcher. To the extent possible, this concern was addressed by attempting to select the final groups in a way that most closely matched the general populations being studied.

Second, it is possible that the duration of the intervention itself (one year) was too short to allow for conclusions to be drawn about the effect of an intervention upon student persistence. Additionally, there was the potential that the design of the intervention, starting in winter term instead of Fall term, might not have given adequate time to show any effects.

Third, it must be noted that the survey designed for this study was not fully tested for reliability. This could call into question the results from this instrument. At the same time, other validated quantitative instruments along with qualitative research methods were utilized to gather data from the subjects. It is through this method of triangulation of data sources that reliability of the findings and conclusions is, realized.

Finally, it should be reemphasized that the context for this study was an urban institution, with its unique setting and student profile. It is possible that the 
findings may not be generalizable to ather types of institutions and their students and staff.

\section{Implications for Future Research}

This study examined the effect of utilizing staff in an early intervention designed to affect student persistence. Looking closely at the experience of students and staff, this investigation initiated a glimpse at a relationship which seems to have beneficial effects for student and staff. But the need for more study related to these issues is clearly indicated.

First, the intervention itself bears additional examination, especially related to the dimension of time. This program linked students with staff as mentor/advisors over the course of two terms, winter and spring. The persistence of the student experimental and control groups was then compared at the beginning of the following Fall. It is possible that more time in the relationship might improve the outcome for students. Further study might examine whether persistence is affected if the staff/ student relationship is extended to a full year, or two years, or six years, for example. In addition, the actual time during which student and staff spent/meeting might be increased to see if that has greater impact upon persistence. 
In addition to the factor of time, this study suggested that not all students benefitted from the intervention as much as others. Additional research needs to examine whether there is a certain profile or type of student who might benefit more from such early intervention.: This would allow institutions to tailor programs more effectively for students, and to make the best use of their resources.

In addition to the intervention, the effect of the daily (unplanned) interaction of staff and students deserves morelexamination as well. Perhaps the most surprising aspect of the literature reviewed for this study was the |absence of acknowledgment of any effect of interaction between front-line staff and students. At the same time, local campus lore and anecdotal reminiscences are rife with |inspirational stories of staff helping students in significant ways--or alarming stories of services which were poorly provided or intentionally denied. Many of these interactions may have little personal or educational consequence to students. But others report the opposite; that there is value to these relationships when they are good and a cost to students when they are bad. Something is happening to students, which deserves more explicit attention.

Just as the literature seems to ignore the effect of staff upon students, little is known of the effect of 
students upon staff. This study also found reciprocal effects related to staff which suggest more study. Further research might explore more thoroughly whether job satisfaction is related to the ability to provide quality service in thigher education settings, as suggested in research related to business settings. This research also suggests the need for some attention to whether educational|attainment plays a factor in staff members feelings of satisfaction related to helping students, given the exceptional level of education possessed by most of the staff subjects.

Finally, related to staff, additional attention needs to be focused on the environment for good service. Special attention is this regard, needs to be paid to institutional hierarchy as exemplified by perception and policy, the effect of human resources policy and procedures in general, and the institutional role and expectation for staff.

\section{Significance to Educational Leadership and Recommendations for Practice}

The results of this study have significance for educational leadership from two primary perspectives. First, this study extends knowledge about the freshmen experience and explores methods for fostering student persistence.' Simultaneously, the study looks closely at how institutions use front-line service staff in support 
of efforts to improve the student experience, and how those efforts may have a reciprocal effect upon positive outcomes for staff and the institution.

In the field of higher education, student persistence continues to be an important issue both for individual students and for institutions. For students, persistence is both an achievement issue and a resource issue. It is clear that the roots of persistence, social and academic integration, are also the roots of successful academic achievement and learning. This study examined a program for involving staff in the process of that integration, both as providers of direct service and as vehicles for fostering and furthering a "staying" environment in which students are supported in their learning.

Along with fostering learning, this is a resource issue for students as well. As college costs increase, students cannot afford to involve themselves in programs which are not organized effectively to promote their goals. Institutions which do not undertake every method to promote persistence cost students money, in addition to time.

For institutions, the examination of student persistence is important for the same reasons. To the extent that it is the institution's primary mission to do everything possible to promote student success and achievement, it continues to be important to explore new 
avenues for serving that goal. Secondary to this motive, but equally important in its ultimate consequence, is the fact that persistence is also a resource issue for institutions. Student retention means tuition revenue and other resources for institutions, which must be maintained in the face of increasing costs and shrinking budgets. student achievement may be the best reason for pursuing all means for fostering student persistence, but keeping the lights burning in the ivory tower is the "bottom line."

This study also has much significance for what it tells us about the use of staff in the achievement of educational goals in higher education institutions. Left alone, staff may have very positive, or very negative impacts upon the student experience and achievement. Once again, both for purposes of student achievement and because institutions cannot afford to be inefficient or ineffective in any aspect of how goals are achieved, they must pay attention to the role in these processes which staff play.

closely linked to this, is the institution's goal of making the best use of its human resources. As resources shrink and institutions downsize, an institution must make efficient use of all employees, including front-line staff. This argues for being more intentional regarding the content and quality of the interaction between staff 
and students. This benefits students through their experience of an environment which is designed and implemented to support their goals. Staff also benefit by being provided experiences which contribute to their satisfaction and development. Finally it benefits institutions as the reciprocal positive effects of the interaction of staff with students contributes to achievement of the institutional mission.

In addition to these general themes of significance, several specific recommendations for improving practice are suggested by the findings and conclusions of this study.

Recommendation \#1

Make use of staff resources in programs designed to enhance the student experience and persistence.

Staff have the education, experience and the inclination to provide meaningful assistance to students. The program developed for this study is one example of an effective way to involve staff. Other methods may be more appropriate for other institutions.

Planning for such programs should include thorough screening of staff, identifying those individuals with the necessary skills and qualifications for the role, especially communication and interpersonal skills. Everitt and Murray-Hicks (1981) suggested qualifications for effective mentors which provide a good framework for 
selecting staff members who would be effective in assisting students.

Additionally there should be significant training for staff involved in this way. Training would include those skills necessary to be a good mentor/advisor in addition to more substantive subject area information training concern information and resources for referral. In particular training should include a basic understanding of academic programs and the academic system, and the ability to link students with knowledgeable faculty or staff who can provide more specific information.

While using staff in this way is recommended, this step should be undertaken with the full knowledge of possible consequences. Indeed, asking staff to provide new services to students or to enlarge the scope of their job could detract from their service to others; e.g., institutional departments, faculty, and administrators. However, it is expected that the overall value added by staff in this way should produce institutional savings (as represented by students persisting and being more prepared) which would replace any loss experienced by this activity.

Recommendation \#2

Gather and utilize data on student intentions for more efficient program design and more effective advising of individual students. 
In our pursuit of retention of students, both for their sake and the institutions sake, we forget that not every student intends to or should graduate from our institutions. Many intend to transfer elsewhere, or to complete goals which might not include receiving a degree, or even continuing during the next quarter or semester. And yet we seldom know, let alone ask them, what their goals are.

Institutions which aspire to undertake programs which will promote student success and persistence must develop practice of collecting data on students' intentions as they enter, and as they proceed in the institution. Without this data, institutions have no real basis of understanding for making retention programs more efficient or effective, let alone providing information which might be helpful for a particular student.

\section{Recommendation \#3}

Review and renew human resources policy and practice which relate to the student/staff relationship.

If, as this study seems to suggest, every interaction with students has an effect upon their educational experience, then significant attention needs to be paid to the policy and procedures which relate to those interactions. Beyond their own internal motivation, staff are moved to pay attention to service though policies and procedures which relate to service. Examples of these 
processes and policies include job descriptions, evaluations, reward systems, staff orientations and recognition programs.

First, it should be made explicit through any formal documentation or conversations concerning the job that service (interactions with customers) is important, and that staff will be evaluated and rewarded for the quality of this interaction, among other important aspects of the job. This begins with the first announcement of the job. Individuals interested in any service position should clearly understand through the job announcement that direct service and quality service are essential requirements of the job.

This and any other essential duties of the position should also be made explicit in the job description. This aspect of the job should then be specifically evaluated, and heavily weighted as the individual is considered for rewards.

In addition to salary, other kinds of rewards for good service should be considered, as well. For example, awards for good service are another effective way to provide community recognition for individual|performance. These have the dual benefit of recognizing the individual and setting an example for others to follow.

The importance of service should be emphasized in any communication of information to staff members. New 
employee orientation programs are opportunities to stress the importance of this responsibility. Staff newsletters are also good vehicles for providing information and tips on best practice.

Finally, include service quality among the criteria used in evaluating supervisors of service employees. Quality must be reinforced from the top down. Evaluating supervisors on the performance of their employees in this regard is one structural way to ensure their attention to this important issue.

\section{Recommendation \#4}

Help to prepare staff to provide quality service through training.

As mentioned earlier, training is also an integral component of any effort to ensure good service from staff. Just as staff who might participate in intentional intervention should be trained, staff who interact with students on an unplanned basis in their daily work role should receive training to assist them in making that interaction valuable for students.

The object of training would be to prepare staff members to be experts in the knowledge of their department, and to be equally adept at knowing where and when to refer a student to some other expert. Training would include enhancement of interpersonal skills and abilities, in addition to training related to departmental 
or topical expertise and general information and referral resources.

Staff would also benefit by being cross trained to do other jobs. This would allow them to more effectively refer students to other staff, and might also serve to link staff more closely together as they participated in training one another.

Recommendation \#5

Acknowledge the importance of staff in relationship to student outcomes, and empower staff to take on as much responsibility for student success as their education. experience and affinity allows.

The effect of staff upon students seems to be one of those axioms which we all agree upon but frequently take for granted. We tacitly agree that staff may have positive effects upon the student experience, or we lament perceived negative effects. Our tendency, however, is to ignore the effects of this interaction either way. In either direction, this lack of attention is bad for students, for staff, and ultimately for the institution. While there are undoubtedly a few staff for whom the intrinsic reward of working with students is sufficient, most staff want to know that their work is appreciated, and that they make a difference for the institution and for individual students. Without this attention quality service and good interactions will not turn bad 
immediately, but over time quality and caring will slowly erode. Other, more extrinsic rewards are helpful and necessary, but ultimately even these have little effect in an environment in which this interaction is not acknowledged for its value.

For those staff members who do not have the natural inclination for positive interactions with students or service in general, indifference concerning their interactions simply validates their feelings and often perpetuates negative interactions. In the case of staff with those attitudes, service and relationships will tend to get worse without attention from the supervisor. The worst example of this outcome is the staff nember who manipulates, or controls information, doling it out slowly and making the service interaction onerous for students in order to bolster their own feeling of importance. Whatever the inclination of the employees, acknowledgment of their importance in this regard is not a difficult task. For some staff members informal verbal acknowledgment is sufficient. For others, formal acknowledgment of the importance of good student relationships should be stated in the job description and considered when evaluation and rewards are considered. For institutions who strive for quality and good outcomes, both types of acknowledgment should be minimum standards. 
Once acknowledged, staff must be empowered to make the most of these relationships. Staff should be given responsibility and authority for providing the highest level of service that their experience, education and interest qualify them to provide. For example, some staff in academic departments provide a significant amount of academic advising for students as a result of their accessibility and student need. In some cases this is openly supported and acknowledged by departments. In other instances it is an underground activity which staff undertake with some/trepidation for fear of being found out, but continue because of the unmet demand which they perceive. Empowering these staff members to undertake an appropriate level of support for students could help to provide more support for the department, broaden the scope of staff jobs, and increase job satisfaction.

At the same time, not all staff may be inclined are able to take on additional roles. Institutions should, as a matter of policy, |consider the abilities and experience of their staff, and / when possible and appropriate, give them the authority and the tools to assume broader roles and responsibilities.

$\underline{\text { Recommendation } \# 6}$

Select staff for their ability to provide good service and relate well with students especially in those positions which have significant student service aspects. 
If we agree that the interaction of students and staff is important, we must also agree that it makes a difference who performs this function. Not everyone is suited to providing good service. Some people enjoy this relationship, and thrive on their ability to provide significant assistance to students and others. Others are simply uncomfortable interacting with people, and disinclined to extend themselves as service providers. We should, but more often do not, select staff for these roles on the basis of their skill and interest in providing good service. If we wrongly assume that the interaction itself is not significant, it follows that we probably do not think it is important who fills these roles, either. But, in fact, this interaction does make a difference, and some people are better at it than others. Institutions and departments which want to make a difference in this regard must begin to be more thoughtful in the descriptions of jobs, and the criteria used to select individuals for specific positions. Given that almost every interaction in an institution may have an effect upon the student experience, service potential is important for every staff job, and a person's ability in this regard should be ascertained during the selection process. This is even more important for those jobs which are deemed to be high service contact positions. Where good service is important, where this interaction sets the 
tone for the student or customer's experience, where substantive transactions are occurring, an institution cannot afford to have anyone but their best people up front. Staff selection is the key to this outcome, and careful consideration concerning this process is essential for its achievement.

\section{Recommendation \#7}

Help to facilitate the connection of employees for their mutual benefit.

As institutions have increased in size and complexity, and employee numbers have decreased though budget cuts and downsizing, the personal and professional associations which linked employees in the past have become severely strained, if not broken. The strong helping network of relationships once forged over coffee and lunch, have given way to less personal communications of voice mail and e-mail. Along with the personal loss, what has suffered is the employee's ability to tap that network for assistance or information on behalf of a student or other service recipient.

One way to resolve that loss is through the building of community in general. opportunities for connection and relationship are enhanced through the establishment of a sense of community on campus. But more intentional network building is possible also. Institutions can help to create networks by design if not through the 
environment. Such networks can be formed around specific issues like advising or referral, and can be facilitated through institutional scheduling, management, and organization. Through networks staff share information and advice and learn new skills. Most important, even when artificially established, networks help individuals create relationships which serve to link staff members in ways which help them to help each other.

Recommendation \#8

Institutions should view the student/staff relationship more wholistically--not so much as discrete experiences, but rather as experiences linked by a common desire for community and connection.

Both in research and in practice we generally attempt to investigate or affect the experience of institutional members through discrete analyses or programs designed to change or improve their specific experience. Seldom do we view these experiences as having much to do with one another, let alone that they might have elements in common.

This kind of thinking results in policies and programs which may act to disconnect institutional components which may be systematically linked. In the case of student and staff if we do not understand and account for the mutual effects of their interaction, we 
stand to develop policy which would reduce the positive nature of that interaction.

looking at the experience of students and staff from a wholistic perspective, we can see that they are linked by the common feeling of wanting to "matter" to others, and the pursuit of a sense of community. Using these as the organizing principles yields a much different course of action then if we viewed each discretely. Viewed separately we might attempt to create programs which would only affect student persistence or staff satisfaction. Viewed together, an institution might instead focks upon efforts which facilitate community and "mattering" in general.

Summary

Like other studies which examined student persistence, this study investigated the effect of student interaction with certain institutional community members upon student satisfaction and persistence to the second year. This study was unique, however, in examining the effects of the student/staff relationship, and testing a program for using this relationship to improve student persistence and to increase staff job satisfaction.

The results of this study suggested that the interaction of students with staff does have the potential of having a positive effect upon both groups. For 
students, those who interact with staff seem to be more connected to the institution and other institutional members than those who do not. Students who are formally linked to staff in a helping relationship like that created for the study also seem to persist at a higher rate. Staff, given the opportunity to help students meaningfully (either through a formal intervention or through their daily work), are more likely to be more satisfied with their jobs.

This study suggested that the reverse was true also. Students who had bad experiences with staff tended to avoid contact and thereby institutional connection. Similarly for staff, where certain institutional conditions were not supportive of the service which staff provided to students, staff tended to be less satisfied. In relation to these conclusions, several specific recommendations for the facilitation of positive student/ staff relationships have been suggested.

In summary, this study supports the hypothesis that the satisfaction and success of students and staff are closely linked. Community, connection, and respect enhance the experience and the mutual interaction of both groups, just as they do for others. To the extent that institutions take direct action to facilitate positive interactions, students, staff and the institution all stand to benefit. 


\section{REFERENCES}

Adams, J. S. (1963). Toward an understanding of inequity. Journal of Abnormal and Social Psychology, $\underline{67}(5), 422-436$.

Albrecht, K., \& Zemke, R. (1985). Service America. Homewood, IL: Dow Jones-Irwin.

Alderfer, C. P. (1969). An empirical test of a new theory of human needs. organizational Behavior and Human Performance, $4(2), 142-175$.

Alderfer, C. P. (1972). Existence, relatedness, and growth: Human needs in organizational settings. New York: Free Press.

American College Testing Program. (1983). Data compiled from the ACT Institutional Data File for 1983. Iowa City, IA: Author.

American College Testing Program. (1986). Data compiled from the ACT Institutional Data File for 1986. Iowa City, IA: Author.

American College Testing Program. (1990). Data compiled from the ACT Institutional Data File for 1990. Iowa City, IA: Author.

American College Testing Program. (1992). Data compiled from the ACT Institutional Data File for 1992. Iowa City, IA: Author.

Arvey, R. D., Bouchard, T. J., Segal, N. L., \& Abraham, L. M. (1987). Job satisfaction: Environmental and genetic components. Unpublished manuscript.

Astin, A. (1973). The impact of dormitory life on students. Educational Record, 54 (9), 204-210.

Astin, A. (1975). Preventing students from dropping out. San Francisco: Jossey-Bass.

Astin, A. (1977). Four critical years. San Francisco: Jossey-Bass. 
Astin, A. (1984, July). student involvement: A developmental theory for higher education. Journal of College Student Personnel, 25(4), 297-308.

Astin, A. (1993). What matters in college: Four critical years revisited. San Francisco: Jossey-Bass.

Atkinson, J. W. (1964). An introduction to motivation. Princeton: Van Nostrand.

Bandura, A. (1986). Social foundation of thought and action: A social cognitive theory. Englewood cliffs, NJ: Prentice-Hall.

Bandura, A. (1987). Self-regulation of motivation and action through goal systems. In $V$. Hamiltion \& N. H. Fryda (Eds.), cognition, motivation and affect: $A$ cognitive science view (pp. 37-61). Dordrecht: Martinus Nijholl.

Beal, P. E., \& Noel, L. (1980). What works in student retention: The report of a joint project of the American college Testing program and the National center for Higher Education Management systems. Iowa City, IA: American College Testing Program.

Bean, J. (1982). Conceptual models of student attrition: How theory can help the institutional researcher. In E. T. Pascarella (Ed.), studying student attrition (pp. 17-34). San Francisco: Jossey-Bass.

Bean, J., \& Metzner, B. (1985, Winter). A conceptual model of nontraditional undergraduate student attrition. Review of Educational Research, 55(4), 485-540.

Bernotavicz, F., \& Clasby, M. (1984). Competency across campus: The university secretary. Portland: University of Southern Maine, Center for Research and Advanced Studies. (ERIC Document Reproduction Service No. ED 252 162)

Billson, J. M. \& \& Terry, M. B. (1982, Fall). In search of the silken purse: Factors in attrition among first-generation students. College and University, $\underline{58}(1), 57-75$.

Bligh, D. M. (1977). Are teaching innovations in post-secondary education irrelevant? In $M$. J. Howe (Ed.), Adult learning: Psychological research and application (pp. 249-266). New York: John Wiley and Sons. 
Bolman, L. G., \& Deal, T. E. (1987). Modern approaches to understanding and managing organizations. San Francisco: Jossey-Bass.

Boyd, V. (1990). Intrusive informing: Mentoring by telephone (Research Report \#11-90). College Park: University of Marylana, Counseling Center. (ERIC Document Reproduction Service ED 325 772)

Brayfield, A., \& crockett, W. (1955). Employee attitudes and employee performance. Psychological Bulletin, 52 (5), 396-424.

Bron, G., \& Gordon, M. (1986). Impact of an orientation center on grade point average and attrition, college Student Journal, 20(3), 242-246.

Cabrerra, A. F., Nora, A. \& Castaneda, M. (1992). The role of finances in the persistence process: A structural model. Research in Higher Education, 33 (4), 571-593.

Caldwell, D. F., \& O'Reilly, C. A. I. (1982). Task perceptions and job satisfaction: A question of causality. Journal of Applied Psychology, 67(3), 361-369.

Carothers, R. (1992). Translating quality for the academy. AAHE Bulletin, 45(3), 6-10.

Carrol, J. (1988). Freshmen retention and attrition factors at a predominately black urban community college. Journal of College student Development, $\underline{29}(1), 52-59$.

Chaney, B., \& Farris, E. (1991). Survey on retention at higher education institutions (Higher Education Survey Report \#14). Washington, DC: U.S. Department of Education, office of the Undersecretary, Planning and Evaluation Service.

Chickering, A. W. (1969). Education and identity. San Francisco: Jossey-Bass.

Chickering, A. W. (1974). Commuting vs. resident students: Overcoming the educational inequities of living off campus. San Francisco: Jossey-Bass.

Churchill, W. D., \& Iwai, S. I. (1981). College attrition, student use of campus facilities, and a consideration of self reported personal problems. Research in Higher Education, 14 (4), 353-365. 
Coate, I. E. (1991). Implementing total quality management in a university setting. In $L_{\text {. }}$. A. Sheer \& D. J. Tetter (Eds.), New directions for institutional research: Total quality management in higher education (pp. 27-38). San Francisco: Jossey-Bass.

Cobb, S. (1976). Social support as a moderator of life stress. Psychosomatic Medicine, 38(5), 300-314.

Cook, J. D., Hepworth, S. J., Wall, T. D., \& Warr, P. B. (1981). The experience of work. London: Academic Press.

Cosgrove, T. (1986). The effects of participation in a mentoring-transcript program on freshmen. Journal of College student Personnel, 27(2), 119-124.

Crocket.t, D. (1985). Academic advising. In L. Noel, R. Levitz, \& D. Saluri (Eds.), Increasing student retention (pp. 244-263). San Francisco: Jossey-Bass.

Crosby, P. B. (1979). Quality is free. New York: McGraw Hill.

Czepial, J., Soloman, M., \& Supprenent, C. (Eds.). (1988). The service encounter: Managing employee/ customer interaction in service businesses. Toronto: D. C. Heath and Company.

Daloz, L. A. (1986). Effective teaching and mentoring. San Francisco: Jossey-Bass.

Davison, M. B. (1964). Educatioral outcomes and implications of academically and vocationally focused small groups of undergraduate students in a women's residence hall (Doctoral dissertation, Pennsylvania State University, 1964). Dissertation Abstracts International, 25, 5072 .

Deming, w. E. (1986). Out of the crisis. Cambridge: Massachusetts Institute of Technology center for Advanced Engineering.

Denzin, N. K. (1978). The research act: A theoretical introduction to sociological methods. New York: McGraw-Hill.

Douglas, J. D. (1985) - Creative interviewing|. London: SAGE Publications. 
Dukes, F., \& Gaither, G. (1984, winter). A campus cluster program: Effects on persistence and academic performance. College and University, 59(2), 150-166.

Durkheim, E. (1951). Suicide: A study in sociology (J. A. Spaulding \& G. Simpson, Trans.). Glencoe, IL: The Free Press. (original work published 1897)

Erkut, S., \& Mokros, J. R. (1984, Summer). Professors as models and mentors for college students. American Educational Research Journal, 21(2), 399-417.

Ethington, C. A., \& Smart, J. C. (1986). Persistence to graduate education. Research in Higher Education, $\underline{24}(3), 287-303$.

Everitt, S., \& Murray-Hicks, M. (1981, October). Models, mentors and sponsors for managers. Paper presented at the National Society for Performance and Instruction Conference, Montreal, Canada.

Festinger, L. (1957). A theory of cognitive dissonance. Evanston, IL: Row-Peterson.

Fidler, P., \& Hunter, M. (1989). How seminars enhance student success. In M. L. Upcraft \& J. N. Gardner (Eds.). The freshman year experience: Helping students survive and succeed in college ( $\mathrm{pp}$. 216-237). San Francisco: Jossey-Bass.

Fishbein, M., \& Aizen, I. (1975). Belief, attitude, intention and behavior: An introduction to theory and research. Reading, MA: Addison Wesley.

Forrest, A. (1982). Increasing student competence and persistence: The best case for general education. Iowa City, IA: American College Testing Program.

Forrest, A. (1985). Creating conditions for student and institutional success. In $L$. Noel, D. Levitz, \& D. Saluri (Eds.), Increasing student retention: Effective programs and practices for reducing student dropout (pp. 62-77). San Francisco: Jossey-Bass.

Gamson, Z. F. (1966). Utilitarian and normative orientation toward education. Sociology of Education, 39(1), 46-73.

Gamson, Z. F. (1967). Performance and personalism in student-faculty relations. Sociology of Education, 40 (4), 279-301. 
Glaser, B. G.l, \& Strauss, A. (1967). The discovery of grounded theory. Chicago: Aldine.

Goetz, J. P. \& Lecompte, M. G.। (1984). Ethnography and qualitative design in educational research. New York: Academic Press.

Gordon, V. (1989). Origins and purposes of the freshman seminar. In M. L. Upcraft \& J. N. Gardner (Eds.), The freshman year experience: Helping students survive and succeed in college (pp. 183-199). San Francisco: Jossey-Bass.

Gurin,. P. \& \& Epps, E. (1975). Black consciousness, identity and achievement: A study of students in historically black colleges. New York: John Wiley and Sons.

Hanks, M. \& Ecklund, B. (1976). Athletics and social participation in the educational attainment process. Sociology of Education, 49(4), 271-294.

Harrington, T. F. (1972). The' literature on commuter students. Journal of College student Personnel, $13(6), 546-550$.

Hearn, J. (1987). Impacts of undergraduate experiences on aspirations and plans for graduate and professional education. Research in Higher Education, 27(2), 119-141.

Herzberg, F. (1966). Work and the nature of man. Cleveland: World Publishing.

Herzberg, F., Mausner, B., Peterson, R. O., \& Capwel1, D. F. (1957). Job attitudes: Review of research and opinion. Pittsburgh: Psychological service of pittsburgh.

Homans, G. (1961). Social behavior. New York: Harcourt, Brace and World.

House, J. S. | (1981). Work stress and social support (vol. 4). Reading, MA: Addison-Wesley.

Husband, R. L. (1976, January 10). Significant others: A new look at attrition. Paper presented at the annual meeting of the Association for Innovation in Higher Education, Philadelphia, PA. (ERIC Document Reproduction Service ED 124 056) 
Iaffaldano, M., \& Muchinsky, P. (1985). Job satisfaction and job performance: A meta-analysis. Psychological Bulletin, 97(2), 251-273.

Jacobi, M. (1991). Mentoring and undergraduate academic success: A literature review. Review of Educational Research, 61(4), 505-532.

Jacobsen, R. (1992, April 15). Colleges face new pressure to increase faculty productivity. Chronicle of Higher Education, 37(32), 1, 16-18.

Jeanotte, L. D. (1982, March 19-23. A study of the contributing factors relating to why American Indian students drop out of or graduate from educational programs at the University of North Dakota. Paper presented at the annual meeting of the American Educational Research Association, New York, NY.

Johnson, C. S. (1989). Mentoring programs. In M. I. Upcraft, \& J. N. Gardner (Eds.), The freshman year experience: Helping students survive and succeed in college (pp. 118-128). San Francisco: Jossey-Bass.

Juran, J. M. (1988). Juran on planning for quality. New York: Free Press.

Juran, J. M. (1989). Juran on leadership for quality: An executive handbook. New York: Free Press.

Knefelkamp, I. J., \& Stewart, S. S. (1983). Toward a conceptualization of commuter students: The developmental perspective. In S. S. Stewart (Ed.), Commuter students: Enhancing their educational experiences (pp. 61-70). San Francisco: Jossey-Bass.

Knisely, G. (1979, January). Greater marketing emphasis by Holiday Inns. Advertising Age, $7(15), 44$.

Kramm, K. (1988). Mentoring at work: Developmental relationships in orqanizational life. Lanham, MD: University Press of America.

Landy, F. J. (1978). An opponent process theory of job satisfaction. Journal of Applied Psychology, 63 (5), 533-547.

Landy, F. J. (1989) . Psychology of work behavior. Belmont, CA: Brooks/Cole Publishing.

Lawler, E. (1973). Motivation in work organizations. Monterey, CA: Brooks/Cole Publishing. 
Lenning, O. T., Beal, P. E., \& Sauer, K. (1980). Retention and attrition: Evidence for action and research. Boulder, CO: National center for Higher Education Management Systems.

Lester, P. (1988). Teacher job satisfaction: An annotated bibliography and guide to research. New York: Garland Publishing.

Levinson, S. J. (1978). The seasons of a man's life. New York: Knopf.

Lewin, K. (1935). A dynamic theory of personality. New York: McGraw-Hill.

Lewis, K. (1951). Field theory in social science: Selected theoretical papers (D. Cartwright, Ed.). New York: Harper Torch Books.

Locke, E. A. (1968). Toward a theory of task motivation and incentives. Organizational Behavior and Human Performance, $3(2), 157-189$.

Locke, E. A. (1970). Job satisfaction and job performance: A theoretical analysis. organizational Behavior and Human Performance, 5(5), 484-500.

Locke, E. A. (1976). The nature and causes of job satisfaction. In M. Dunnette (Ed.), Handbook of industrial and organizational psychology (pp. 1,297-1,349). Chicago: Rand McNally.

Loher, B. T., Noe, R. A., \& Moeller, N. L. (1985). A meta-analysis of the relation of job characteristics to job satisfaction. Journal of Applied Psychology, $\underline{70}(2), 280-289$.

Loher, B. T., Noe, R. A., Moeller, N. L., \& Fitzgerald, M. (1985). A meta-analysis of the relation of job characteristics to job satisfaction. Journal of Applied Psychology, $\underline{70}(2), 280-289$.

Mallinckrodt, B. (1988, January). Student retention, social support, and dropout intention: Comparison of black and white students. Journal of college student Development, 29 (1), 60-64.

Mangan, K. S. (1991, November 13). More colleges resort to faculty and staff layoffs in response to sluggish U.S. economy. Chronicle of Higher Education, 38(12), A37-38. 
Marks, M. L., Mirvis, P. H., Hackett, E. J. , \& Grady , J. F. (1986). Employee participation in a quality circle program: Impact on quality of work life, productivity, and absenteeism. Journal of Applied Psychology, 71(1), 61-69.

Mascciochi, J. (1990). Job satisfaction of classified employees in a public suburban school district. Unpublished doctoral dissertation, Portland State University, Portland, OR.

Maslow, A. H. (1943). A theory of human motivation. Psychological Review, 50, 370-396.

Mayo, E. (1933). The human problems of an industrial civilization. New York: Macmillan.

McClelland, D. C. (1951). Personality. New York: Dryden Press.

McGregor, D. (1960). The human side of enterprise. New York: McGraw Hill.

Miles, R. E. (1975). Theories of management: Implications for organizational behavior and development. New York: McGraw Hill Book Company.

Miller, T., \& Brickman, S. (1982, winter). Faculty and staff mentoring: A Modei for improving student retention and service. NASPA Journal, 19(1), 23-27.

Munro, B. (1981). Dropouts from higher education: Path analysis of a national sample. American Educational Research Journal, 18(1), 133-141.

Murray, H. A. (1938). Explorations in personality. New York: Oxford University Press.

Murray, M. (1991). Beyond the myths and magic of mentoring. San Francisco: Jossey-Bass.

National clearinghouse for Commuter Programs. (1985). Serving commuter students: Examples of good practice. College Park: University of Maryland, College Park, National Clearinghouse for Commuter Programs.

Nelson, R., \& Scott, T. (1984, January). Precollege characteristics and early college experiences as predictors of freshmen year experience. Journal of College student Personnel, 25(1), 50-54. 
Neumann, W. F. (1985). Persistence in the community collegie: The student perspective (Doctoral dissertation, Syracuse University, 1985). Dissertation Abstracts International, 46, 3232A.

Noe, R. A. ( 1988 , Fall). An investigation of the determinants of successful assigned mentoring relationships. Personnel Psychology, 41(3), 457-479.

Noel, L., Levitz, R., \& Saluri, D. (1985). Increasing student retention. San Francisco: Jossey-Bass.

o'Reilly, C. A., \& Caldwell, D. F. (1981). The commitment and job tenure of new employees: Some evidence of postdecisional justification. Administrative Science Quarterly, 26(4), 597-616.

Pascarella,|E. (1980). Student faculty informal contact and college outcomes. Review of Educational Research, 50 (4), 545-595.

Pascarella, |E., Duby, P. B., Terenzini, P. T., \& Iverson, B. K. (1983, september). Student-faculty relationships and freshmen year intellectual and personal growth in a nonresidential setting. Journal of College Student Personnel, 24(5), 395-402.

Pascarella, E. , Ethington, C. , \& Smart, J. (1988, July) August). The influence of college on humanitarian/ civic involvement values. Journal of Higher Education, 59(4), 412-437.

Pascarella, |E. \& S Smart, J. (1990). Impacts of intercollegiate athletic participation for Black-lmerican and White-American men: Some further evidence. Unpublished manuscript, University of Illinoj.s, chicago.

Pascarella, |E., Smart, J. C., \& Ethington, C. A. (1986). Long-term persistence of two-year college students. Research in Higher Education, 24(1), 47-71.

Pascarella, E., \& Terenzini, P. (1976). Informal interaction with faculty and freshman ratings of academic and non-academic experience. Journal of Educational Research, 70(1), 35-41.

Pascarella, |E., \& Terenzini, P. (1977). Patterns of student-faculty informal interaction beyond the classroom and voluntary freshman attrition. Journal of Higher Education, 48(5), 540-552. 
Pascarella, E., \& Terenzini, P. (1979a). Interactive influences in Spady's and Tinto's conceptual models of college attrition. Sociology of Education, $\underline{52}(4)$, 197-210.

Pascarella, E., \& Terenzini, P. (1979b). Student-faculty informal contact and college persistence: A further investigation. Journal of Educational Research, 72 (4), 214-218.

Pascarella, E., \& Terenzini, P. (198C). Student-faculty and student-peer relationships as mediators of the structural effects of undergraduate residence arrangements. Journal of Educational Research, $\underline{73}(6), 344-353$.

Pascarella, E., \& Terenzini, P. (1983). Predicting voluntary freshman year persistence/withdraw/behavior in a residential university: $A$ path analytic validation of Tinto's model. Journal of Educational Psychology, 75(2), 215-226

Pascarella, E., \& Terenzini, P. (1991). How college effects students: Findings and insights from twenty years of research. San Francisco: Jossey-Bass.

Pascarella, E., Terenzini, P., \& Wolfle, L. (1986). orientation to college and freshman year persistence/withdrawal decisions. Journal of Higher Education, 57(1), 155-175.

Pascarella, E., \& Wolfle, I. (1985, October). Persistence in higher education: A nine year test of a theoretical model. Paper presented at the meeting of the American Educational Research Association, Chicago, IL.

Patton, M. (1990). Qualitative evaluation and research methods. London: Sage Publications.

Perry, W. G. (1970). Forms of intellectual and developmental growth in the college years. New York: Holt, Rinehart, and Winston.

Peters, T. (1987). Thriving on chaos. New York: Harper and Row.

Phelan, W. (1979). Undergraduate orientations toward scientific and scholarly careers. American Educational Research Journal, 16(4), 422-441. 
Portland state University. (1995). First time freshman retention, new from high school. Portland, OR: Portland State University, Office of Institutional Research and Planning.

Pulakos, E. D., \& Schmidt, N. (1983). A longitudinal study of a valence model approach for the prediction of job satisfaction for new employees. Journal of Applied Psychology, 68(2), 307-312.

Rafaeli, A. (1985, Autumn). Quality circles and employee attitudes. Personnel Psychology, 38(3), 603-615.

Ramist, L. (1981). College student attrition and retention (College Board Report, No. 81-1). New York: College Entrance Examination Board.

Rodgers, B. H., \& Pratt, L. (1989), March). The relationship between freshman intentions, motivations, academic aptitude and college performance to persistence in college. Paper presented at the annual meeting of the Association for Institutional Research, Baltimore, MD.

Roethlisberger, F. J., \& Dickson, W. J. (1939). Management and the worker. Cambridge: Harvard University Press.

Schachter, S., \& Singer, J. E. (1962). Cognitive, social and psychological determinants of emotional state. Psychological Review, $\underline{69}(5), 379-399$.

Schein, E. G. (1985). organizational culture and leadership. New York: Jossey-Bass.

Schlesinger, L., \& Zornitsky, J. (1991). Job Satisfaction, service capability, and customer satisfaction: An examination of linkages and management implications. Human Resource Planning, 14 (2), 141-157.

Schlossberg, N. K. (1989) . Marginality and mattering: Key issues in building community. In D. C. Roberts (Ed.), Designing campus activities to foster a sense of community (pp. 14-34). San Francisco: JosseyBass.

Schlossberg, N. K., Lynch, A. Q., \& Chickering, A. W. (1989). Improving higher education environments for adults: Responsive programs and services from entry. to departure. San Francisco: Jossey-Bass. 
Schroeder, C. C., \& Freesh, N. (1977). Applying environmental management strategies in residence hallsi. Journal of the National Association of Student Personnel, 15(1), 51-57.

Schuchman, H. P. (1974). Special tasks of commuter students. Personnel and Guidance Journal, 52(7), 465-470.

Seymour, D. T. (1991). TQM on campus: What the pioneers are finding. AAHE Bulletin, 44(3), 10-13.

Seymour, D. T. (1993) : on o: Causing quality in higher education. Phoenix: Oryx Press.

Shanley, M. G. (1987). An exploratory lonqj.tudinal comparison of retention, persistence, and graduate rates between University 101 freshman seminar participants and non-participants at the University of South Carolina during the period 1979-1986. Unpublished doctoral dissertation, University of South Carolina, Columbia.

Sheehy, G.: (1976). Passages: Predictable crises of adult Iife. New York: E. P. Dutton.

Sherr, L. A., \& Lozier, G. L. (1991). Total quality management in higher education. In L. A. Sheer \& D. J. Teeter (Eds.), Total quality management in higher education (pp. 3-12). San Francisco: Jossey-Bass.

Simpson, C., Baker, K. \& Mellinger, G. (1980). Conventional failures and unconventional dropouts: Comparing different types of university withdrawals. Sociology of Education, $\underline{53}(4), 203-214$.

Smith, P. C., Kendall, L. M., \& Hulin, C. L. (1969). The measurement of satisfaction in work and retirement. Chicago: Rand-MeNally.

Spady, W. G. (1970). Dropouts from higher education: An interdisciplinary review and synthesis. Interchange, $1(1), 64-85$.

Spady, W. G. (1971): Dropouts from higher education: Toward an empirical model. Interchange, $\underline{2}(3), 38-62$.

Stage, F. (1989a). Motival, academic and social integration and the early dropout. American Educational Research Journal, 2.6(3), 385-402. 
Stage, F. (1989b). Reciprocal effects between the academic and social integration of college students. Research in Higher Education, 30(3), 517-530.

Stoecker, J., Pascarella, E., \& Wolfle, L. (1988, May). Persistence in higher education: A nine-year test of a theoretical model. Journal of college student Development, 29(3), 196-209.

Taylor, F. W. (1911). Scientific management. New York: Harper and Brothers.

Taylor, R. G., \& Hanson, G. R. (1971). Environmental impact on achievement and study habits. Journal of College student Personnel, 12(6), 445-454.

Taylor, S. J., \& Bogdan, R. (1984). Introduction to qualitative research methods. New York: John Wiley \& Sons.

Terenzini, P., \& Pascarella, E. (1977). Voluntary freshman attrition and patterns of social and academic integration in a university: $A$ test of a conceptual model. Research in Higher Education, $\underline{6}(1), 25-43$.

Terenzini, P., \& Pascarella, E. (1978). The relation of students' precollege characteristics and freshman year experience to voluntary attrition. Research in Higher Education, $9(4), 347-366$.

Terenzini, P., \& Pascarella, E. (1980). Student/faculty relationships and freshman year educational outcomes: A further investigation. Journal of college student Personnel, 21(6), 521-528.

Terenzini, P. T., Pascarella, E., \& Lorang, W. G. (1982). An assessment of the academic and social influences on freshman year educational outcomes. Review of Higher Education, 5(2), 86-110.

Tinto, V. (1975). Dropout from higher education: A theoretical synthesis. Review of Educational Research, 45(1), 89-129.

Tinto, V. (1982, November/December). Limits of theory and practice in student attrition. Journal of Higher Education, 53(6), 687-700.

Tinto, V. (1987). Leaving college: Rethinking the causes and cures of student attrition. Chicago: The University of Chicago Press. 
Tinto, V. (1993). Leaving college: Rethinking the causes and cures of student attrition (2nd ed.). Chicago: The University of Chicago Press.

Titley, B. (1985). Orientation programs. In L. Noel, R. Levitz, \& D. Saluri (Eds.), Increasing student retention (pp. 211-243). San Francisco: Jossey-Bass.

Tschohl, J. (1989). Connections: Practice for excellence, path to success. Bloomington: Better Than Money Corp.

Turnow, W. \& Wiley, J. (1991). Service quality and management practices: A look at employee attitudes, customer satisfaction, and bottom-line consequences. Human Resource Planning, 14(2), 105-115.

Ulrich, D., Halbrook, R., Meder, D., Stuchlik, M., \& Thorpe, S. (1991). Employee and customer attachment: Synergies for competitive advantage. Human Resource Planning, 14(2), 89-103.

United States Department of Education, National Center for Educational statistics. (1977). Withdrawal from institutions of higher education. Washington, DC: Author.

Upcraft, M. L., \& Gardner, J. N. (1989). The freshmen year experience: Helping students survive and succeed in college. San Francisco: Jossey-Bass.

Upcraft, M. L., Peterson, P. C., \& Moore, B. I. (1981). The academic and personal development of Penn state freshmen. Unpublished manuscript, Pennsylvania state University, college Station.

Vaughn, R. (1968). Involvement in extracurricular activities and dropout. Journal of college student Personnel, $9(1), 60-61$.

Vieira, R. (1991). Report on activities to increase student persistence from fall 1990 to winter 1991 at Portland State University. Portland, OR: Portland State University.

Vreeland, R. S., \& Bidwell, C. E. (1966). Classifying university departments: An approach to the analysis of their effects upon undergraduate values and attitudes. Sociology of Education, $\underline{39}(3), 237-254$.

Vroom, v. (1964). Work and motivation. New York: Wiley. 
Warr, P. B. (1987). Work, unemployment and mental health. Oxford: Clarendon Press.

Weber, M. (1947). The theory of social and economic organization. New York: Oxford University Press.

Whiteley, J. M. (1982). Character development in college students (Vol. 1). Schenectady, NY: Character Research Press.

Wiley, J. (1991). Customer satisfaction: A supportive work environment and its financial cost. Human Resource Planning, 14(2), 117-127.

Wilmes, M. B., \& Quade, S. L. (1986, Summer). Perspective on programming for commuters: Examples of good practice. NASPA Journal, 24(1), 25-35.

Wilson, C. R., Gaff, J. G., Dienst, E. R., Wood, D. \& \& Bavry, J. L. (1975). College professors and their impacts on students. New York: John Wiley and Sons.

winter, D. G., Mcclelland, D. C., \& Stewart, A. J! (1981). Understanding the effects of "IVy College": An integrated model. In D. G. Winter, D, C. Mcclelland, \& A. J. Stewart (Eds.), A new case for the liberal arts: Assessing institutional goals and student development (pp. 118-150). San Francisco: Jossey-Bass. 
APPENDIX A

STUDENT SURVEYS 


\section{New Student Experience Survey}

Thank you in advance for completing this questionnaire. The information which you provide will help to assess the student experience at PSU. All information which you provide will be held confidential, and only summaries of responses will be reported.

1. Please indicate the extent to which you agree with the following statements: (circle one)

1 =Strongly disagree $2=$ Disagree $3=$ Agree 4 = Strongly Agree $\quad \bullet=$ Undecided

SD D $A$ SA $\quad$ U

1 feel personally connected to PSU

I feel comfortable at PSU.

It's easy to meet people at PSU

Teaching faculty members care about students at PSU.

Clerical staff members care about students at PSU.

$\begin{array}{lllll}1 & 2 & 3 & 4 & : \\ 1 & 2 & 3 & 4 & : \\ 1 & 2 & 3 & 4 & \end{array}$

Other staff members care about students at PSU.

$\begin{array}{llllll}1 & 2 & 3 & 4 & \\ 1 & 2 & 3 & 4 & - \\ 1 & 2 & 3 & 4 & \end{array}$

There are many opportunities for me to be involved at PSU.

123

I feel attached to at least one teaching faculty member at PSU.

I feel attached to at least one clerical staff member at PSU.

I feel attached to at least one "other" staft member at PSU.

$\begin{array}{llll}1 & 2 & 3 & 4 \\ 1 & 2 & 3 & 4\end{array}$

I feel that I know where to go for help at PSU when I have a problem. 
2. We would like to know if you have had any interaction with teaching faculty, clerical staff and other staff, in seltings other than the classroom for teaching faculty and students, and in settings other than the work place for clerical staff and other staff.

2a. Teaching faculty: Yes__ No___

2b. If yes, how many times since Fall term 1991?
$1-2$
$3-6$
$7 \cdot 10$
$10+$

2c. Clerical staff:

Yes

No

2d. If yes, how many times since Fall term 1991?
1.2
3-6
$7 \cdot 10$
$10+$

2e. Other staff:

$$
\text { Yes___ No ___ }
$$

2f. If yes, how many times since Fall term 1991?
$1-2$
3-6
$7 \cdot 10$
$10+$

2g. Students:

Yes__ No___

2h. If yes, how many times since Fall term 1991?
$1-2$
3.6
$7 \cdot 10$
$10+$

3. Did you attend the summer New Student Orientation Program during July and August of 1991 ?

Yes

No

4. Have you taken the one credit University Survival Course (IST 199)?

its

ivo

5. Do you intend to continue your enrollment during Fall term 1992?

Yes

No

5a. If no, why? 
6. Do you intend to obtain your degree at Portland State?

Yes___ No

6a. If no, why? 
\#

New Student Experience Survey

Thank you in advance for completing this questionnaire. The information which you provide will help to assess the student experience at PSU. All information which you provide will be held confidential, and only summaries of responses will be reported.

1. Please indicate the extent to which you agree with the following statements (circle one):

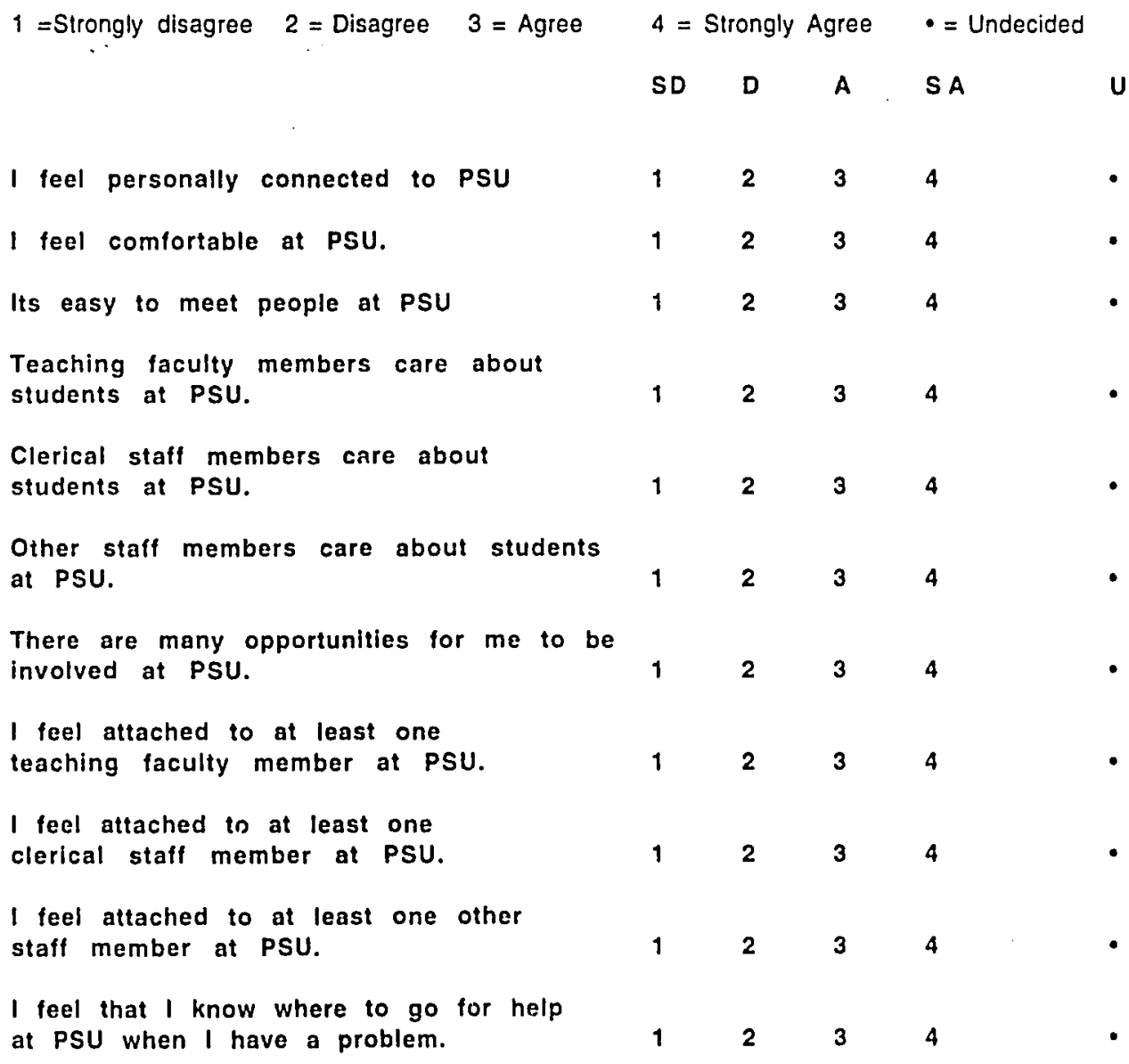


2. We would like to know it you have had any interaction with teaching faculty, clerical stafl and other staff, in settings other than the classroom for teaching faculty and students, and in settings other than the work place for clerical staff and other staff.

2a. Teaching faculty: Yes__ No

2b. If yes, how many times since Fall term 1991?

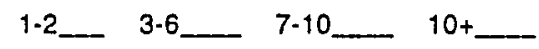

2c. Clerical staff: Yes__ No

2d. If yes, how many times since Fall term 1991?

$1.2+3.6\left[7.10 \_10+\right.$

2e. Other staff: Yes__ No _

2f. If yes. how many times since Fall term 1991?

$1.2+3.6\left[7.10 \_10+\ldots\right.$

2g. Students: Yes__ No _

2h. If yes, how many times since Fall term 1991?

$$
1.2+3.6\left[\quad 7.10 \_10+\right.
$$

3. Did you attend the summer New Student Orientation Program?

Yes

No___

4. Have you taken the one credit University Survival Course (IST 199)?

Yes___ No____

5. Do you intend to continue your enrollment during Fall term 1992?

Yes___ No

5a. If no, why? 
6. Do you intend to obtain your degree at Portland State?

Yes No_

6a. If no, why?

7. How many times did you meet with your "staft link" adviser during the term?

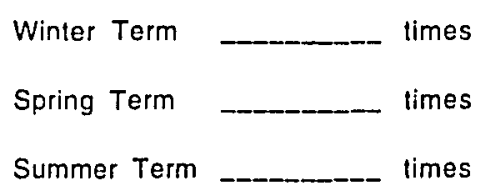

8. Please indicate the extent to which you agree with the following statements (circle one):

1 =Strongly disagree 2 = Disagree $3=$ Agree $\quad 4=$ Strongly Agree $\quad 9=$ Undecided

\begin{tabular}{|c|c|c|c|c|}
\hline & SD & $\mathbf{D}$ & A & SA \\
\hline My staff link adviser was well informed. & 1 & 2 & 3 & 4 \\
\hline My staff link adviser was helpful. & 1 & 2 & 3 & 4 \\
\hline $\begin{array}{l}\text { My staff link adviser helped me to solve } \\
\text { problems related to my attendance at PSU. }\end{array}$ & 1 & 2 & 3 & 4 \\
\hline $\begin{array}{l}\text { My staff link advisor referred me to } \\
\text { others at PSU when appropriate. }\end{array}$ & 1 & 2 & 3 & 4 \\
\hline $\begin{array}{l}\text { Meeting with my staff link advisor was } \\
\text { a valuable use of my time. }\end{array}$ & 1 & 2 & 3 & 4 \\
\hline $\begin{array}{l}\text { My staff link adviser cared about me as } \\
\text { a person. }\end{array}$ & 1 & 2 & 3 & 4 \\
\hline $\begin{array}{l}\text { I would like to continue my relationship } \\
\text { with my staff link adviser. }\end{array}$ & 1 & 2 & 3 & 4 \\
\hline $\begin{array}{l}\text { I would recommend that other students } \\
\text { have a staff link adviser. }\end{array}$ & 1 & 2 & 3 & 4 \\
\hline
\end{tabular}


APPENDIX B

STAFF SURVEYS 


\section{Staff Satisfaction Survey}

Thank you in advance for completing this questionnaire. The information which you provide will help to assess the experience of new students and staff satisfaction at PSU. All information which you provide will be held confidential, and only summaries of responses will be reported.

1. How long have you worked for the University? years

2. How many years of school have you attented? (circle highest)

$\begin{array}{llllllllllllllllllll}1 & 2 & 3 & 4 & 5 & 6 & 7 * & 8 & 9 & 10 & 11 & 12 & 1: 3 & 14 & 15 & 16 & 17 & 18 & 19 & 20\end{array}$

3. What academic degrees have your received (circle as a many as apply)
HS/GED
AA
BA/BS
Masters Doctorate
Other

4. What is the primary function of your deparlment? (circle lone)

Academic Student Service Admin. Support I Other support_____ (specify)

5. Please indicate the term which most closely describes your work. (circle one)

Clerical/Administrative Managerial | Prolessional/Technical

Other (specify)

6. To what extent do you interact formally with students in your daily work.

Frequently Sometimes Seldom Never

7. Please indicate the ways in which you interact with students in your daily work: (check as many as apply)

Friend

Counselor

Academic Advisor

General Advisor

Related to work only 
8. Please indicate the extent to which you agree with the following statements (circle one):

1 =Strongly disagree $2=$ Disagree $3=$ Agree 4 = Strongly Agree $\quad \cdot=$ Undecided

SD D A SA

My daily interaction with students in

my work role is very satisfying.

$\begin{array}{llll}1 & 2 & 3 & 4\end{array}$

My daily work provides me with oppor.

tunities to help students.

$\begin{array}{lllll}1 & 2 & 3 & 4\end{array}$

I am able to clearly see the consequences

of my helping students.

$\begin{array}{lll}1 & 2 & 3\end{array}$

My daily work is an important part of

the educational process.

$\begin{array}{lllll}1 & 2 & 3 & 4\end{array}$

I am satisfied with the opportunities to

help students which my job provides.

Overall, I am very satisfied with my lob. $1 \quad 2 \quad \begin{array}{lllll} & 3 & 4\end{array}$ *

4. Think of the work you do at present. How well does each of the following words or phrases describe your work? In the blank beside each word or phrase below, write:

- Y_ for "Yes" if it describes your work

- N_ for "No if it does NOT describe it

_. _ if you cannot decide 
Work on my present job is:

___ Fascinating

_- Routine

___ Satisfying

__ Boring

- Good

-

_- Respected

___ Uncomfortable

_ Pleasant

__ Useful

_... Tiring

__ Healthful

Challenging

_ Too much to do

-__- Frustrating

- Simple

__ Repetitive

___ Gives sense of accomplishment 
\#

\section{Staff Satisfaction Survey}

Thank you in advance for completing this questionnaire. The information which you provide will help to assess the student experience and staff satisfaction at PSU. All information which you provide will be held confidential, and only summaries of responses will be reported.

1. How long have you worked for the University?

years

2. How many years oi school have you attended? (circle highest)
123
5
$\begin{array}{llll}7 & 8 & 9 & 10\end{array}$
$11 \quad 12$
$13 \quad 14 \quad 15 \quad 16$
$17 \quad 18$
1920

3. What academic degrees have you received (circle as a many as apply)
HS/GED
AA BA/BS
Masters
Doctorate
Other

4. What is the primary function of your department? (circle one)

Academic Student Service Admin. Support Other support_____-_ (specify)

5. Please indicate the term which most closely describes your work. (circle one)

Clerical/Administrative Managerial Professional/Technical

Other (specify)

6. To what extent do you interact formally with students in your daily work.

Frequently Sometimes

Seldom Never

7. Please indicate the ways in which you interact with students in your daily work: (check as many as apply)

Friend

Counselor

Academic Advisor

General Advisor

Related to work only 
8. Please indicate the extent to which you agree with the following statements (circle one):

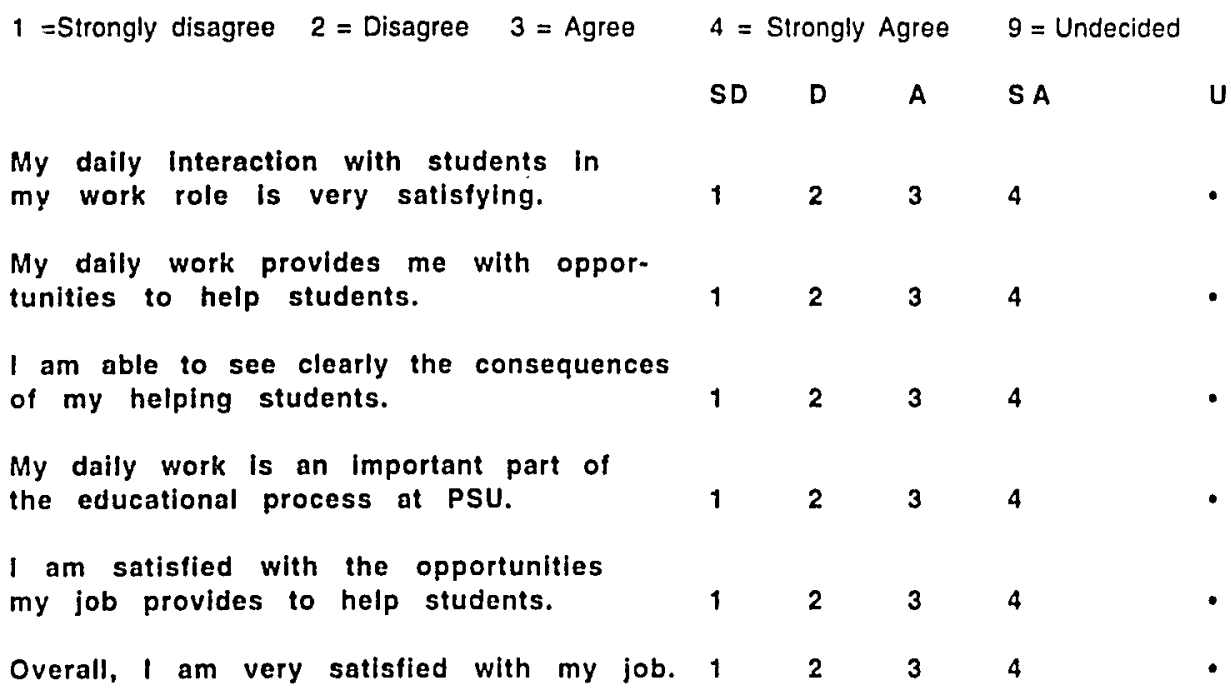

9. How many times did you meet with your "staff link" advisee during the term?

Winter Term _-_--

Spring Term

10. Please indicate the extent to which you agree with the following statements (circle one):

1 = Strongly disagree $2=$ Disagree $3=$ Agree $4=$ Strongly Agree $9=$ Undecided
$\begin{aligned} & \text { feel that I made a personal difference in } \\ & \text { the experience of my advisee. }\end{aligned}$
$\begin{aligned} & \text { The role of staff link advisor is an } \\ & \text { appropriate one for staff members. }\end{aligned}$
$\begin{aligned} & \text { Working with students In this way } \\ & \text { makes my job more interesting. }\end{aligned}$
$\begin{aligned} & \text { I feel recognized by the university } \\ & \text { tor my work with students. }\end{aligned}$




I feel my skills and abilities as an employee
are more fully used since I have become
a staff link advisor.
$\begin{aligned} & \text { I feel that I am a part of the educational } \\ & \text { process at psu. }\end{aligned}$
$\begin{aligned} & \text { Working with students in this way makes } \\ & \text { my job more challenging. }\end{aligned}$
$\begin{aligned} & \text { Working with students in this way will help } \\ & \text { to provide me with opportunities for } \\ & \text { professional advancement. }\end{aligned}$
$\begin{aligned} & \text { Working with students in this way is } \\ & \text { personally enriching. }\end{aligned}$
$\begin{aligned} & \text { Working with students in this way is a } \\ & \text { normal part of my job. }\end{aligned}$

11. How would you rate the quality of the interaction between you and your "staff link" advisee.

$\begin{array}{ccccc}\text { Very Poor } & \text { Poor } & \text { Average } & \text { Good } & \text { Very Good } \\ 5 & 4 & 3 & 2 & 1\end{array}$

12. Have you had occasion to meet and interact informally, out of class with students other than your staff link advisee.

Yes_ No_

If yes, how many?

$1-2+3 \cdot 6 \_7 \cdot 10 \_10+\ldots$

13. Would you be interested in being assigned as an adviser in the future?

Yes_ No__ 
14. Think of the work you do at present. How well does each of the following words or phrases describe your work? In the blank beside each word or phrase below, write

_. Y_ for "Yes" if it describes your work

- N_ for "No if it does NOT describe it

- ? it you cannot decide

My Work on my present job is:

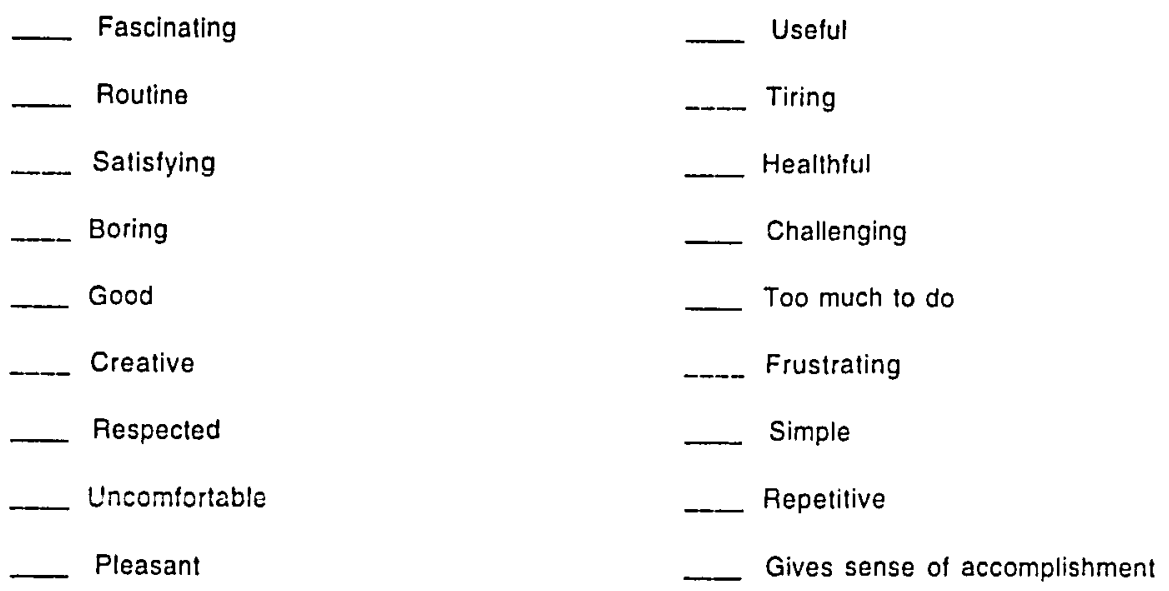

10. Is there any particular experience that occurred during your participation in this program which "slood out" for you?

11. Do you have any suggestions, comments or feelings that you would like to share about your participation in this program? 
APPENDIX C

JOB DESCRIPTIVE INDEX 


\section{SCORING KEY .- WORK}

1. Place blue card on comesponding page of person's white answer booklet, covering all but the answers, so that Col. 1 on blue card is to right of answer column of white page. Align corresponding solid lines. Write a 3 on the white page beside each $Y$ answer which matches a $Y$ on the card.

2. Slide the blue card to far left so that Col. 2 is to left of white page. Align corresponding lines. Write a 3 on the white page for every $N$ answer which matches an $N$ on the card.

3. Write $\mathrm{a} 1$ on the white page beside each ? or omission.

4. Total all 3 's and 1 's and enter on white page where the arrow on blue card indicates, WORK: TOTAL.

\section{col..} WORK ON PRESENT JÖB

Fascinating

Y

Routine N

Satisfying

Boring N

$Y$

Good Creative

$\bar{Y}$
Respected

$Y$ Uncomforable N

Y Pleasant

Y Useful

Tiring

$N$

$\underline{Y}$ Healthful

Y Challenging

$\overline{ }$

To much to do N

Frustrating N Simple N

Repetitive N Gives sense of accomplishment

WORK: TOTAL $\Rightarrow$ 
SCORINI THE JOB DESCRIPTIVE INDEX (JDI)

\section{General Instructions:}

All favorable answers are scored 3 , all unfavorable are scored $\underline{0}$, and a 11 omissions or ?s are scored 1 . The favorable $Y$ answers are given in Column 1 , and the favorable $\mathrm{N}$ answers in Column 2 of the scoring keys.

The Pay and Promotions scores are doubled in order to make them numerically equivalent to the scores on the other scales:

Total JDI scores (not recommended);

We do not recommend computing' a total JDI score, a) though numerous investigators have done so. The subscales are discriminably different, have loaded on separate group factors with no general factor in repeated factor analytic studies, and do not intercorrelate highly despite their high reliabilities. I Different aspects of, and changes in, the situation alsol affect the five subscales differently. Adding sub-scores is like adding apples and oranges.

Job in General scores (recommended):

A summary score may be desired to determine whether overall satisfaction is related to such behaviors as quitting the job, seeking career change, or other longterm actions. If so, the Job in General scale, completed after the JDI, provides such a measure. It is scored in the same manner as the JDI. 